Prepared in cooperation with the Bureau of Reclamation

\title{
Evaporation from Lake Mead, Nevada and Arizona, March 2010 through February 2012
}

Scientific Investigations Report 2013-5229

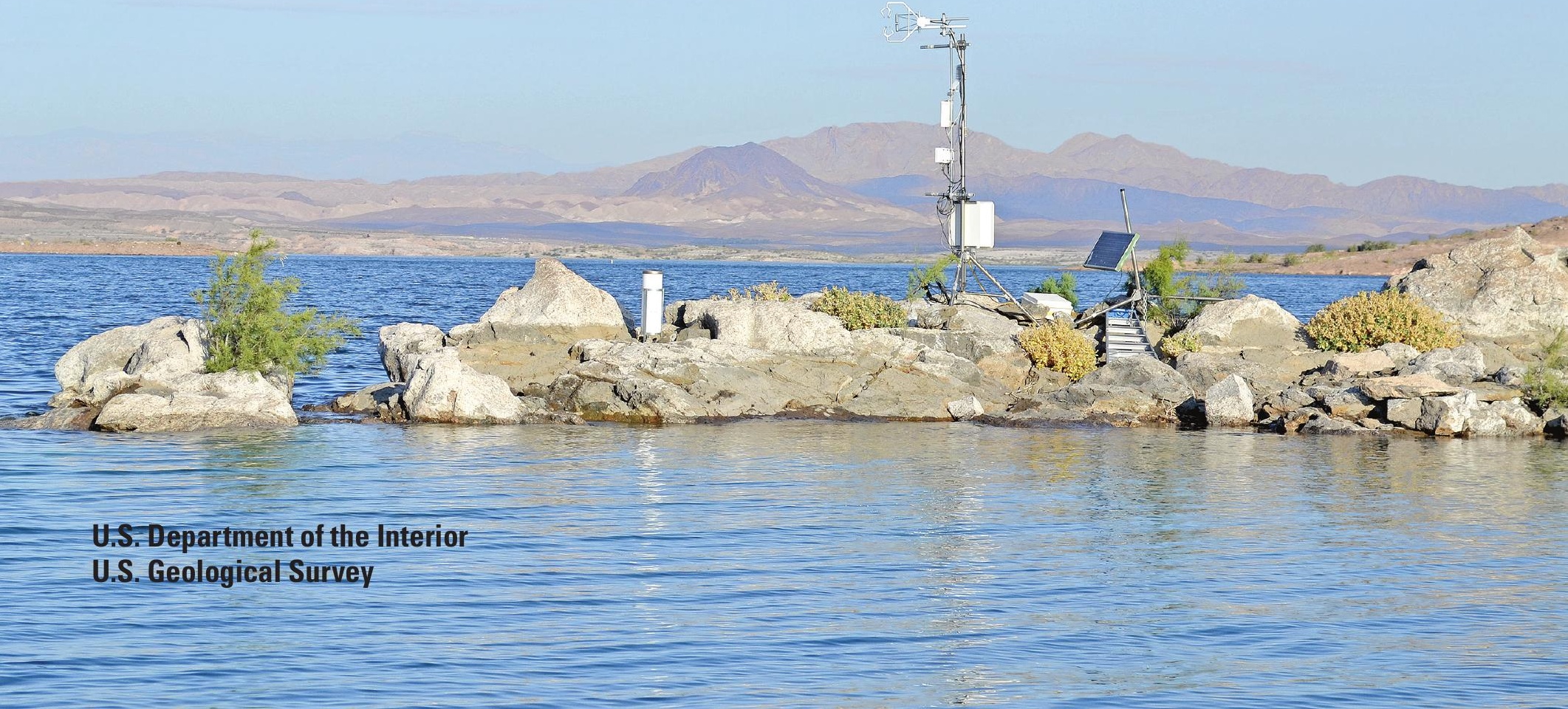


Cover: Photograph showing eddy-covariance station at site EC-2, Lake Mead, Nevada and Arizona (Photograph taken by Michael Moreo, U.S. Geological Survey, August 2011.) 


\section{Evaporation from Lake Mead, Nevada and Arizona, March 2010 through February 2012}

By Michael T. Moreo and Amy Swancar

Prepared in cooperation with the Bureau of Reclamation

Scientific Investigations Report 2013-5229 


\title{
U.S. Department of the Interior \\ Sally Jewell, Secretary
}

\section{U.S. Geological Survey \\ Suzette M. Kimball, Acting Director}

\author{
U.S. Geological Survey, Reston, Virginia: 2013
}

For more information on the USGS - the Federal source for science about the Earth, its natural and living resources, natural hazards, and the environment, visit http://www.usgs.gov or call 1-888-ASK-USGS.

For an overview of USGS information products, including maps, imagery, and publications, visit http://www.usgs.gov/pubprod.

To order this and other USGS information products, visit http://store.usgs.gov.

Any use of trade, firm, or product names is for descriptive purposes only and does not imply endorsement by the U.S. Government.

Although this information product, for the most part, is in the public domain, it also may contain copyrighted materials as noted in the text. Permission to reproduce copyrighted items must be secured from the copyright owner.

Suggested citation:

Moreo, M.T., and Swancar, A., 2013, Evaporation from Lake Mead, Nevada and Arizona, March 2010 through February 2012: U.S. Geological Survey Scientific Investigations Report 2013-5229, 40 p., http://dx.doi.org/ 10.3133/sir20135229.

ISSN 2328-0328 


\section{Contents}

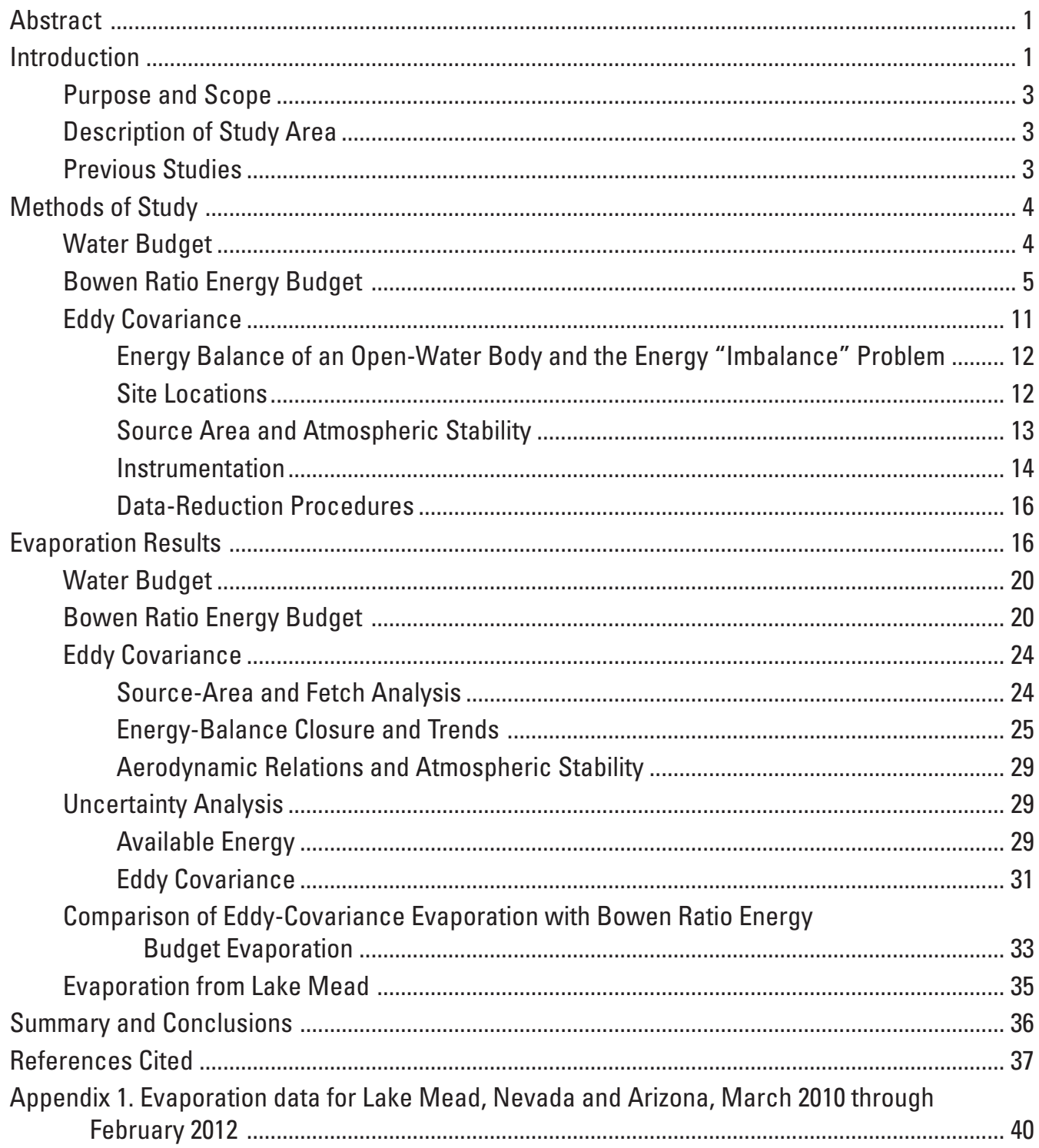

\section{Figures}

1. Map showing location of Lake Mead, Nevada and Arizona ................................................ 2

2. Schematic diagram showing major energy-budget components of Lake Mead ................. 6

3. Photograph showing Sentinel Island platform in Lake Mead, with radiometer extending from the platform to the south, and inset showing radiometer

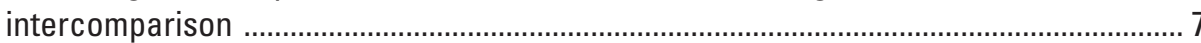


4. Overview showing eddy-covariance and Sentinel Island platform sites in Boulder Basin, Lake Mead. A, Background image showing Lake Mead near full capacity, and $B$, High-resolution image from May 2010, showing rock outcrops with lake elevation at 334.14 meters, which is about 40 meters below full capacity

5. Photograph of eddy-covariance sensors at site EC-1 showing positioning 15

6. Graphs showing daily $A$, Mean and maximum net radiation, $B$, Mean air and watersurface temperature, $C$, Mean atmospheric and water-surface vapor pressure, and $D$, Mean wind speed, Lake Mead, March 2010 through February 2012

7. Graphs showing monthly water-temperature profiles at Sentinel Island platform, Lake Mead

8. Graph showing daily elevation and surface area, Lake Mead, March 2010 through February 2012

9. Graphs showing monthly $A$, Water budget, $B$, Total gain, loss, and change in volume, and $C$, Side inflow, evaporation, SNWP withdrawal, and change in bank storage, Lake Mead, March 2010 through February 2012

10. Graph showing monthly net radiation, heat stored, and latent-heat, sensible-heat, and net advected-heat fluxes, Lake Mead, March 2010 through February 2012

11. Graph showing monthly average temperature of inflow to and outflow from Lake Mead, March 2010 through February 2012

12. Graph showing monthly evaporation, Lake Mead, March 2010 through February 2012

13. Graph showing monthly net radiation, and latent- and sensible-heat fluxes, Lake Mead, March 2010 through February 2012

14. Graph showing energy-balance closure, turbulent energy, available energy, and change in stored heat energy, Lake Mead, March 2010 through February 2012

15. Graphs showing relations between daily mean latent-heat flux and $A$, Wind speed, $B$, Vapor pressure difference, and $C$, Mass-transfer product; and relations between daily mean sensible-heat flux and $D$, Wind speed, $E$, Temperature difference, and $F$, Wind speed-temperature difference product, Lake Mead

16. Graph showing relations between monthly mean latent-heat flux and monthly mean mass-transfer product, Lake Mead

17. Graphs showing monthly available energy and maximum-probable uncertainty, Lake Mead, March 2010 through February 2012

18. Graph showing monthly corrected eddy-covariance evaporation and uncertainty, and Bowen ratio energy-budget evaporation, Lake Mead, March 2010 through February 2012

19. Graph showing monthly corrected eddy-covariance evaporation and uncertainty, and 24-Month Study (24MS) evaporation, Lake Mead, March 2010 through February 2012 


\section{Tables}

1. Instruments used to measure energy-budget components from the Sentinel Island

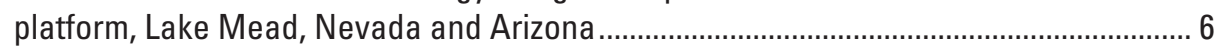

2. Location and general description of eddy-covariance sites, Lake Mead, Nevada and Arizona.

3. Instruments used to measure turbulent fluxes and precipitation at eddy-covariance sites, Lake Mead, Nevada and Arizona

4. Monthly and annual energy budget and micrometeorological data, Lake Mead, Nevada and Arizona, March 2010 through February 2012

5. Monthly and annual water budget, Lake Mead, Nevada and Arizona, March 2010 through February 2012

6. Source-area and fetch analysis, Lake Mead, Nevada and Arizona .

7. Monthly and annual available energy and turbulent energy computed using the eddy-covariance method, Lake Mead, Nevada and Arizona, March 2010 through February 2012

8. Monthly and annual minimum, maximum, and most probable (corrected) eddycovariance (EC) evaporation, Lake Mead, Nevada and Arizona, March 2010 through February 2012 


\section{Conversion Factors and Datums}

SI to Inch/Pound

\begin{tabular}{|c|c|c|}
\hline Multiply & By & To obtain \\
\hline \multicolumn{3}{|c|}{ Length } \\
\hline centimeter $(\mathrm{cm})$ & 0.3937 & inch (in.) \\
\hline millimeter (mm) & 0.03937 & inch (in.) \\
\hline meter (m) & 3.281 & foot (ft) \\
\hline kilometer (km) & 0.6214 & mile (mi) \\
\hline \multicolumn{3}{|c|}{ Area } \\
\hline square meter $\left(\mathrm{m}^{2}\right)$ & 0.0002471 & acre \\
\hline square kilometer $\left(\mathrm{km}^{2}\right)$ & 0.3861 & square mile $\left(\mathrm{mi}^{2}\right)$ \\
\hline square kilometer $\left(\mathrm{km}^{2}\right)$ & 247.1044 & acre \\
\hline \multicolumn{3}{|c|}{ Volume } \\
\hline cubic meter $\left(\mathrm{m}^{3}\right)$ & 0.0002642 & million gallons (Mgal) \\
\hline cubic meter $\left(\mathrm{m}^{3}\right)$ & 0.0008107 & acre-foot (acre-ft) \\
\hline million cubic meter $\left(\mathrm{Mm}^{3}\right)$ & 0.8107132 & thousand acre-foot (Kaf) \\
\hline \multicolumn{3}{|c|}{ Flow rate } \\
\hline cubic meter per year $\left(\mathrm{m}^{3} / \mathrm{yr}\right)$ & 0.000811 & acre-foot per year (acre-ft/yr) \\
\hline meter per second $(\mathrm{m} / \mathrm{s})$ & 2.2369 & miles per hour (mi/h) \\
\hline millimeter per year (mm/yr) & 0.03937 & inch per year (in/yr) \\
\hline centimeter per day (cm/d) & 0.3937 & inch per day (in/d) \\
\hline \multicolumn{3}{|c|}{ Mass } \\
\hline gram (g) & 0.03527 & ounce, avoirdupois (oz) \\
\hline kilogram (kg) & 2.205 & pound avoirdupois (lb) \\
\hline \multicolumn{3}{|c|}{ Pressure } \\
\hline kilopascal (kPa) & 0.1450 & pound per square inch $\left(\mathrm{lb} / \mathrm{in}^{2}\right)$ \\
\hline \multicolumn{3}{|c|}{ Density } \\
\hline kilogram per cubic meter $\left(\mathrm{kg} / \mathrm{m}^{3}\right)$ & 0.06242 & pound per cubic foot $\left(\mathrm{lb} / \mathrm{ft}^{3}\right)$ \\
\hline gram per cubic centimeter $\left(\mathrm{g} / \mathrm{cm}^{3}\right)$ & 62.4220 & pound per cubic foot $\left(\mathrm{lb} / \mathrm{ft}^{3}\right)$ \\
\hline gram per cubic meter $\left(\mathrm{g} / \mathrm{m}^{3}\right)$ & 0.00006242 & pound per cubic foot $\left(\mathrm{lb} / \mathrm{ft}^{3}\right)$ \\
\hline \multicolumn{3}{|c|}{ Energy } \\
\hline joule $(\mathrm{J})$ & 0.0000002 & kilowatthour (kWh) \\
\hline joule per cubic meter $\left(\mathrm{J} / \mathrm{m}^{3}\right)$ & 0.00000738 & watthour per cubic foot $\left(\mathrm{Wh} / \mathrm{ft}^{3}\right)$ \\
\hline watt per square meter $\left(\mathrm{W} / \mathrm{m}^{2}\right)$ & 0.0222 & $\begin{array}{l}\text { calorie per second per square foot } \\
\left(\mathrm{cal} / \mathrm{s} / \mathrm{ft}^{2}\right)\end{array}$ \\
\hline
\end{tabular}

Temperature in degrees Celsius $\left({ }^{\circ} \mathrm{C}\right)$ may be converted to degrees Fahrenheit $\left({ }^{\circ} \mathrm{F}\right)$ as follows:

${ }^{\circ} \mathrm{F}=\left(1.8 \mathrm{x}^{\circ} \mathrm{C}\right)+32$

Vertical coordinate information is referenced to the North American Vertical Datum of 1988 (NAVD 88).

Horizontal coordinate information is referenced to the North American Datum of 1983 (NAD 83).

Lake Mead elevation, as used in this report, is referenced to the U.S. Geological Survey datum, adjustment of 1912, locally known as "Power House Datum." 


\section{Acronyms and Additional Abbreviations}

$\begin{array}{ll}\text { 24MS } & \text { 24-Month Study } \\ \text { ASL } & \text { atmospheric surface layer } \\ \text { CNF } & \text { cumulative normalized flux } \\ \text { CSAT3 } & \text { three-dimensional sonic anemometer } \\ \text { BREB } & \text { Bowen ratio energy budget } \\ \text { EBC } & \text { energy-balance closure } \\ \text { EBR } & \text { energy-balance ratio } \\ \text { EC } & \text { eddy covariance } \\ \text { KH2O } & \text { krypton hygrometer } \\ \text { MDV } & \text { mean diurnal variation } \\ 0_{\mathrm{e}} & \text { latent-heat flux } \\ 0_{\mathrm{h}} & \text { sensible-heat flux } \\ 0_{n} & \text { net radiation } \\ 0_{v} & \text { net advected heat } \\ 0_{\mathrm{x}} & \text { change in stored heat } \\ \mathrm{R}^{2} & \text { coefficient of determination } \\ \text { SI } & \text { Sentinel Island } \\ \text { SNWP } & \text { Southern Nevada Water Project } \\ \text { USGS } & \text { U.S. Geological Survey }\end{array}$




\section{Acknowledgments}

The authors wish to thank Bruce Williams, Shana Tighi, Noe Santos, Daniel Bunk, and the rest of Bureau of Reclamation's Lower Colorado River Operations Group, and Paul Miller (formerly of the Bureau of Reclamation and now with the National Oceanic and Atmospheric Administration's Colorado Basin River Forecast Center) for supporting this work. Jiahong Li (formerly a postdoctoral student at the University of Central Florida and currently with LI-COR, Inc.) provided assistance with eddy-covariance data post-processing, and Sasha Ivans from Campbell Scientific, Inc. provided the datalogger program to run the eddy-covariance station.

USGS employees in Henderson, Nevada who deserve special acknowledgment were Ron Veley, who constructed, deployed, maintained, and processed data from the Sentinel Island platform, and Erin Orozco, who supported all aspects of data collection and processing. This report benefitted greatly from insightful reviews by Dave Stannard and Don Rosenberry from the National Research Program of the USGS in Lakewood, Colorado. Dave Stannard also mentored both USGS authors as well as many other hydrologists throughout their careers in the nuances of evaporation and evapotranspiration studies. 


\title{
Evaporation from Lake Mead, Nevada and Arizona, March 2010 through February 2012
}

\author{
By Michael T. Moreo and Amy Swancar
}

\section{Abstract}

Evaporation from Lake Mead was measured using the eddy-covariance method for the 2-year period starting March 2010 and ending February 2012. When corrected for energy imbalances, annual eddy-covariance evaporation was 2,074 and 1,881 millimeters (81.65 and 74.07 inches), within the range of previous estimates. There was a 9-percent decrease in the evaporation rate and a 10-percent increase in the lake surface area during the second year of the study compared to the first. These offsetting factors resulted in a nearly identical 720 million cubic meters (584,000 acre feet) evaporation volume for both years. Monthly evaporation rates were best correlated with wind speed, vapor pressure difference, and atmospheric stability. Differences between individual monthly evaporation and mean monthly evaporation were as much as 20 percent. Net radiation provided most of the energy available for evaporative processes; however, advected heat from the Colorado River was an important energy source during the second year of the study. Peak evaporation lagged peak net radiation by 2 months because a larger proportion of the net radiation that reaches the lake goes to heating up the water column during the spring and summer months. As most of this stored energy is released, higher evaporation rates are sustained during fall months even though net radiation declines. The release of stored heat also fueled nighttime evaporation, which accounted for 37 percent of total evaporation. The annual energy-balance ratio was 0.90 on average and varied only 0.01 between the 2 years, thus implying that 90 percent of estimated available energy was accounted for by turbulent energy measured using the eddy-covariance method. More than 90 percent of the turbulent-flux source area represented the open-water surface, and 94 percent of 30-minute turbulentflux measurements originated from wind directions where the fetch ranged from 2,000 to 16,000 meters. Evaporation uncertainties were estimated to be 5 to 7 percent.

A secondary evaporation method, the Bowen ratio energy budget method, also was employed to measure evaporation from Lake Mead primarily as a validation of eddy-covariance evaporation measurements at annual timescales. There was good agreement between annual corrected eddy-covariance and Bowen ratio energy budget evaporation estimates, providing strong validation of these two largely independent methods. Annual Bowen ratio energy budget evaporation was 6 and 8 percent greater than eddy-covariance evaporation for the
2 study years, and both methods indicated there was a similar decrease in evaporation from the first to the second year. Both methods produced negative sensible-heat fluxes during the same months, and there was a strong correlation between monthly Bowen ratios $\left(\mathrm{R}^{2}=0.94\right)$. The correlation between monthly evaporation $\left(\mathrm{R}^{2}=0.65\right)$, however, was not as strong. Monthly differences in evaporation were attributed primarily to heat storage estimate uncertainty.

\section{Introduction}

Lake Mead is part of a system of dams and reservoirs that control the Colorado River and enable its efficient use. Water demand has steadily increased since the implementation of the Colorado River Compact of 1922 as the upper- and lowerbasin states have built the infrastructure needed to capture their full apportionment. From 2000 to 2010, the stage of Lake Mead fell about $40 \mathrm{~m}$ (131 ft), raising concerns among water managers about future water shortages. Inflow to Lake Powell (fig. 1), which can be used as a drought indicator, exceeded the long-term mean inflow only twice during this period (http://www.usbr.gov/uc/feature/drought.html). Future water shortages in the Colorado River system could result from decreased runoff caused by continuing short-term drought and/or long-term climate change. Accordingly, imbalances between the water supply and demand may develop. Increasingly scarce water resources have underscored a need to improve water accounting and forecast accuracy.

The Bureau of Reclamation (Reclamation) Lower Colorado Region is responsible for delivering water from the lower Colorado River to Arizona, California, Nevada, and Mexico. These responsibilities include (1) accounting for diversions, consumptive use, and return flows, and (2) projecting Lower Basin water availability. Management of the river system is informed by a hydrologic model called the 24-Month Study (24MS) (see http://www.usbr.gov/lc/region/g4000/24mo.pdf). Each month, the 24MS simulates water budgets and projects future reservoir conditions and potential dam operations for the next 24-month period. Simulated water budgets and projections are based on current and forecasted hydrologic conditions, and operational policies and guidelines. Increasing the accuracy of the 24MS model and improving projections are high priorities for Reclamation. 


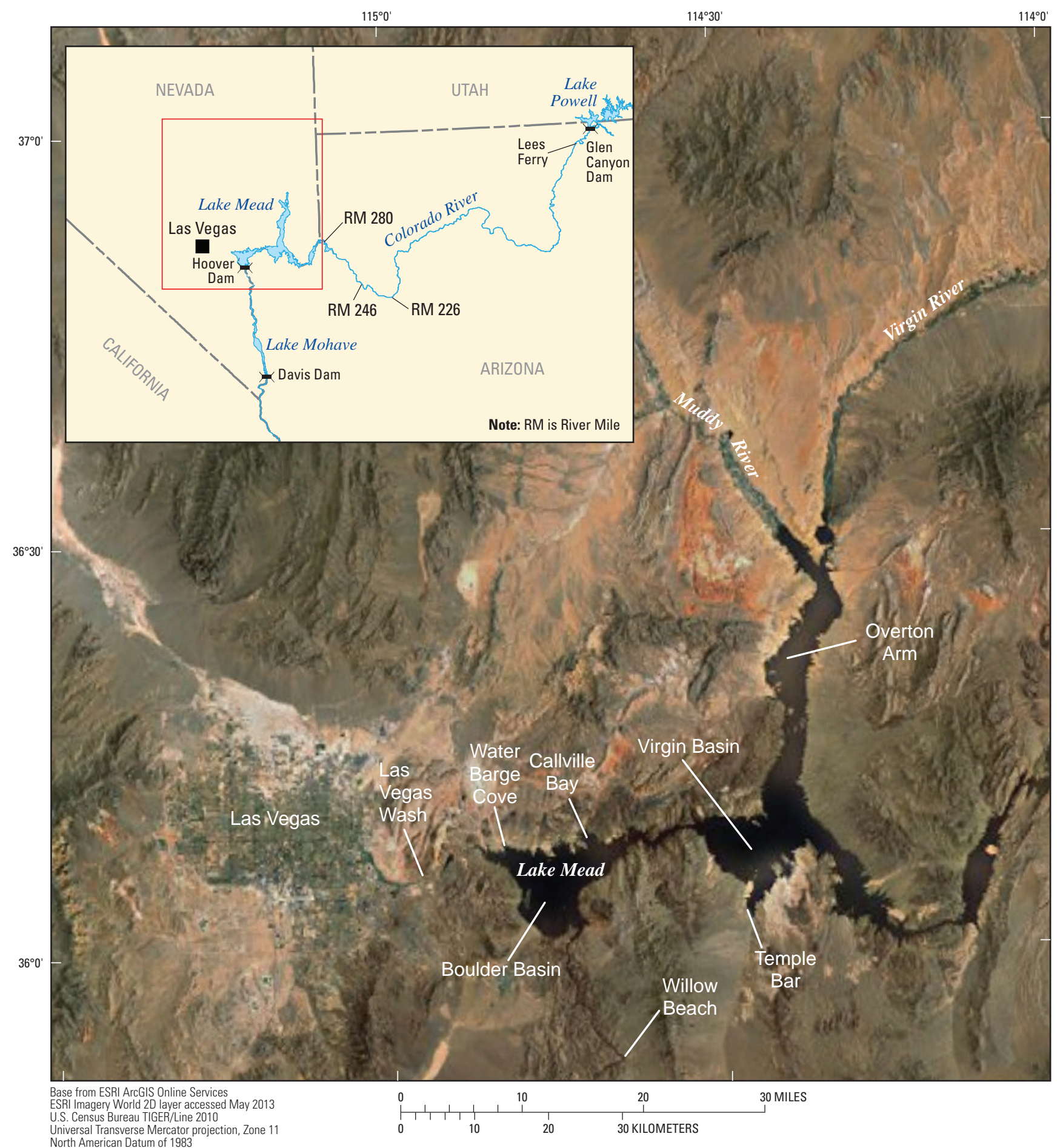

Figure 1. Location of Lake Mead, Nevada and Arizona.

The U.S. Geological Survey (USGS) and Reclamation are cooperating on a multi-phase study to improve 24MS model projections by improving monthly estimates of evaporation from Lake Mead and other lower Colorado River Basin reservoirs. Monthly evaporation from Lake Mead is a water-budget term currently used in the model that is based on poorly-documented modifications to early efforts to measure and estimate evaporation (Harbeck and others, 1958). Phase 1 of the study (the subject of this report) adds a new method, eddy covariance (EC), to the body of Lake Mead evaporation research. EC is a state-of-the-art method that has long been used for estimating evapotranspiration, but has not often been used to estimate lake evaporation. Phase 2 of the study will continue evaporation monitoring at Lake Mead for 4 additional years and begin 3 years of evaporation monitoring at another lower Colorado River Basin reservoir, Lake Mohave. 


\section{Purpose and Scope}

The purpose of this report is to present updated monthly evaporation estimates for Lake Mead using the EC method. This study covers the 2-year period March 2010 through February 2012, when EC equipment was deployed at the lake. The primary objective of this study was to provide accurate monthly evaporation rates, which are expected to improve the water budget and forecasting accuracy of Reclamation's 24MS model. The relative influence of well-known drivers of openwater evaporation and interannual (year-to-year) evaporation variability are investigated. A secondary objective of the study was to describe how the EC method compares to the Bowen ratio energy budget (BREB) method. The report discusses differences between the methods and potential errors associated with each method over monthly and annual timescales. Daily EC evaporation and other micrometeorological data are given in an electronic spreadsheet that is included with this report.

\section{Description of Study Area}

The watershed area draining to Lake Mead is about $435,000 \mathrm{~km}^{2}\left(168,000 \mathrm{mi}^{2}\right)$, or 5 percent of the United States (Thomas, 1954). It took 6 years for the Colorado River to fill Lake Mead following the 1935 completion of Hoover Dam (fig. 1). Located in the Mohave Desert, Lake Mead is the largest reservoir in the United States by volume, and second only to Lake Powell (formed by Glen Canyon Dam) in surface area (http://www.usbr.gov/pmts/eco_research/eco5.html). The reservoir is at full capacity when the water-level elevation is

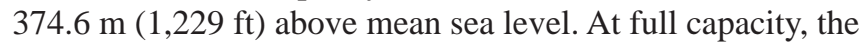
total storage is $34,069 \mathrm{Mm}^{3}(27,620 \mathrm{Kaf})$, and the surface area is $659.3 \mathrm{~km}^{2}$ (162,916 acres) (Tighi and Callejo, 2011). Lake Mead consists of a series of basins separated by narrower reaches. Boulder Basin (the most downstream basin nearest to Hoover Dam) and Virgin Basin (the next upstream basin) hold about 60 percent of the total storage in the lake (Thomas, 1954). Lake depths are up to about $140 \mathrm{~m}$ (460 ft), and widths range from $200 \mathrm{~m}$ (656 ft) in the narrow canyons to $16 \mathrm{~km} \mathrm{(10}$ $\mathrm{mi}$ ) in the larger basin areas. Lake water generally is clear and small currents are related to lake circulation (Thomas, 1954). The average residence time has been estimated as 3.9 years (Westenburg and others, 2006) and 2.6 years (Turner and others, 2012).

The Colorado River accounts for about 97 percent of inflows to Lake Mead (Westenburg and others, 2006; Turner and others, 2012). From 1935 through 2001 the computed average inflow was $13,400 \mathrm{Mm}^{3} / \mathrm{yr}(10,860 \mathrm{Kaf} / \mathrm{yr}$ ) (Ferrari, 2008). During the 1999 through 2010 drought period average inflows were reduced to $10,100 \mathrm{Mm}^{3} / \mathrm{yr}(8,190 \mathrm{Kaf} / \mathrm{yr})$ (Turner and others, 2012). The remaining 3 percent of inflows are from the Las Vegas Wash, Muddy River, Virgin River, and ephemeral streams (Westenburg and others, 2006; Turner and others, 2012). Water released through Hoover Dam serves nearly 25 million downstream users and can generate 2,079 megawatts of electricity (http://www.usbr.gov/projects/ Powerplant.jsp?fac_Name=Hoover+Powerplant).
The climate in the Lake Mead area is hot, arid, and windy. There are three historical National Weather Service Cooperator sites (http://www.nws.noaa.gov/om/coop/; http://www.wrcc.dri.edu/summary/Climsmnv.html) with longer periods of record in the area-Callville Bay (period of record 1989-2011; http://www.wrcc.dri.edu/cgi-bin/ cliMAIN.pl?nv1371), Willow Beach (period of record 1967-2007; http://www.wrcc.dri.edu/cgi-bin/cliMAIN. pl?az9376), and Temple Bar (period of record 1987-2007; http://www.wrcc.dri.edu/cgi-bin/cliMAIN.pl?az8516). There is little variation between these sites in terms of temperature and precipitation amounts. The mean daily maximum temperature is $43^{\circ} \mathrm{C}\left(110^{\circ} \mathrm{F}\right)$ in July and $16^{\circ} \mathrm{C}\left(61^{\circ} \mathrm{F}\right)$ in December, and the mean daily minimum temperature is $27^{\circ} \mathrm{C}\left(80^{\circ} \mathrm{F}\right)$ in July and $3{ }^{\circ} \mathrm{C}\left(38^{\circ} \mathrm{F}\right)$ in December. Period of record annual precipitation was $13.87 \mathrm{~cm}$ (5.46 in.) at Callville Bay, $14.12 \mathrm{~cm}$ (5.56 in.) at Willow Beach, and 14.27 cm (5.62 in.) at Temple Bar. The annual mean wind speed measured at EC stations for the first year of the study was $3.9 \mathrm{~m} / \mathrm{s}(8.7 \mathrm{mi} / \mathrm{hr})$, and for the second year was $3.6 \mathrm{~m} / \mathrm{s}(8.1 \mathrm{mi} / \mathrm{hr})$. These measured wind speeds are similar to the mean annual wind speed of $3.9 \mathrm{~m} / \mathrm{s}$ recorded at the Las Vegas airport from 1984 to 2010 (National Weather Service, 2013).

\section{Previous Studies}

The earliest attempt to estimate evaporation from Lake Mead based on meteorological and limnological data was by Anderson and Pritchard (1951). Their work was part of a series of comprehensive surveys conducted by the USGS, Reclamation, the U.S. Navy Electronics Laboratory, and others to evaluate sedimentation and salinity in 1948-49 (Smith and others, 1960). Lake temperature profiles were measured monthly at more than 60 locations. The BREB method was used to estimate an annual evaporation rate of $1,626 \mathrm{~mm}$ (64 in.). Their study highlighted a need to more fully develop the BREB method at a lake where evaporation was known. These same agencies then participated in a landmark study of lake evaporation at Lake Hefner, Oklahoma in 1950-51 (U.S. Geological Survey, 1954). This location was chosen because, in contrast to Lake Mead, the water budget could be determined with sufficient accuracy ( \pm 5 percent) to serve as a control for testing evaporation methods including energy budget and mass transfer. The study group subsequently moved back to Lake Mead in 1952-53 to conduct further research into methods and the equipment needed to measure evaporation accurately (Harbeck and others, 1958). The BREB method was chosen as the control to test mass-transfer equations against, even though the method was not expected to be as accurate as the water-budget control at Lake Hefner. The annual evaporation estimates for the BREB and mass-transfer methods were in such close agreement, partly because these methods were not completely independent as applied, that those investigators decided to combine them into an average annual evaporation rate of 2,172 mm (85.52 in.). The resulting average evaporation volume of $1,079 \mathrm{Mm}^{3}$ (875 Kaf) is nearly three times Nevada's annual allocation from the Colorado 
River of $370 \mathrm{Mm}^{3}$ (300 Kaf). As a more practical way to estimate monthly evaporation than these large-scale study efforts, a mass-transfer equation was devised whereby monthly evaporation could be estimated with a combination of variables measured at Lake Mead and at the Las Vegas airport. This equation was used by Reclamation to estimate evaporation until 1994. The mean annual evaporation rate for the period 1953-1994 was 1,930 mm (76 in.), but the mean for 1953-73 was $2,032 \mathrm{~mm}$ (80 in.) and the mean for 1974-94 was 1,829 $\mathrm{mm}$ (72 in.) (Westenburg and others, 2006, fig. 11). The lower annual evaporation rates during the latter period also were more variable, which may have resulted either from a series of programmatic modifications or faulty equipment. Westenburg and others (2006) established four floating platforms in different basins in Lake Mead for varying lengths of time between 1997 and 1999. Using the BREB method, they estimated an annual evaporation rate of 2,286 mm (90 in.).

\section{Methods of Study}

Methods to estimate lake evaporation generally fall into three categories: aerodynamic methods, energy-balance methods, and methods that combine these two approaches (Allen and others, 1998; Finch and Hall, 2005; Rosenberry and others, 2007). The mass-transfer method is included in the first category. Eddy covariance (EC) is a micrometeorological method that also falls into the first category; when EC is corrected for energy-balance closure it falls within the third category. The BREB method is in the second category.

The selection of a method or methods to estimate evaporation, each with its own strengths and weaknesses, is typically dictated by study objectives, the size and complexity of the study area, and costs. The primary objective of this study was to provide accurate monthly evaporation rates, which are expected to improve 24MS water budget and model output accuracy. The EC method was chosen as the primary method because it was thought to provide the most direct and least uncertain measure of monthly evaporation from Lake Mead. Furthermore, even though the focus of this report is on monthly estimates, one significant advantage of the EC method over other methods is the ability to accurately measure daily and sub-daily evaporation. Processes that control open-water evaporation become more evident at these shorter time steps (Blanken and others, 2003; Liu and others, 2009; Granger and Hedstrom, 2011). A secondary and indirect method, the BREB, also was employed. This widely-used lake evaporation method is relatively accurate at annual timescales; however, quantifying energy budgets at monthly timescales at Lake Mead is subject to relatively high uncertainty. Therefore, the BREB method is employed here primarily as an independent validation of EC evaporation measurements at annual timescales. Both of these evaporation methods are described in this section.

\section{Water Budget}

The water budget in this report was based on the March 2011 and March 2012 24MS reports (http://www.usbr.gov/ lc/region/g4000/24mo/index.html) with some modifications. This project does not attempt to improve on the 24MS inputs specifically (except for the evaporation rate), but it was necessary to estimate water-budget terms because there are links between the energy budget and the lake water budget. The equation used to compute the Lake Mead water budget is

$$
d S=P+S_{C R}+S_{S}-S_{o}-E-B-Q
$$

where

$d S$ is change in storage,

$P$ is precipitation,

$S_{C R}$ is surface-water inflow from the Colorado River,

$S_{S}$ is surface-water inflow from side channels (side inflow),

$S_{o}$ is surface-water outflow,

$E$ is evaporation,

$B$ is bank storage, and

$Q$ is direct withdrawal for the Southern Nevada Water Project (SNWP).

Units for the water budget in this report are in $\mathrm{Mm}^{3}$.

Releases from Glen Canyon Dam $\left(S_{C R}\right)$ and Hoover Dam $\left(S_{0}\right)$, and SNWP withdrawals $(Q)$ were taken directly from the 24MS reports. Other terms were estimated differently, as described below.

Change in storage for the current study was based on hourly stage and related volume (bathymetry) data provided by Reclamation. The bathymetry of Lake Mead was updated in 2011 based on an underwater bathymetric survey conducted in 2001 and a Light Detection and Ranging (LiDAR) survey conducted in 2009 (Tighi and Callejo, 2011). The new bathymetric data show increased storage in Lake Mead of less than 1 percent over the previous bathymetric dataset due to compaction and a decrease in sediment loading from the completion of Glen Canyon Dam (Tighi and Callejo, 2011). The 24MS reports that cover the current study period used the older dataset to estimate volume and surface area through December 2011, and the updated dataset thereafter. For month-to-month consistency within the current study water budget, only the updated bathymetric data were used.

Change in bank storage was calculated as 6.5 percent of the change in storage, using the same method as in the 24MS except that values presented here were slightly different because of our use of only the updated bathymetric dataset. Bank storage increases when the lake rises as some water from the lake flows into the banks and washes, becoming part of the groundwater flow system. By convention, changes in bank storage are considered negative relative to the lake when stage rises, similar to other loss terms in the water budget, and positive when stage falls. 
The evaporation rate from Lake Mead in the 24MS is constant for a given month (Bureau of Reclamation, 2007, table A-20). The BREB evaporation values were used in this water budget because it is necessary for the water and energy-budget equations to be balanced; therefore, the same evaporation numbers must be used in both.

Side inflow is calculated as a residual to the water budget in both the 24MS and in this report, so that the water budget is balanced. This term, therefore, includes any errors or unmeasured flows in the water budget. Because other water-budget terms in this report vary from the 24MS, side inflows also are different; however, side inflows calculated for this study were only 2 percent higher than the original 24MS values for the 2011 water year (October 2010 through September 2011).

To evaluate the assumption that side inflows represent all inflows to Lake Mead other than releases from Glen Canyon Dam, side inflows from the 24MS were compared to measured flows for water years 2010 and 2011 (October 2009 through September 2011). Flow in the Colorado River is measured at a site about $389 \mathrm{~km}$ (242 mi) downstream from Glen Canyon Dam (USGS gaging station 09404200, Colorado River above Diamond Creek near Peach Springs, AZ) and much closer to Lake Mead (http://wdr.water.usgs.gov/). Flows at this site were 11 percent higher on average than releases from Glen Canyon Dam in water years 2010 and 2011, and slightly higher than 24MS side inflows on average, which were 10 percent of releases. Other sites with routinely measured flows that reflect contributions to Lake Mead that are not explicitly accounted for in the 24MS are Virgin River above Lake Mead near Overton, NV (09415250), Las Vegas Wash below Lake Las Vegas near Boulder City, NV (09419800), and Diamond Creek near Peach Springs, AZ (09404208), along with a few other sites with much lower flows that are not included in this list. Combined flows from these three sites along with the Colorado River above Diamond Creek were 15 percent higher on average than Glen Canyon Dam releases in water years 2010 and 2011. In terms of computing an energy budget, the small difference between measured flows and flows estimated using the residual method (side inflows) is negligible; therefore, using the residual method is reasonable for computing available energy estimates and evaporation with the BREB method.

Precipitation (rain) was measured at the EC sites (data in appendix 1), but is not included explicitly in the 24MS, and is not considered further here because it is small relative to other water-budget terms. In the desert climate that surrounds Lake Mead annual precipitation averages less than $150 \mathrm{~mm}$ (6 in.), which was about 0.4 percent of the annual volume of water released from Glen Canyon Dam during the current study period and is an order of magnitude less than even the smaller water-budget terms.

\section{Bowen Ratio Energy Budget}

The BREB method estimates the energy used for evaporation by quantifying energy gains and losses and change in stored energy (Anderson, 1954; Parkhurst and others, 1998). The energy-budget equation is

$$
Q_{s}-Q_{r}+Q_{a}-Q_{a r}-Q_{b s}-Q_{e}-Q_{h}+Q_{w}+Q_{v}=Q_{x}
$$

where

$Q_{s}$ is incoming solar radiation,

$Q_{r}$ is reflected solar radiation,

$Q_{a}$ is incoming longwave radiation,

$Q_{a r}$ is reflected longwave radiation,

$Q_{b s}$ is emitted (backscattered) longwave radiation,

$Q_{e}$ is energy used for evaporation, or the latent-heat flux,

$Q_{h}$ is energy conducted from the lake to the atmosphere as sensible heat,

$Q_{w}$ is energy advected from the lake to the atmosphere by the evaporating water,

$Q_{v}$ is net energy advected into the lake, and

$Q_{X}$ is change in stored heat.

Heat exchange with bottom sediments is another energy term that is assumed to be negligible given the depth of Lake Mead and the minimal water temperature variation there below about $60 \mathrm{~m}(200 \mathrm{ft})$. The first five terms can be measured or estimated separately, or combined as net radiation, $Q_{n}$. All $Q$ terms are expressed in $\mathrm{W} / \mathrm{m}^{2}$.

The evaporation rate, $E$, in $\mathrm{m} / \mathrm{s}$ is

$$
E=\frac{Q_{e}}{\lambda \rho_{w}}
$$

where

$\lambda$ is latent heat of vaporization, $2.45 \times 10^{6} \mathrm{~J} / \mathrm{kg}$ at $20^{\circ} \mathrm{C}$,

$\rho_{w}$ is the density of water, $1,000 \mathrm{~kg} / \mathrm{m}^{3}$ at $4{ }^{\circ} \mathrm{C}$.

$Q_{h}$ is derived from the Bowen ratio, $R$, the ratio of $Q_{h}$ to $Q_{e}$ (Bowen, 1926)

$$
Q_{h}=R Q_{e}
$$

$Q_{w}$ is calculated from

$$
Q_{w}=c_{w} \rho_{w} E\left(T_{e}-T_{b}\right)
$$

where

$C_{w}$ is the specific heat of water, $4,186 \mathrm{~J} / \mathrm{kg}{ }^{\circ} \mathrm{C}$ at $15^{\circ} \mathrm{C}$,

$T_{e}$ is the temperature of evaporating water (assumed equal to the water-surface temperature), in ${ }^{\circ} \mathrm{C}$, and

$T_{b}$ is the base temperature, set to $0^{\circ} \mathrm{C}$.

Inserting equations $3-5$ into equation 2, and solving for $E$ (in $\mathrm{cm} / \mathrm{d})$ gives

$$
E=8.64 \times 10^{6} \times \frac{\left(Q_{n}-Q_{x}+Q_{v}\right)}{\rho_{w} \lambda\left[(1+R)+C w\left(T_{o}-T_{b}\right)\right]}
$$

The $8.64 \times 10^{6}$ multiplier is used to convert units from $\mathrm{m} / \mathrm{s}$ to $\mathrm{cm} / \mathrm{d}$. 
For this form of the energy budget (called the Bowen ratio energy-budget variant), $R$ is calculated from the vapor pressure and temperature differences using the following equation:

$$
R=0.0648 P \frac{\left(T_{o}-T_{a}\right)}{\left(e_{o}-e_{a}\right)}
$$

where

$P$ is average atmospheric pressure, set to $97.4 \mathrm{kPa}$ for this study,

$T_{O}$ is water-surface temperature, in ${ }^{\circ} \mathrm{C}$,

$T_{a}$ is air temperature, in ${ }^{\circ} \mathrm{C}$,

$e_{o}$ is saturation vapor pressure at the water-surface temperature, in $\mathrm{kPa}$, and

$e_{a}$ is vapor pressure of the air, in $\mathrm{kPa}$, and 0.0648 is the psychrometric constant, defined as $0.665 \times 10^{-3} P$, in $\mathrm{kPa} /{ }^{\circ} \mathrm{C}$ (from equation 8 in Allen and others, 1998).
Vapor pressures were calculated every 30 minutes or hourly from temperature and relative humidity data, then averaged daily and monthly. A schematic of the major components of the Lake Mead energy budget is shown in figure 2.

The sensors necessary to measure all energy-budget terms except $Q_{v}$ were located in Boulder Basin on the Sentinel Island (SI) floating platform (table 1, figs. 3 and 4a). An automated variable-depth winch on the platform lowered a multiparameter sonde to measure a water temperature profile every 6 hours starting at midnight (Veley and Moran, 2012). The first water temperature measurement was at $1 \mathrm{~m}$, and each successive measurement was $5 \mathrm{~m}$ deeper until just above the lake bottom. The total depth of the temperature profile during the study varied from $61 \mathrm{~m}$, when the lake stage was at its low point, to $81 \mathrm{~m}$ at its high point. Water-surface temperature, net radiation, incoming solar radiation, air temperature, humidity,

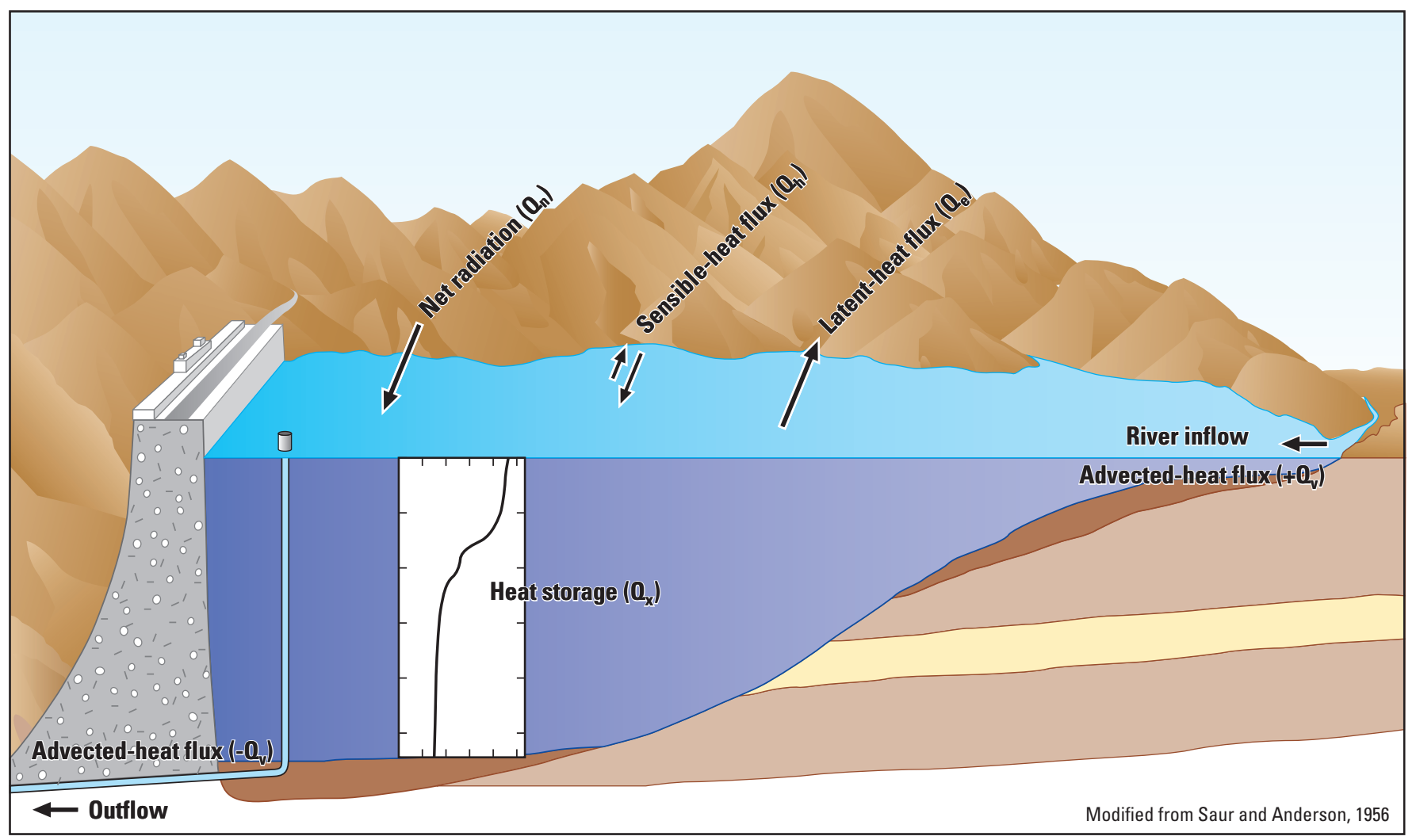

Figure 2. Major energy-budget components of Lake Mead.

Table 1. Instruments used to measure energy-budget components from the Sentinel Island platform, Lake Mead, Nevada and Arizona.

\begin{tabular}{cccc}
\hline Type of measurement & Company name & Instrument and model number & Placement \\
\hline Air temperature / humidity & Vaisala & HMP45C TRH probe & 2.2 meters above water surface \\
Wind speed / direction & R.M. Young & 5106 wind monitor, marine & 2.9 meters above water surface \\
Solar radiation & LI-COR & LI-200 & 2.8 meters above water surface \\
Net radiation & Kipp \& Zonen & CNR-1, CNR-2 & 1 meter above water surface \\
Surface-water temperature & Campbell Scientific & 107 temperature sensor & Water surface \\
Water temperature & YSI & 6600 multiparameter sonde & 1 to 81 meters below water surface \\
Voltage & Campbell Scientific & CR10X, CR3000 Datalogger & 1.5 meters above water surface \\
\hline
\end{tabular}




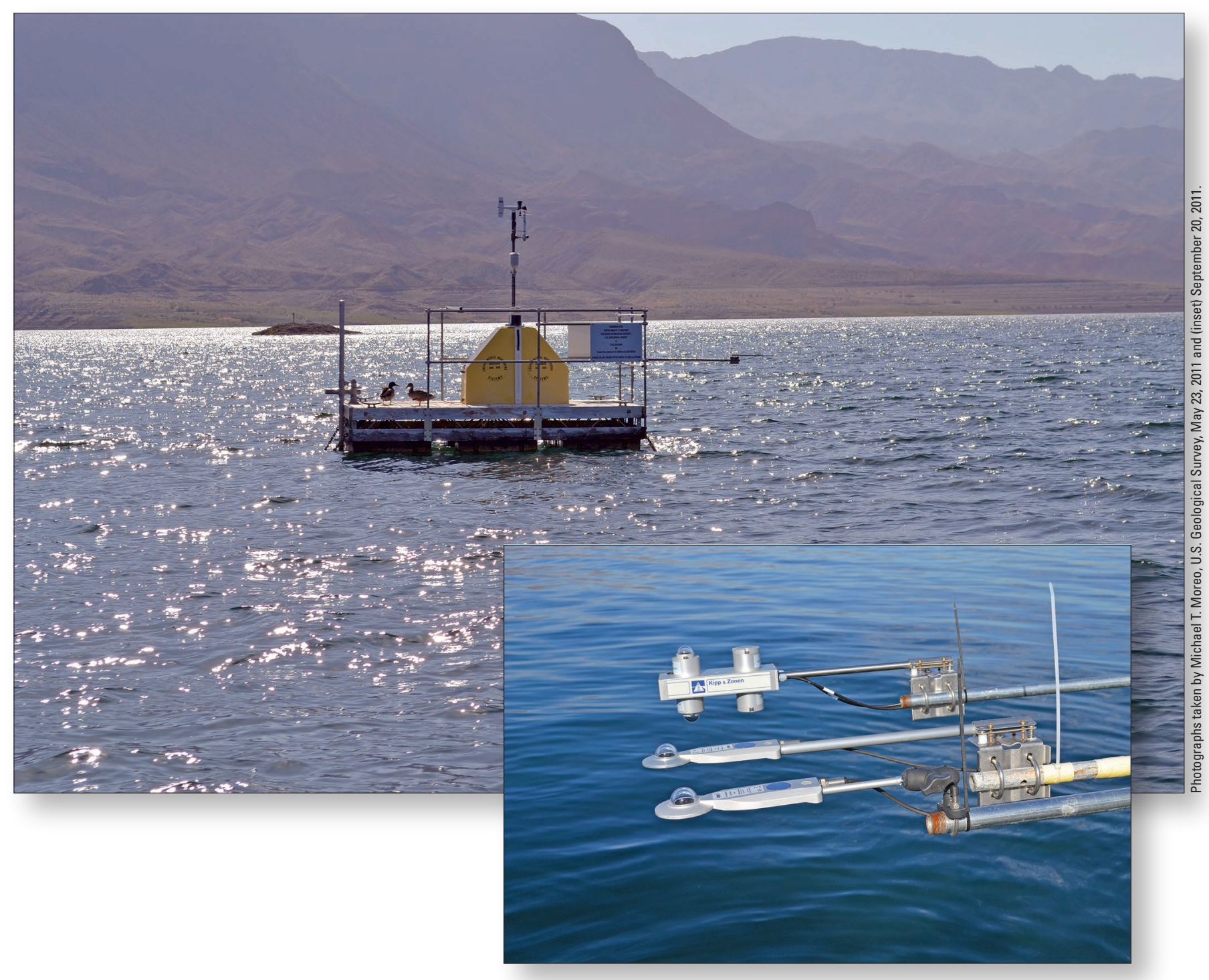

Figure 3. Sentinel Island platform in Lake Mead, with radiometer (CNR2) extending from the platform to the south, and inset showing radiometer intercomparison (CNR1 in the background and CNR2s in foreground).

wind speed, and wind direction were also measured from the SI platform during most of the study. Radiation sensors were oriented facing south to eliminate shading from other parts of the platform. Platform orientation was maintained by having two anchors, with lines adjusted periodically as the lake stage rose and fell to maintain tension. Some shifting of the platform orientation and level is inevitable, especially during strong winds, but was assumed to be less than 10 degrees in any direction and not to have affected the net radiation measurements substantially.

Most periods of missing meteorological data were less than 2 hours in length. Missing temperature, relative humidity, wind speed, and net radiation data were filled with the averages of values recorded before and after data gaps for these short periods of missing record. In summer 2011, however, there were 50 days when about 20 percent of the readings were missing. For these periods, missing temperature, relative humidity, and wind speed were substituted as before, because this substitution method produced the lowest error. For net radiation, however, a relation between daily net radiation at the SI platform and daily average solar radiation from the Community Environmental Monitoring Program station at Boulder City (http://www.cemp.dri.edu/index.html) was used to fill gaps (coefficient of determination $\left(R^{2}\right)=0.93$ ). Net radiation was treated differently because of the non-linearity of this variable through the day caused by changes in cloud cover.

Net radiation $\left(Q_{n}\right)$ was measured by three radiometers over the course of the study. The primary sensor was a 2-component (net short- and longwave radiation) radiometer (Model CNR2) located at the SI platform (figs. 3 and 4); however, for the first 81 days at the beginning of the study another CNR2 that extended over the water a short distance from the first EC site (EC-1), was the only radiometer (fig. 5). Both CNR2s ran 


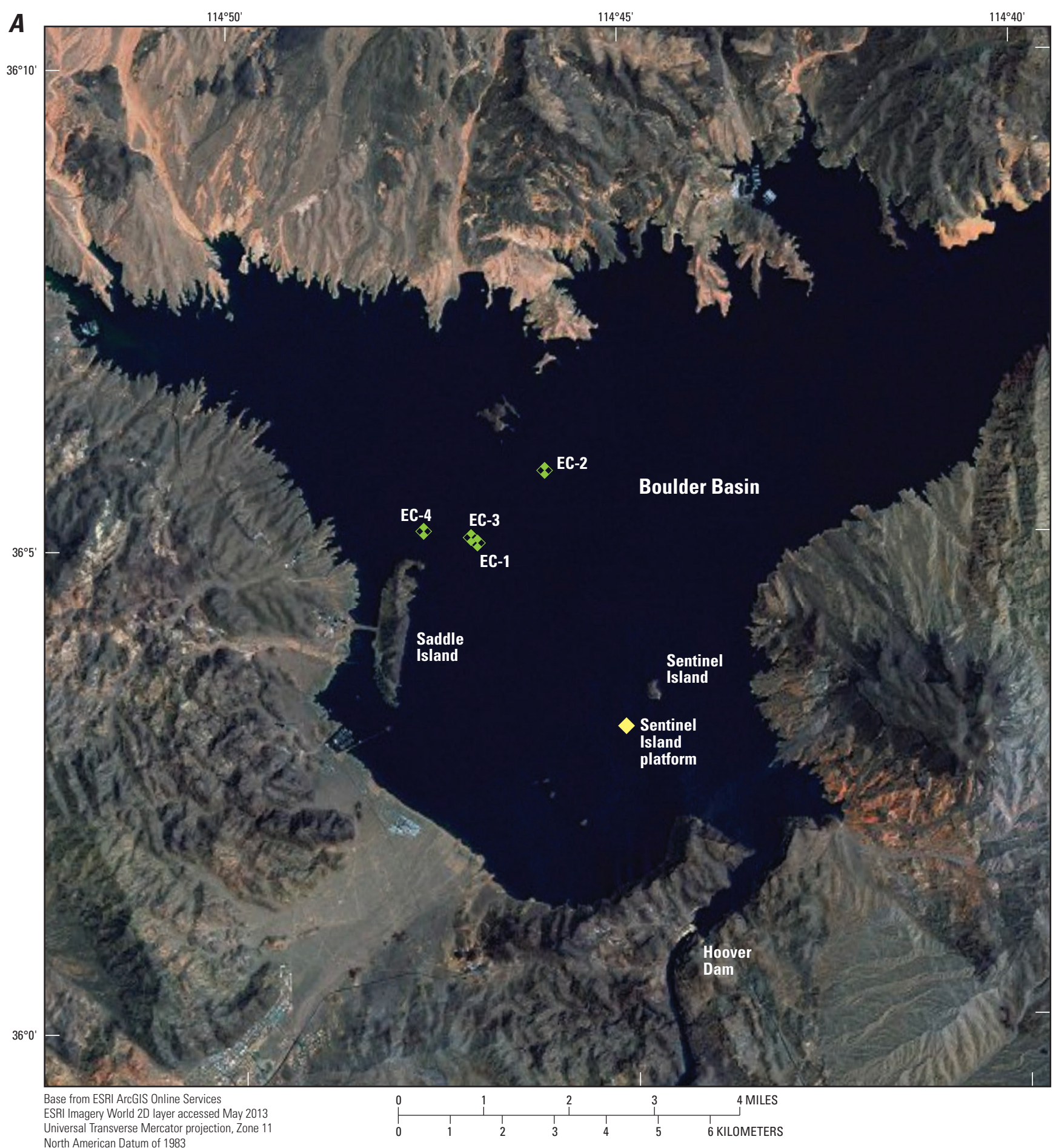

Figure 4. Eddy-covariance $(\mathrm{EC})$ and Sentinel Island platform sites in Boulder Basin, Lake Mead. $A$, Background image showing Lake Mead near full capacity, and $B$, High-resolution image from May 2010, showing rock outcrops with lake elevation at 334.14 meters $(1,096.25$ feet), which is about 40 meters (131 feet) below full capacity. 


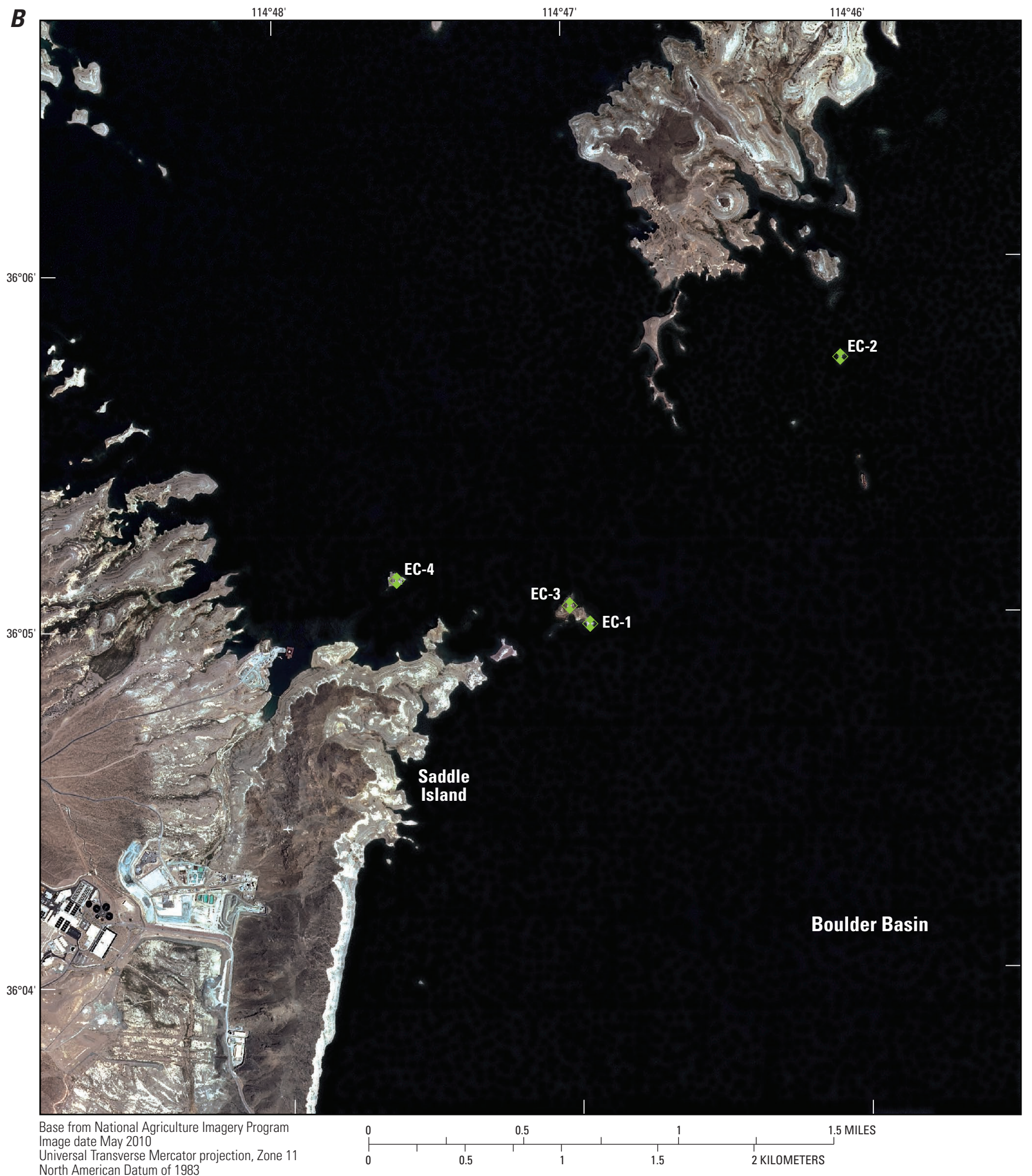

Figure 4. Eddy-covariance $(\mathrm{EC})$ and Sentinel Island platform sites in Boulder Basin, Lake Mead. $A$, Background image showing Lake Mead near full capacity, and $B$, High-resolution image from May 2010, showing rock outcrops with lake elevation at 334.14 meters $(1,096.25$ feet), which is about 40 meters (131 feet) below full capacity.-Continued 
concurrently from May 20, 2010 to April 7, 2011 when the CNR2 at EC-1 was inundated because of the rising lake stage. A 4-component (incoming and outgoing short- and longwave radiation) radiometer (Model CNR1) of higher quality than the CNR2s was deployed to the SI platform from October 12, 2011 to February 29, 2012 for use as a reference (figs. 3 and 4). Net radiation measurements were adjusted to achieve consistency between sensors and station locations based on comparisons to readings from the CNR1. Net radiation data from the CNR2 at the SI platform was corrected downward based on a side-by-side comparison to the CNR1 $\left(\mathrm{R}^{2}=0.99\right)$. Net radiation data from the CNR2 at the SI platform was biased high by about $13 \mathrm{~W} / \mathrm{m}^{2}$ on average compared to the CNR1. For the 81 days when a CNR2 at EC-1 was the only net radiation sensor, data from that sensor were corrected based on the relation between it and the corrected values from the CNR2 at the SI platform over the 322 days when both sensors were simultaneously in operation. Net radiation measured by the CNR2 near EC-1 was about 2.5 percent lower than values from the CNR2 at the SI platform corrected to the CNR1 $\left(R^{2}=0.98\right)$, so values were corrected upward by that amount for consistency. Corrections made to the net radiation data are within the accuracy of the CNR2 sensors (less than 10-percent uncertainty in daily total (Campbell Scientific, Inc., 2010)), and similar in magnitude to differences described for these sensors by Blonquist and others (2009).

Change in stored heat $\left(Q_{X}\right)$ was calculated from watertemperature profiles at the SI platform. Temperatures to $76 \mathrm{~m}$ (or the maximum depth measured if greater than $76 \mathrm{~m}$ ) were used to calculate change in stored heat. Below this depth, water temperature varies little (Veley and Moran, 2012). The temperature data were combined with lake stage and bathymetric data to obtain the change in stored heat using the following equation (modified from equation 93 in Anderson and Pritchard (1951), p. 101, and from Dave Stannard, U.S. Geological Survey, written commun., 2010):

$$
Q_{X}=\frac{1}{A_{s} t}\left[\begin{array}{c}
C_{w} \sum_{i=1}^{n}\left(T_{i}^{t}-T_{b}\right) A_{i}^{t} T H_{i}+\left(T_{c}^{t}-T_{b}\right) A_{c}^{t} T H_{c}^{t}- \\
C_{w} \sum_{i=1}^{n}\left(T_{i}^{t-1}-T_{b}\right) A_{i}^{t-1} T H_{i}+\left(T_{c}^{t-1}-T_{b}\right) A_{C}^{t-1} T H_{c}^{t-1}
\end{array}\right]
$$

where

$Q_{x}$ is change in heat stored per unit surface area of water body, in $\mathrm{W} / \mathrm{m}^{2}$,

$C_{w}$ is volumetric specific heat of water, equal to $4.187 \mathrm{x}$ $10^{6} \mathrm{~J} / \mathrm{m}^{3}{ }^{\circ} \mathrm{C}$,

$t$ is length of measurement period, in seconds,

$\mathrm{TH}$ is thickness of layer in which temperature change is measured, in $\mathrm{m}$,

$T$ is the average temperature of a layer, in ${ }^{\circ} \mathrm{C}$,

$T_{b}$ is the base temperature (assumed zero), in ${ }^{\circ} \mathrm{C}$, and

$A$ is surface area of lake, in $\mathrm{m}^{2}$.

subscript $i$ refers to the $i$ th layer, 1 refers to the first (top) layer, $n$ refers to the second from the bottom layer (constant thickness layer), and $c$ refers to the bottom layer (variable thickness layer).

superscript $t$ refers to the end of the measurement period and $t-1$ refers to the beginning of the measurement period.
Temperature profiles measured just after midnight (00000060 hour) on the first day of the month were used to quantify the monthly change in stored heat. The average temperature of each layer $(T)$ was computed as the average of the temperatures measured at the top and the bottom of the layer. Layer thickness $(\mathrm{TH})$ was $5 \mathrm{~m}$ except for the top and bottom layers; the top layer was 1-m thick and the bottom layer thickness varied based on the lake level. Layer area $(A)$ was the average of the top and bottom layer areas, determined from lake stage and bathymetric data. The total stored heat for the lake at the beginning of each month was the sum of the heat contents of all the layers. Change in stored heat was then calculated as the difference between the total stored heat from one month to the next. Anderson and Pritchard (1951) determined that a single temperature profile was representative of all of Lake Mead for the purpose of quantifying $Q_{x}$ based on 12 surveys over a year at 60 locations distributed throughout the lake. They found that differences between temperature profiles in shallow and deep parts of the lake were not significant and that "energy storage for any standard layer and the monthly change in this storage are essentially uniform regardless of the depth of the water." A Wilcoxon signed-rank statistical test of monthly stored heat calculated using temperature data from floating platforms at Sentinel Island, Temple Basin, and Virgin Basin (Veley and Moran, 2012) found no significant difference between the median monthly change in stored heat for paired values from any two of these locations ( $p=0.64$ to 0.93 ).

Net advected heat $\left(Q_{v}\right)$ to Lake Mead is the difference between inflowing and outflowing heat that enters and leaves the lake along with water gains and losses. Net advected heat was calculated using the following equation (Omar and ElBakry, 1981):

$$
Q_{V}=\frac{\left[\sum_{i=1}^{n} C_{w} V_{i}\left(T_{i}-T_{b}\right)-\sum_{o=1}^{m} C_{w} V_{o}\left(T_{o}-T_{b}\right)\right]}{A t}
$$

where

$V$ is the volume of inflow or outflow during the period, in $\mathrm{m}^{3}$, subscript $i$ refers to the $i$ th of $n$ inflows, subscript $o$ refers to the oth of $m$ outflows, and other terms are as previously defined.

Advected heat is calculated using the lake water budget and mean monthly measurements or estimates of inflow and outflow temperatures. Inflows to Lake Mead were calculated based on 1) releases from Glen Canyon Dam, and 2) side inflows, which are approximated as the water-budget residuals. Precipitation is a small component of the Lake Mead water budget and is not considered in $Q_{v}$. Outflows from Lake Mead were calculated based on 1) Hoover Dam releases, 2) SNWP withdrawals, and 3) changes in bank storage. Energy advected by evaporating water is accounted for separately as $Q_{w}$ (equations 2 and 5). The energy and water budgets are linked through the advected and stored heat terms, and those two budgets were solved iteratively until convergence was achieved (Saur and Anderson, 1956). Change in stored heat does not vary with each iteration, but advected heat does because the side inflow (residual) term is recalculated at each 
iteration when new evaporation values are added. Convergence of these two equations was rapid, occurring within a few iterations.

The farthest downstream measured water temperature between Glen Canyon Dam and Lake Mead was used to estimate inflow temperatures of both the Colorado River and side inflows when calculating $Q_{v}$. Temperature of the Colorado River in that section is measured at many locations by the Grand Canyon Monitoring and Research Center (Voichick and Wright, 2007; Wright and others, 2009). These measurements use distance downstream from Lees Ferry as a reference system in river miles (RM); Lees Ferry is RM 0, which is about 15 river miles downstream from Glen Canyon Dam (http://www.gcmrc.gov/; Wright and others, 2009). During the period of record for the study, the farthest downstream measurements were at either RM 226 or RM 246 (fig. 1). The upstream end of the lake was at approximately RM 280 using this reference system and the average lake stage during the study. Accordingly, the temperature used for inflow was measured about 34 to 54 river miles upstream from the end of the lake, on average. On the basis of Grand Canyon Monitoring and Research Center data collected over 10 years, monthly mean water temperature increases downstream except in the winter, with the rate of increase varying seasonally and being highest in June $\left(0.02{ }^{\circ} \mathrm{C} / \mathrm{km}\right.$; Wright and others, 2009). Wright and others (2009) developed a simple model to estimate temperature changes in the Grand Canyon based on a linear increase in temperature with distance downstream that reproduced measured monthly average temperatures within $0.5^{\circ} \mathrm{C}$. Based on this model, temperatures at RM 280 could range from zero to $1.5^{\circ} \mathrm{C}$ higher than the farthest downstream measured temperature, with the largest differences occurring between May and September. But Wright and others (2009) also note that the increase in temperature is lower than predicted in the fall in the lower part of this reach (closer to the lake). A sensitivity analysis of the effects of variations in flows and temperatures on $Q_{v}$ found that $Q_{v}$ was not particularly sensitive to the difference between the farthest downstream measured temperature and inflow temperatures estimated using relations from Wright and others (2009). Therefore, temperature data from RM 226 or RM 246 (depending on availability) were used to compute $Q_{v}$, and temperature changes in the river downstream from the last measurement point and their effects on $Q_{v}$ and lake evaporation were assumed negligible.

Temperature of the outflow from Hoover Dam is measured at the tailrace and was provided by Reclamation. Temperatures of SNWP withdrawals were assumed to be equal to the monthly average lake-surface temperature. Temperatures of water going into and out of bank storage were assumed to be equal to the monthly average lake-surface temperature when the lake level was rising, and equal to the long-term (24-month) average lake-surface temperature (a surrogate for groundwater temperature) when the lake level was falling.

\section{Eddy Covariance}

Eddies are turbulent airflow caused by wind, surface roughness, and convective heat flow in the atmospheric surface layer (Swinbank, 1951; Brutsaert, 1982; Kaimal and Finnigan, 1994). Eddies transfer energy and mass between land and water surfaces and the atmosphere through a process referred to as turbulent exchange, or turbulent transport (Brutsaert, 1982). The EC method provides the most direct measure of turbulent exchange currently available (Baldocchi, 2003; Foken, 2008; Stannard and others, 2013). Fluxes of water vapor and heat can be measured directly without the application of empirical constants by finding the covariance between these scalars and vertical wind speed (Foken, 2008; Campbell Scientific, 2010c). Evaporation (positive latent-heat flux) occurs when water vapor in upward moving eddies is greater than in downward moving eddies. Likewise, sensible-heat flux is positive (from the surface to the atmosphere) when upward moving eddies are warmer than downward moving eddies.

Latent-heat flux is the energy removed (in this study) from Lake Mead during the liquid-to-vapor phase change of water, and is the product of the latent heat of vaporization of water $(\lambda)$ and water-vapor flux density. The latent heat of vaporization, although slightly temperature dependent, is nearly a constant. Water-vapor flux density is calculated as the covariance of instantaneous deviations from the time-averaged product of water-vapor density and vertical wind speed. EC latent-heat flux can be expressed mathematically as

$$
Q_{e c}=\lambda \overline{w^{\prime} \rho_{v}^{\prime}}
$$

where

$\mathrm{w}$ is vertical component of wind speed, in $\mathrm{m} / \mathrm{s}$, and

$\rho_{v}$ is water vapor density, in $\mathrm{g} / \mathrm{m}^{3}$.

The prime symbols are deviations from mean values and the overbar denotes mean value. Deviations from mean values were measured 10 times per second, and mean values were computed over a 30-minute period. $Q_{e c}$ is converted to evaporation using equation 3 .

Sensible-heat flux is the movement of heat energy that results from a temperature difference between the surface and the atmosphere. The EC method computes sensible heat from temperature and vertical wind speed as

$$
Q_{h c}=\rho_{a} C_{p} \overline{w^{\prime} T_{a}^{\prime}}
$$

where

$\rho_{a}$ is air density, in $\mathrm{kg} / \mathrm{m}^{3}$,

$C_{p}$ is specific heat of air, in $\mathrm{J} / \mathrm{kg}{ }^{\circ} \mathrm{C}$, and

$T_{a}$ is air temperature, in ${ }^{\circ} \mathrm{C}$.

The sum of latent- and sensible-heat fluxes is referred to as turbulent flux, or turbulent energy, in $\mathrm{W} / \mathrm{m}^{2}$.

In addition to water vapor and heat, a turbulent flux of horizontal momentum also occurs from the atmosphere to the surface. Horizontal wind speed is zero at the surface 
and increases with height above the surface. This transfer of momentum downward can be expressed as

$$
\tau=-\rho_{a} \overline{w^{\prime} u^{\prime}}
$$

where

$u$ is horizontal wind speed, in $\mathrm{m} / \mathrm{s}$.

The downward gradient implies a flux of horizontal momentum from the upper atmosphere to the surface, also recognized as a drag force exerted on the surface by the air (Stannard, 2013). This concept is important for determining the source area of turbulent-flux measurements.

\section{Energy Balance of an Open-Water Body and the Energy "Imbalance" Problem}

Equation 2 describes all of the known energy fluxes for an open-water body. Excluding the energy fluxes considered negligible for the current study, equation 2 can be rearranged to describe the Lake Mead energy balance as follows:

$$
Q_{n}-Q_{x}+Q_{v}=Q_{e}+Q_{h}
$$

Each of the energy fluxes in equation 13 is measured independently for the EC method. The left side of the equation represents available energy, and the right side represents turbulent energy. According to the first law of thermodynamics, the available energy is partitioned into either $Q_{e}$ or $Q_{h}$. The ratio of turbulent to available energy, called the energy-balance ratio (EBR), is computed as follows:

$$
E B R=\frac{Q_{e}+Q_{h}}{Q_{n}-Q_{X}+Q_{v}}
$$

If all known energy fluxes appear in equation 2 , and if all energy fluxes are measured accurately (within the limits of measurement accuracy), then the EBR would equal unity. This concept is commonly called energy-balance closure. The EBR is a commonly used metric to quantify energy-balance closure; notwithstanding, good energy-balance closure can result from offsetting erroneous measurements. In reality, the sum of EC turbulent energy is consistently less than the sum of available energy, with various explanations for the source of the discrepancy (Wilson and others, 2002; Foken, 2008; Foken and others, 2012; Leuning and others, 2012). Wilson and others (2002) studied the results of other investigators and report annual EBR values ranging from 0.39 to 1.69 for 50 site-years of data at $22 \mathrm{EC}$ sites, with an average value of 0.8 , thus implying that on average 80 percent of available energy is accounted for by turbulent-energy measurements. This lack of energy-balance closure is quantifiable because the EC system measures latent- and sensible-heat energy independently.

Resolving the so-called "energy imbalance problem", or balancing the latent- and sensible-heat energy against independently-measured available energy, is an active area of research in the EC community. There currently is no consensus on whether closure should be forced, in other words, whether latent- and sensible-heat energy should be adjusted upward to fit the available energy. Leuning and others (2012) argue that 30-minute turbulent-flux measurements systematically underestimate the available energy at most EC sites because of phase lags caused by incorrect estimates of the energy storage in soils, air, and biomass below the measurement height. After correcting for these phase lags, they conclude the remaining imbalance may be explained by advective flux divergence that can move energy either toward or away from EC sensors. These investigators also question the currently accepted practice of forcing the mean vertical wind speed measured by the sonic anemometer to zero (described in Data-Reduction Procedures), and suggest that a better method may be to maximize the covariance between the vertical wind speed and temperature/water vapor. Foken and others (2012) suggest that the lack of closure at many EC sites is not related to errors in the EC method, but instead is related to atmospheric conditions that cannot be measured using the EC method. When airflow contacts significant landscape heterogeneities, large eddies are formed and a secondary atmospheric circulation pattern is developed; therefore, these secondary circulation patterns are not uniformly distributed over an area. Furthermore, these secondary circulation patterns are characterized by the transfer of energy from small to very large (greater than $1 \mathrm{~km}$ ) eddies. The time of passage of these very large eddies likely is too long for the typical 30-minute to 1-hour averaging periods to capture; however, longer averaging periods begin to violate the principles of stationarity. The resulting advective flux divergence is difficult to detect. These investigators also add that the scalar similarity, represented by the EC-measured Bowen ratio, may not be representative of advected fluxes. There is evidence to suggest that a large part of the unclosed energy budget is related to the sensible-heat flux; however, the authors go on to suggest that as a first approximation the energy budget may be closed according to the EC-measured Bowen ratio.

\section{Site Locations}

For this study, and in general, the ideal site placement for an EC station is one where the terrain surrounding the site is flat and homogeneous, and where the fetch for the surface-ofinterest is longer than the turbulent-flux source area. Fetch is defined in this study as the upwind distance from the measurement point to the shore and the surface-of-interest is open water. The fetch needs to be long enough for airflow measured by EC sensors to equilibrate to the open-water evaporating surface (Rosenberry and others, 2007). Deploying EC sensors from a raft is impractical because the wave-induced raft movement interferes with the EC measurements. One option was to locate multiple EC stations along the shore to ensure representative open-water measurements with wind originating from all possible directions (360 compass degrees). This option was rejected because the terrain surrounding Lake Mead is topographically complex — characterized by sparsely vegetated gently-to-moderately sloping alluvial fans, and steep, barren, 
rocky cliffs (Westenburg and others, 2006). These features create complex airflow regimes at the shore, which are problematic for the EC method. A second option was made possible by the historically low lake stage during 2010. A series of small rock outcrops surrounded on all sides by the open-water surface became exposed and could be used to support EC sensors (fig. 4b). This option, which was selected, had the additional cost-effective advantage of requiring only a single EC station. As the lake stage rose $16.04 \mathrm{~m}$ between November 2010 and January 2012, primarily because of an unusually wet winter (2010-2011) in the Rocky Mountains, the EC station (equipment array) was relocated to successively higher outcrops (sites). Each of the four sites selected for this study had limitations in terms of fetch; however, all locations afforded wide angles where the fetch was between 2,000 and 16,000 m. Figure $4 \mathrm{~b}$ is a high-resolution image showing a snapshot of the available fetch for each site during May 2010 when the lake elevation was $334.14 \mathrm{~m}$ (1,096.25 ft). Fetch varies with lake stage and wind direction, and can change abruptly with small changes in wind direction because of shoreline irregularities; as a result, the fetch estimates presented here are approximate. Table 2 and the following paragraphs summarize the details about each site location and its period of record. EC sites 1 through 4 are numbered based on the chronological order in which they were occupied, with the first site (EC-1, fig. 4a and $4 \mathrm{~b})$ having the longest record of just under 14 months.

Site EC-1 was established on the southeastern tip of a 170-m long by 18- to 100 -m wide southeast-to-northwest trending triangular-shaped rock outcrop. EC sensor height (z) was $3.18 \mathrm{~m}$ above the water surface on March 1, 2010, which was the beginning of the period of record. As the water level declined, and eventually rose again, $z$ varied from $3.18 \mathrm{~m}$ to $9.66 \mathrm{~m}$. Fetch limitations at EC-1 included 1) wind coming from compass directions $275^{\circ}$ through $345^{\circ}$, which includes the rock outcrop itself beginning at the EC station, 2) wind coming across a peninsula (the exposed northeastern tip of Saddle Island) extending from the mainland from $242^{\circ}$ to $253^{\circ}$ that limited fetch in that direction to $600 \mathrm{~m}$, and 3) wind coming from the mainland from $225^{\circ}$ to $265^{\circ}$ that limited fetch to $1,300 \mathrm{~m}$. The fetch from all other directions ranged from 2,000 to $16,000 \mathrm{~m}$ (fig. $4 \mathrm{~b}$ ).

Site EC-2 was located on a roughly oblong rock outcrop that varied from about 15 -m wide by 30 -m long when the lake stage was highest to $25-\mathrm{m}$ wide by $50-\mathrm{m}$ long when the stage was lowest. Sensor height above the water surface ranged from 4.52 to $9.24 \mathrm{~m}$. Fetch at this site was limited to $800 \mathrm{~m}$ by the nearest mainland beginning at $305^{\circ}$, with fetch increasing to $2,000 \mathrm{~m}$ at $18^{\circ}$ going clockwise. The small rock outcrops to the north and west are believed to have a negligible impact on EC flux measurements. The fetch from all other directions was between 2,000 and 14,000 $\mathrm{m}$.

Site EC-3 was located on the same outcrop as EC-1. The difference was the outcrop was mostly inundated when this location was active except for a higher elevation section about $150 \mathrm{~m}$ to the northwest of EC-1. This last section of exposed outcrop was about 20-m wide by $35-\mathrm{m}$ long. Sensor height above the water surface ranged from 5.16 to $8.72 \mathrm{~m}$. Fetch at this site was limited to $700 \mathrm{~m}$ between $231^{\circ}$ and $251^{\circ}$ by the same peninsula that limited fetch for EC- 1 , and by the mainland to 1,300 to $1,900 \mathrm{~m}$ between $224^{\circ}$ and $283^{\circ}$. The fetch from all other directions was between 2,000 and 16,000 m.

Site EC-4 was located on a roughly circular outcrop $30 \mathrm{~m}$ in diameter. Sensor height above the water surface ranged from 3.70 to $6.86 \mathrm{~m}$. Fetch at this site was limited to $500 \mathrm{~m}$ by the north section of Saddle Island beginning at $189^{\circ}$, with fetch increasing to $1,000 \mathrm{~m}$ at $286^{\circ}$ going clockwise. The fetch from all other directions was between 2,000 and 16,000 m.

\section{Source Area and Atmospheric Stability}

The source area contributing to the mean measured turbulent fluxes is the area from which the measured variables (water vapor and heat) originate. Turbulent-flux measurements can be conceptualized as weighted averages of the flux originating from a series of elemental surfaces that represent contributing areas upwind of the sensors. The cumulative normalized contribution to the measured turbulent flux (cumulative normalized flux, or CNF) increases with distance from the sensors (Schuepp and others, 1990). The relative contribution of turbulent flux (also called the footprint) is zero at the sensor location, increases rapidly to a maximum a relatively short distance upwind of the sensors, then decreases asymptotically with increasing distance from the sensors. The source area mathematically extends to infinity, but because no measured surface is infinite, 50-, 75-, and 90-percent source areas contributing to a point flux measurement are often considered (Rannik and others, 2012).

Table 2. Location and general description of eddy-covariance sites, Lake Mead, Nevada and Arizona.

[U.S. Geological Survey site identification: Unique identification number for site as stored in files and databases of the U.S. Geological Survey; UTM, Universal Transverse Mercator (zone 11)]

\begin{tabular}{cccccc}
\hline $\begin{array}{c}\text { Site number } \\
\text { (see fig. 4) }\end{array}$ & $\begin{array}{c}\text { U.S. Geological Survey } \\
\text { site identification }\end{array}$ & North UTM & East UTM & Altitude, in meters & Period of reported measurements \\
\hline EC-1 & 360500114465601 & 3995454 & 699677 & 337.02 & $03 / 01 / 2010$ to 05/24/2011 \\
EC-2 & 360500114465601 & 3996845 & 700974 & 341.09 & $05 / 24 / 2011$ to 08/25/2011 \\
EC-3 & 3605001144656601 & 3995555 & 699560 & 345.33 & $08 / 25 / 2011$ to $11 / 23 / 2011$ \\
EC-4 & 360500114465601 & 3995677 & 698662 & 347.10 & $11 / 23 / 2011$ to 02/29/2012 \\
\hline
\end{tabular}


In this study, an analytical model was used to quantify the $\mathrm{CNF}$ as a fraction of the turbulent flux originating within defined extents (Kormann and Meixner, 2001). Source area characteristics are dependent upon the sensor height $(z)$ above the zero plane displacement $(d)$, the surface roughness $\left(z_{o}\right)$, and atmospheric surface layer (ASL) stability. The sensor height above the water surface at each site location was determined based on 1) a steel-tape measurement of the sensor height above the tripod base, 2) a differential Global Positioning System survey of the tripod base and water surface (vertical accuracy of $0.025 \pm .010 \mathrm{~m}$ ), and 3) the water-surface elevation reported hourly by Reclamation. The zero plane displacement, which is the height above a surface where semi-logarithmic wind-speed profiles extrapolate to near zero, is assumed to be zero because wind is not obstructed on the open-water surface. The roughness length $\left(z_{o}\right.$, in $\left.\mathrm{m}\right)$, a measure of the friction effect of wind created by the surface roughness, was computed with the following equation (Brutsaert, 1982):

$$
z_{O}=\frac{z-d}{\exp \left(\frac{k U}{u_{*}}\right)}
$$

where

$z$ is the sensor height above the water surface, in $\mathrm{m}$,

$d$ is zero-plane displacement (0.0), in $\mathrm{m}$,

$k$ is the von Karman constant (0.4), dimensionless,

$U$ is mean wind speed at sensor height, in $\mathrm{m} / \mathrm{s}$, and

$u_{*}$ is friction velocity, in $\mathrm{m} / \mathrm{s}$.

Friction velocity is computed as

$$
u_{*}=\sqrt{\frac{\tau}{\rho_{a}}}
$$

where $u_{*}$ represents the effect of shear stress on the surface, and its magnitude depends on the nature of the surface and wind speed. Equation 15 is strictly valid only for neutral ASL stability, where $u_{*}$ describes a logarithmic wind profile and wind speeds increase with increasing height above the surface. The wind profile does depart slightly from logarithmic depending on ASL stability; however, for applications within $10 \mathrm{~m}$ of the surface, the wind profile is assumed to be almost always logarithmic (Kaimal and Finnigan, 1994, p. 11).

ASL stability can be generally categorized as stable, unstable, or neutral. Under stable conditions the air temperature increases with increasing height above the surface. Turbulence is almost entirely mechanical in origin and a capping inversion acts as a lid dampening vertical motions and suppressing turbulent exchanges. Air flow is characterized by strong wind shear and smaller eddies. Conversely, for unstable conditions the air temperature decreases with increasing height above the surface. Turbulence is developed by both mechanical and convective (buoyant) forces, which enhance turbulent exchange processes. Increasing the temperature gradient for either of these diabatic conditions increases the degree of stability/ instability. Neutral conditions exist when air parcels displaced up and down adiabatically maintain exactly the same density as the surrounding air and thus experience no net buoyancy forces (Kaimal and Finnigan, 1994). A parameter representing ASL stability ( $z / L$, dimensionless) was estimated using the following equation (Monin and Obukhov, 1954; Kaimal and Finnigan, 1994):

$$
\frac{z}{L}=-\frac{k(z-d) g Q_{h}}{T_{v} \rho C_{p} u_{*}^{3}}
$$

where

$L$ is the Monin-Obukhov length, in m,

$g$ is the gravitational acceleration constant (9.81), in $\mathrm{m} / \mathrm{s}^{2}$,

$Q_{h}$ is sensible-heat flux, in $\mathrm{W} / \mathrm{m}^{2}$,

$T_{v}$ is virtual air temperature (ambient temperature minus the impact of relative humidity, or the temperature at which dry air would have the same density as moist air at the same pressure), in ${ }^{\circ} \mathrm{C}$, and

$C_{p}$ is specific heat of air, in $\mathrm{J} / \mathrm{kg}{ }^{\circ} \mathrm{C}$.

The source area is larger and $z / L$ is positive during stable conditions, and the source area is smaller and $z / L$ is negative for unstable conditions. The mean $z$ was computed for each processing period (approximately monthly), and $z_{0}, z / L$, and the CNF were computed for 50-, 500-, 1,000-, 2,000-, and 3,000-m fetch distances at 2-hour intervals for the period of record.

\section{Instrumentation}

The EC method uses fast-response sensors to measure the rapid fluctuations in water-vapor density, wind-speed components, and air temperature to compute latent- and sensible-heat fluxes. Two specialized sensors developed for EC measurements by Campbell Scientific, Inc. were used - a krypton hygrometer (Model KH2O) measured the water-vapor density fluctuations, and a three-dimensional sonic anemometer (Model CSAT3) measured the wind vector and air temperature fluctuations (table 3). A krypton lamp in the KH20 sensor

\begin{tabular}{|c|c|c|c|}
\hline Type of measurement & Company name & Instrument and model number & Placement \\
\hline Evaporation & Campbell Scientific & $\begin{array}{l}\text { CSAT3 3-D sonic anemometer } \\
\text { KH20 krypton hygrometer }\end{array}$ & $\begin{array}{l}2.4 \text { meters above land surface; } \\
3.2 \text { to } 9.7 \text { meters above water surface }\end{array}$ \\
\hline Air temperature / humidity & Vaisala & HMP45C TRH probe & 2.0 meters above land surface \\
\hline Precipitation & Novalynx & $260-2510$ rain and snow gauge & 1 meter above land surface \\
\hline Voltage & Campbell Scientific & CR3000 Datalogger & 1 meter above land surface \\
\hline
\end{tabular}

Table 3. Instruments used to measure turbulent fluxes and precipitation at eddy-covariance sites, Lake Mead, Nevada and Arizona. [Placement: The intervals given are approximate] 
emits an ultraviolet radiation signal along an approximately 1-cm path open to the atmosphere. The signal is attenuated according to Beer's Law as water vapor is absorbed. A voltage output proportional to the attenuated signal is recorded and related to vapor density by a regression function developed by the manufacturer (Campbell Scientific, Inc., 2010b). The CSAT3 measured turbulent fluctuations of horizontal and vertical wind speed using three pairs of non-orthogonally oriented transducers to transmit and receive an ultrasonic signal. The Doppler effect relates the flight time of the signal to wind speed. The speed of sound is also measured by the CSAT3 and used to estimate "sonic" air temperature (Campbell Scientific, Inc., 2010c). An electronic datalogger received output from these sensors at a frequency of $10 \mathrm{~Hz}$ (10 times per second). The centers of the KH2O and CSAT3 signal paths were separated by $10 \mathrm{~cm}$ and both sensors were positioned vertically (fig. 5). The CSAT3 was oriented facing $180^{\circ}$ for site EC-1, and $270^{\circ}$ for sites EC-2, EC-3, and EC-4 ("facing” means away from the support structure). The height of the paired sensors ranged from 3.18 to $9.66 \mathrm{~m}$ above the water surface. The orientation and positioning of the sensors were selected during each installation to minimize airflow disruptions that could be caused by the support structure and other sensors. All instruments were calibrated by the manufacturer shortly before installation and recalibrated according to manufacturer guidelines. Each site was visited approximately monthly for routine site maintenance and data acquisition.

Precipitation data were collected at each EC site using a National Weather Service type standard 8-in. diameter volumetric rain gage (appendix 1). The 8-in. rain gage is considered the most accurate means of collecting precipitation data and is the standard by which other rain gage designs are evaluated (Gordon, 2002). Water accumulated in the rain gage was measured and recorded during monthly site visits. Once measured, the water was discarded. Because of the very dry climate in the study area, a thin layer of mineral oil was added to the gage reservoir after each measurement to prevent evaporative losses of the collected precipitation between site visits. Gage-catch errors due to wind were not corrected. A gage-catch deficiency of about 10 percent can be expected during rainfall events where the average wind speed is $4 \mathrm{~m} / \mathrm{s}$ (Larson and Peck, 1974).

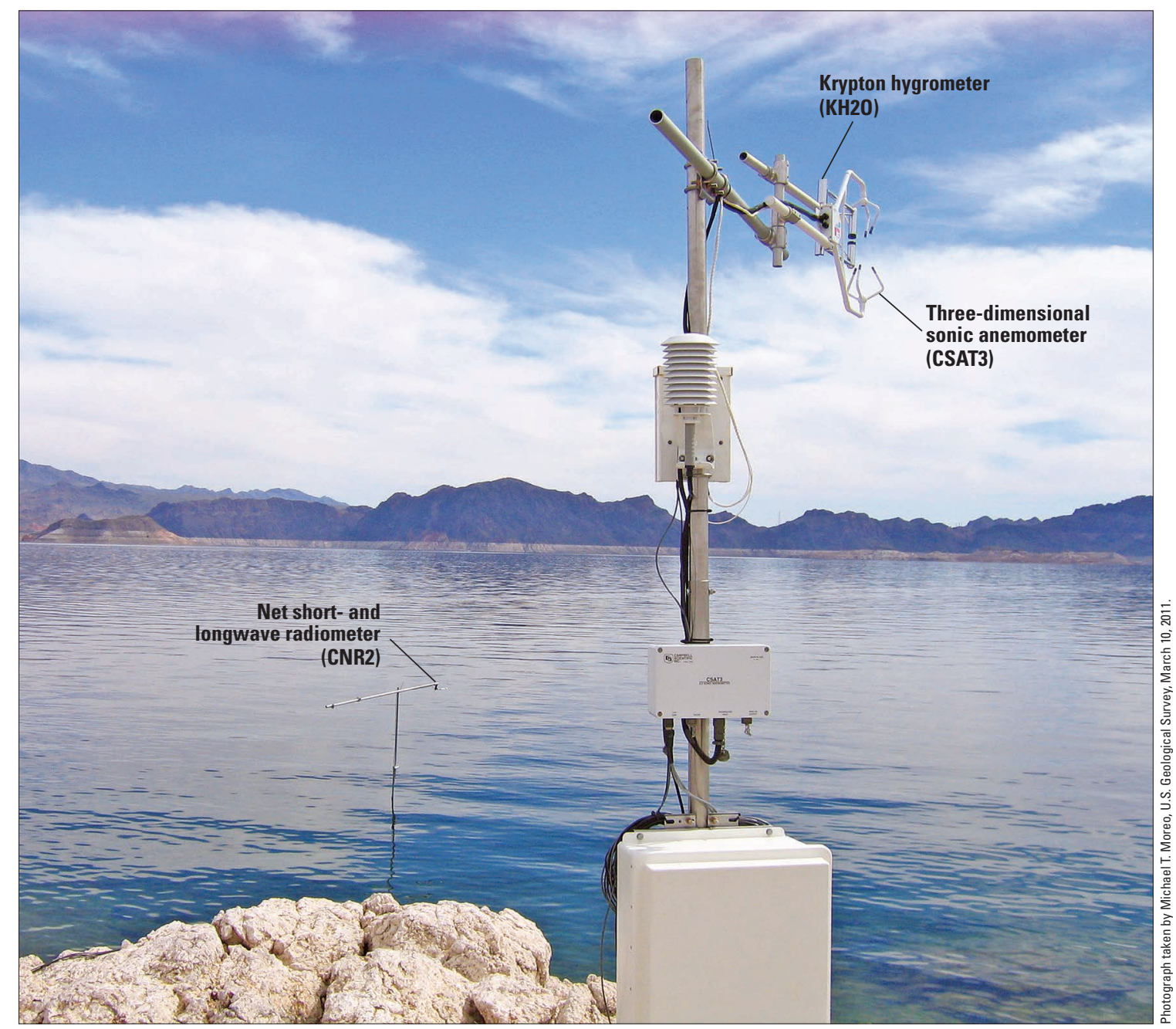

Figure 5. Eddy-covariance sensors at site EC-1 showing positioning. Corrected data from the radiometer were used for the first 81 days of the study. 


\section{Data-Reduction Procedures}

Several commonly used corrections must be applied to raw EC measurements to compensate for limitations both in the EC theory and equipment design. Raw 30-minute block-averaged covariances (equations 10 and 11) are computed from sampled 10-Hz data after filtering spikes (Højstrup, 1993) and removing any lag between CSAT3 and KH2O signal outputs. To correct errors associated with small misalignments of the CSAT3, raw covariances are two-dimensionally rotated to align with the mean streamlines of airflow, which forces the mean vertical and crosswind velocities to zero (Kaimal and Finnigan, 1994). Frequency response corrections were applied that compensate for the inability of eddy sensors to measure contributions from the largest (greater than $1 \mathrm{~km}$ ) and smallest (less than $10 \mathrm{~cm}$ ) eddies due to averaging time and sensor geometry such as path-length averaging and sensor separation (Moore, 1986). The contribution to non-zero average vertical wind speed caused by variations in the density of rising and falling air is corrected following Webb and others (1980). The slight attenuation of the $\mathrm{KH} 20$ signal caused by oxygen in the 1-cm signal path, which is proportional to the sensibleheat flux, is corrected as suggested by Tanner and Greene (1989). In addition, sensible-heat flux data are corrected for air density and sound-path deflection of sonic-derived temperatures (Schotanus and others, 1983). All 10-Hz EC data were post-processed and corrections applied using EdiRe software (Clement, 1999).

Poor-quality or unrepresentative 30-minute flux data were identified and removed by applying the following filters: (1) attenuation of the KH2O millivolt output signal caused by water accumulation during precipitation events, (2) greater than 10 percent of the 18,000 individual measurements by the CSAT3 that make up a 30-minute block average either filtered or missing, and (3) wind angle between $275^{\circ}$ and $345^{\circ}$ degrees at EC-1 where the fetch was insufficient because the island on which the station was located was large enough to contaminate the signal (turbulent-flux measurements were not representative of open water). About 22 percent of all 30-minute flux periods were filtered; of these, 15 percent were removed because of insufficient fetch at EC-1, 4 percent were removed because of rain events, and 3 percent were missing because the station at EC-3 was found toppled and was therefore inoperative from November 1-23, 2011.

Once questionable data were identified and removed, the resulting gaps were filled using estimated values. The estimation method depended on the gap length. Any gaps in latentor sensible-heat-flux data occurring for less than 2 hours were filled by linear interpolation between values measured before and after the gap period. For gaps spanning 2 hours or more, the mean diurnal variation (MDV) method was applied. The MDV method replaces missing values with the average of measured values for the same half-hour period for the 7 days before and after the gap (Falge and others, 2001). This gap-filling method was tested by randomly selecting, removing, and gap-filling 20 percent of valid latent-heat-flux values from June 8, 2011 to February 21, 2012 (excluding the period October 23, 2011 to November 30, 2011) and comparing the filled values with measured values. The overall difference between the measured and predicted values (bias) was less than 1 percent, and individual monthly biases were less than 5 percent. Daily latent- and sensible-heat fluxes from November 1-23, 2011, when all turbulent flux data were missing, were estimated by 1) interpolating a monthly turbulent flux based on rates for adjacent months, 2) subtracting the total measured flux between November 24, 2011 and November 30, 2011 from the interpolated monthly flux, and 3) dividing the remainder by the number of missing days to produce daily estimates for the gap period.

Thirty-minute averaged, filtered, and gap-filled evaporation rates were summed into daily, monthly, and annual evaporation rate estimates for the period of record (March 1, 2010 through February 29, 2012). Thirty-minute evaporation rates and other micrometeorological data are archived in the USGS National Water Information System database, which can be accessed through the Nevada Water Science Center evapotranspiration web portal (http://nevada.usgs.gov/water/et/ index.htm). Daily evaporation and other micrometeorological data and plots are also compiled in an electronic spreadsheet distributed with this report (appendix 1).

\section{Evaporation Results}

Evaporation from Lake Mead is dependent mainly on energy coming from the sun which heats water at the surface until it converts to vapor. The rate of evaporation is controlled by energy at the free-water surface and the ease with which water vapor diffuses into the atmosphere (Finch and Hall, 2005). The evaporation rate increases with increasing water temperature because water molecules at the free-water surface have greater kinetic energy with which to escape the intermolecular bonds of other water molecules. The vapor pressure at the water surface (at saturation, $e_{o}$ ) increases with increasing water temperature, and the evaporation rate increases with increasing $e_{o}$ and with increasing vapor pressure difference. The vapor pressure difference is the difference between the saturation vapor pressure at the free-water surface and the partial vapor pressure at some reference height above the surface ( $e_{a} ;$ Petrucci, 1985). Because Lake Mead is surrounded by the arid Mohave Desert, and because the reservoir has a high shoreline to surface area ratio, the vapor pressure difference over the lake generally increases with increasing wind speed as dry air blowing overland reaches the lake. Even though Lake Mead is a large lake, from an evaporation perspective it is essentially a series of smaller interconnected lakes. Boulder Basin is probably characterized by a continuous boundary layer governed by upwind land-surface conditions (Granger and Hedstrom, 2011). Under these advective conditions, evaporation decreases with distance downwind of shore as the evaporating surface causes the air temperature to decrease and the humidity to increase until some equilibrium is reached (Weisman and Brutsaert, 1973; Finch and Hall, 2005). 
Net radiation at Lake Mead follows a typical sinusoidal, mid-latitude, northern hemisphere pattern with a peak in June and trough in December (fig. 6A). Net radiation is greater than at most land-based sites because the surface reflectivity of clear, open water is low. Except for weather-induced intermittent periods, the air temperature above the lake $\left(T_{a}\right)$ generally is warmer than the surface-water temperature $\left(T_{0}\right)$ during spring and summer, and cooler during fall and winter (fig. 6B). Accordingly, the vapor pressure of the atmosphere $\left(e_{a}\right)$ and the water surface $\left(e_{o}\right)$ both increase and decrease with increasing and decreasing temperature (fig. $6 \mathrm{C}$ ). Turbulent
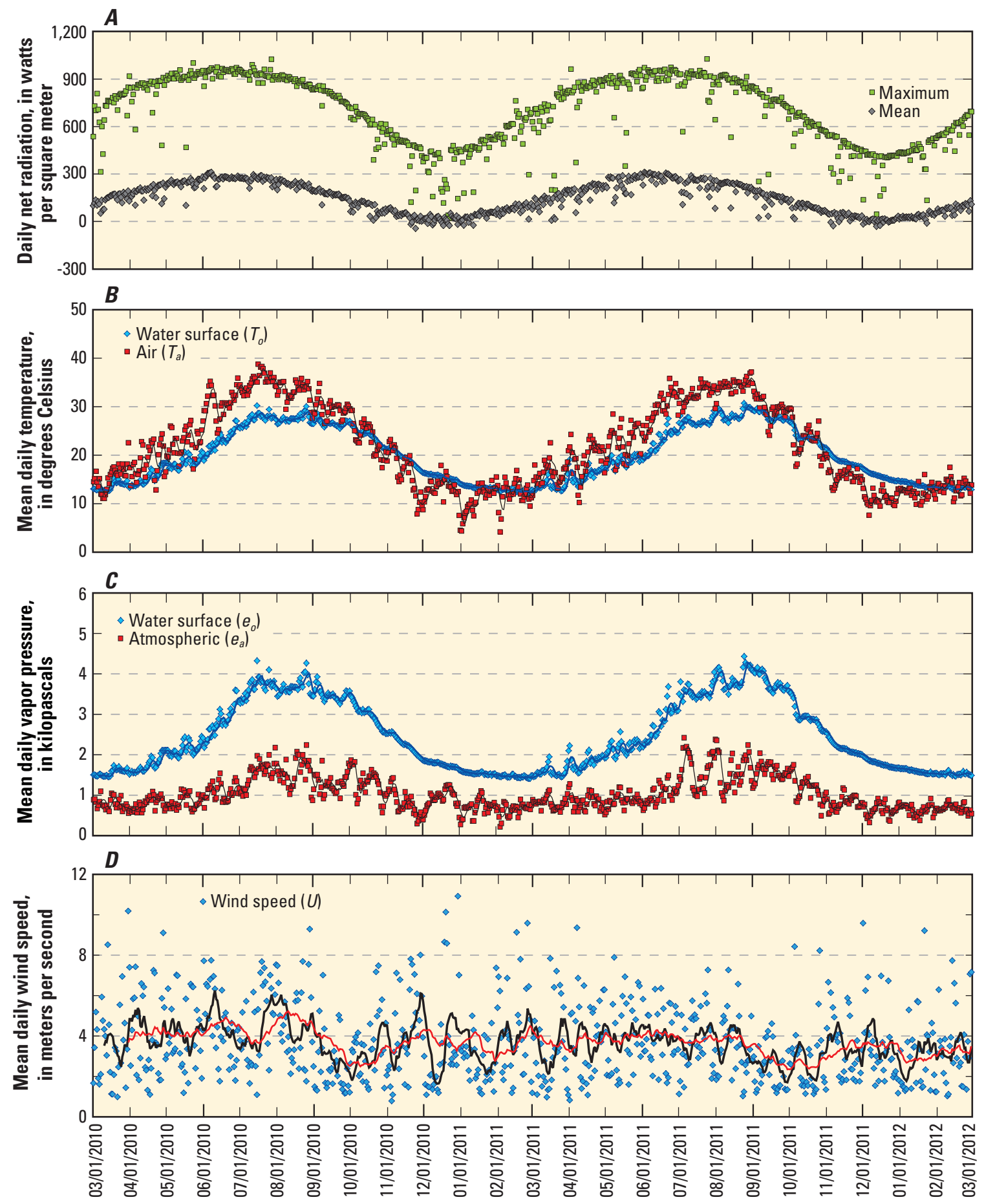

Figure 6. Daily $A$, Mean and maximum net radiation, $B$, Mean air and water-surface temperature, $C$, Mean atmospheric and watersurface vapor pressure, and $D$, Mean wind speed, Lake Mead, March 2010 through February 2012. 


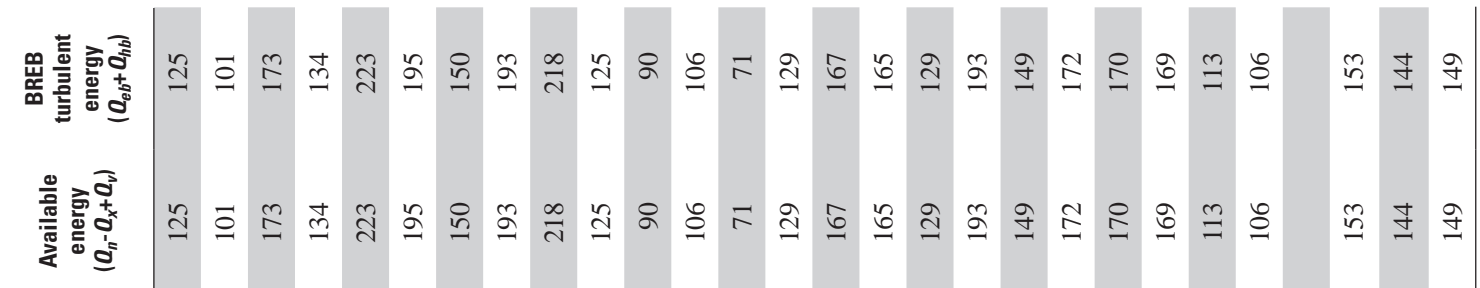

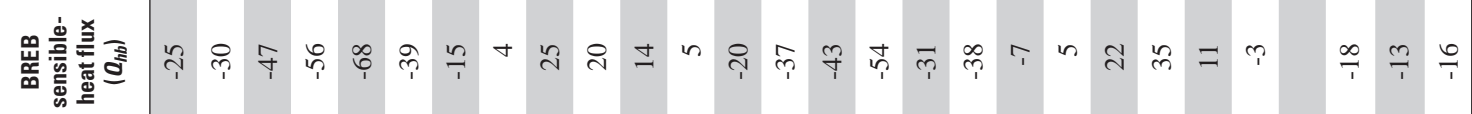
次

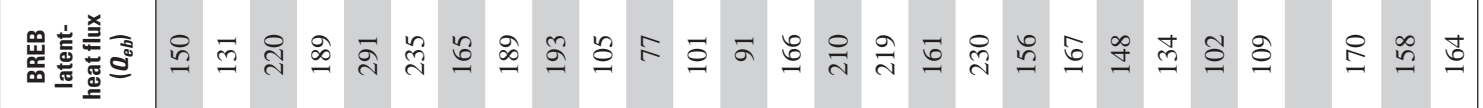

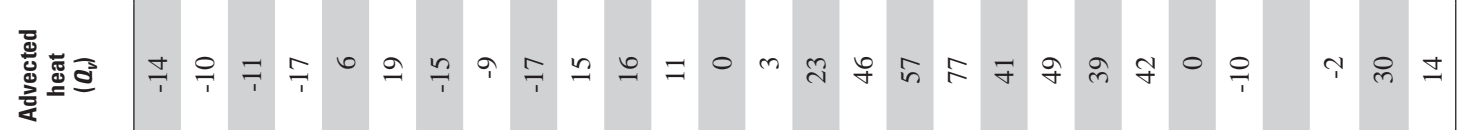

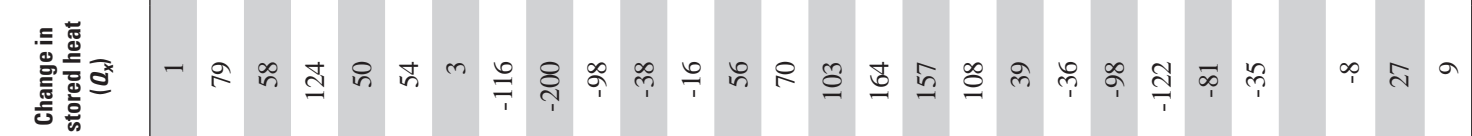

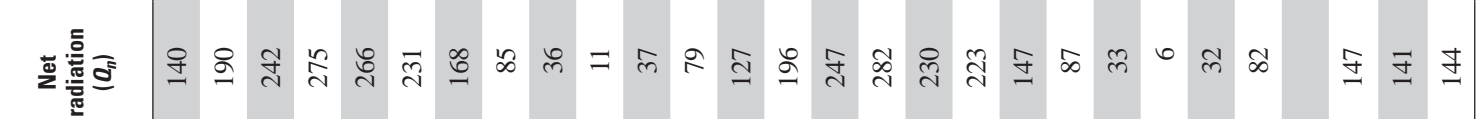

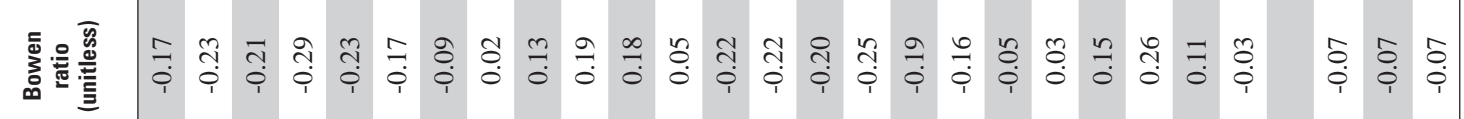

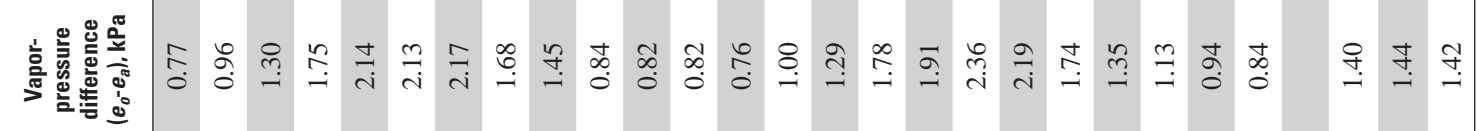

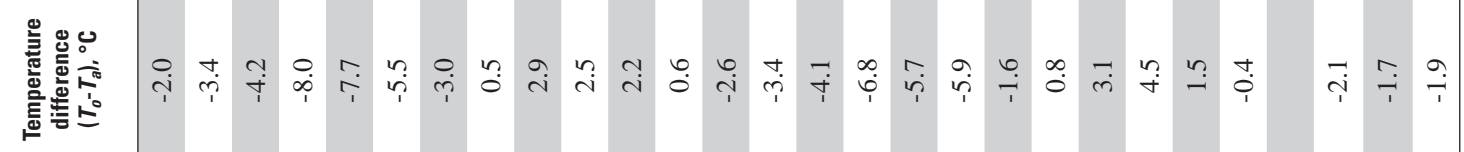

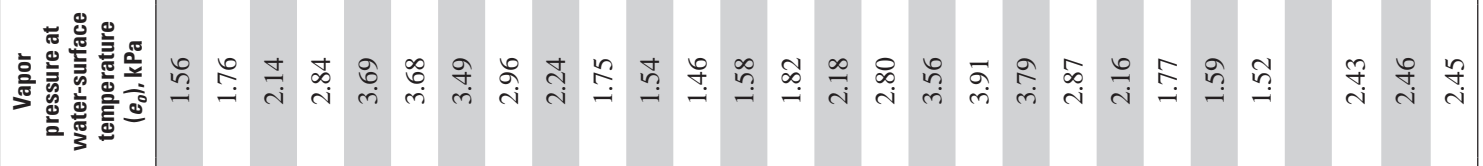

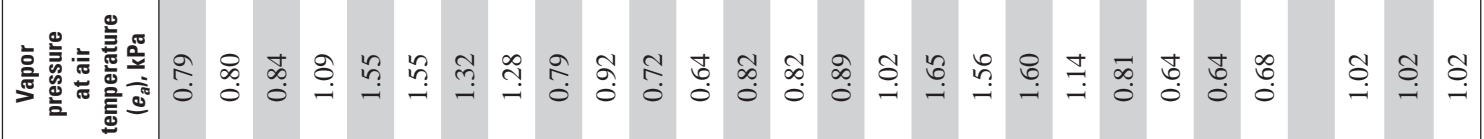

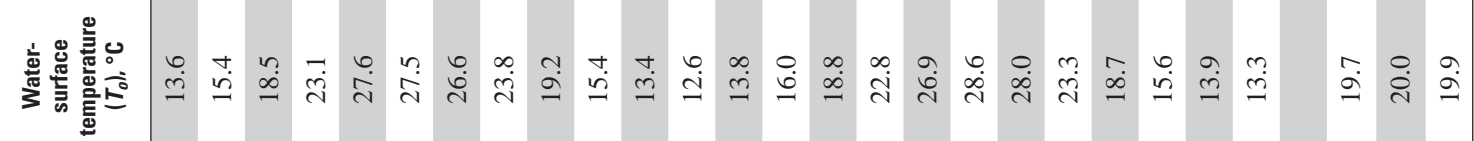

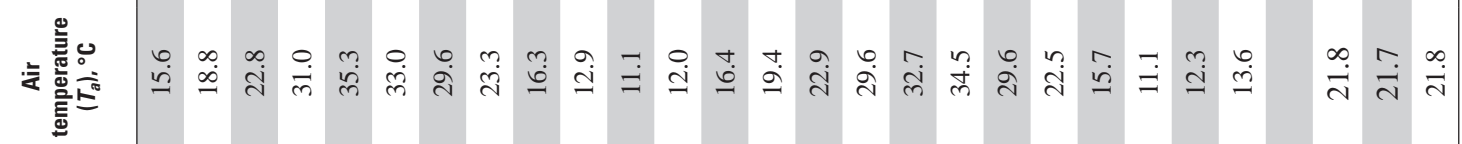


mixing was sustained by a daily mean wind speed of $3.74 \mathrm{~m} / \mathrm{s}$, with a median and standard deviation of 3.27 and $1.76 \mathrm{~m} / \mathrm{s}$, respectively, for the period of record (fig. $6 D$ ). These and other daily micrometeorological data are presented in table 4 and appendix 1 .

Water-temperature profiles to the lake bottom or to a depth where temperatures no longer vary are critical to creating an accurate energy budget. Lake Mead has a warm monomictic thermal regime (Wetzel, 1975); the lake does not freeze and temperatures stratify in the summer but not in the winter (fig. 7). Spring and summer temperature profiles for both years of the study were similar, but the lake was cooler in late fall and winter of the first year compared to the second. The slower rate of cooling during the second year can be explained by the greater volume and depth of the lake that year.
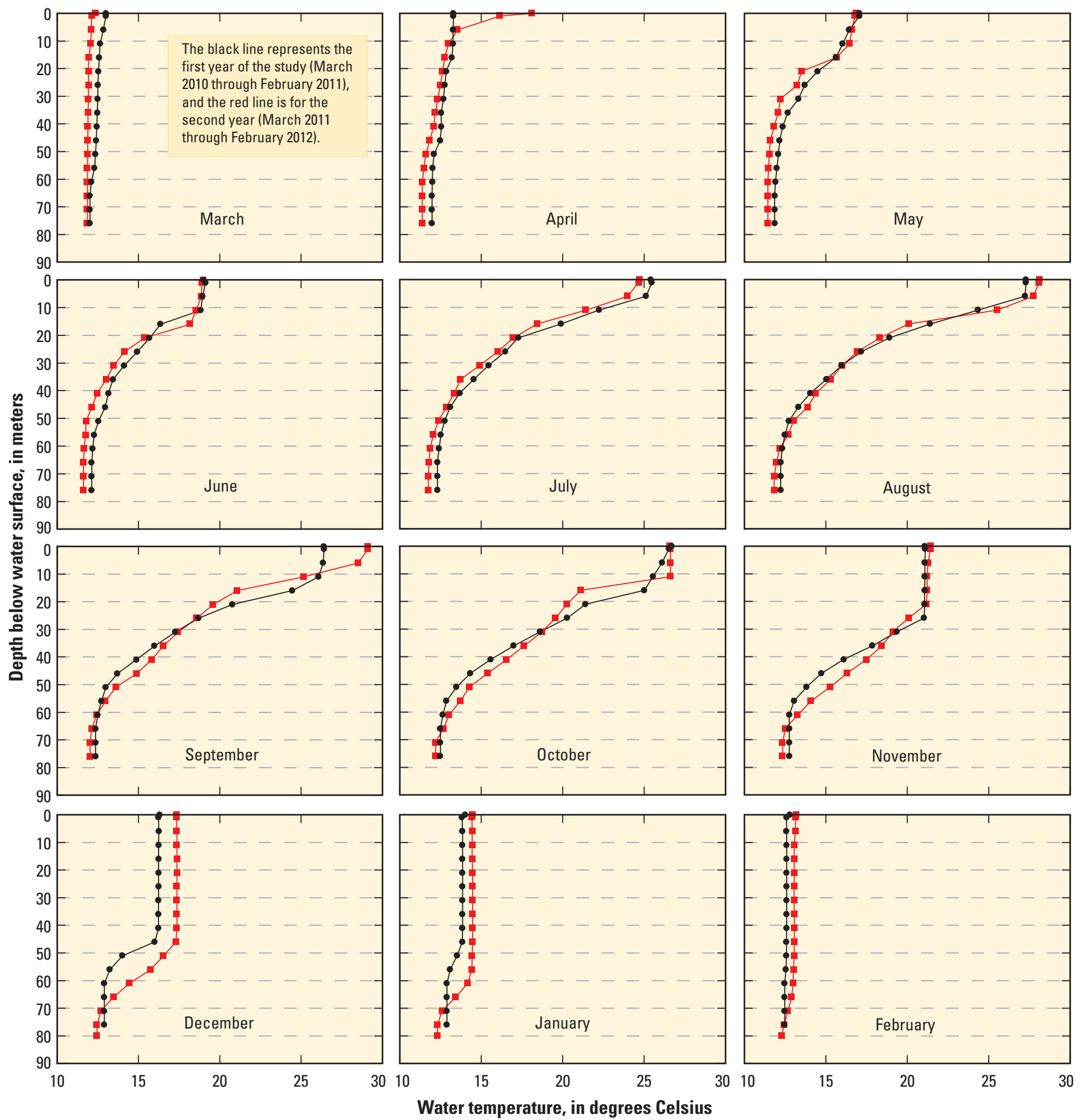

Figure 7. Monthly water-temperature profiles at Sentinel Island platform, Lake Mead. 


\section{Water Budget}

The Lake Mead water budget was estimated to relate evaporation to other water-budget terms, and because the water and energy budgets are linked through the advected and stored heat terms. In the first year of this study (2010), the elevation of Lake Mead was at historically low levels. The lowest daily level $(329.760 \mathrm{~m}$ or $1081.89 \mathrm{ft})$ since the reservoir was first filled occurred in November 2010 (fig. 8); levels below $330 \mathrm{~m}$ had not been seen since 1956. Fortunately, the lake level increased by the end of 2010 and continued to rise in 2011 as a result of the significant snowpack in the upper Colorado River Basin during the 2010-2011 winter. Increased water levels in upper Basin reservoirs resulted in increased releases from Glen Canyon Dam into the lower Colorado River Basin in accordance with the 2007 interim operational guidelines (Bureau of Reclamation, 2007). There was a net stage decline of $2.265 \mathrm{~m}$ (7.43 ft) during the first year of this study (March 1, 2010-February 28, 2011), and a net increase of $11.363 \mathrm{~m}$ (37.28 ft) during the second year (March 1, 2011-February 29, 2012) (fig. 8).

Total gains to the lake were the sum of releases from Glen Canyon Dam and side inflow, and total losses were the sum of Hoover Dam releases, evaporation, SNWP withdrawals, and bank storage. Releases from Glen Canyon and Hoover Dams dominate the Lake Mead water budget, accounting for greater than 90 percent of total gains or losses, respectively, during the current study (table 5, fig. 9A,B). Change in volume was the next largest term, with a net loss of $817 \mathrm{Mm}^{3}$ the first year and a substantial gain of 4,373 $\mathrm{Mm}^{3}$ the second year (table 5, fig. 9B). The smaller water-budget terms, side inflow, evaporation, and change in bank storage, account for the remaining gains and losses (fig. 9C). Monthly side inflows ranged from 3.2 to 29.1 percent of Glen Canyon Dam releases, averaging 9.6 percent for the period of record. Outflows averaged 91 percent for releases from Hoover Dam, 5.9 percent for evaporation, and 2.2 percent for withdrawals by SNWP. The change in bank storage ( 0.9 percent) was also an outflow because there was a net increase in lake stage during the current study.

The Lake Mead water budget is balanced because side inflow is calculated as a residual. Potential errors in the water budget are mostly due to errors in measurements or estimates of surface-water flows because these are the largest terms. Even small errors in the primary inflows and outflows are of the same magnitude as some water-budget terms, including evaporation and bank storage. Because of this, it is difficult to improve the accuracy of the Lake Mead water budget without using independent approaches. Bank storage is probably the least understood water-budget term. A substantial investment in drilling and other hydrogeologic research would likely be needed to better understand bank storage.

\section{Bowen Ratio Energy Budget}

Evaporation computed using the BREB method was 2,201 and 2,039 $\mathrm{mm}$ (86.67 and $80.26 \mathrm{in}$.) for the first and second years of the study (March 2010-February 2011, and March 2011-February 2012), respectively. Monthly energy-budget terms are shown in figure 10 and listed in table 4. Other than latent-heat flux $\left(Q_{e b}\right)$, which averaged $164 \mathrm{~W} / \mathrm{m}^{2}$, net radiation $\left(Q_{n}\right)$ was the largest energy-budget term on average $\left(144 \mathrm{~W} / \mathrm{m}^{2}\right)$. July 2011 was cloudier (and cooler) than the same period in the previous year, with average $Q_{n}$ lower than the previous year by $6 \mathrm{~W} / \mathrm{m}^{2}$. Change in stored heat $\left(Q_{x}\right)$ and advected heat $\left(Q_{v}\right)$ were both important energy fluxes during this study, with average absolute values of 79 and $23 \mathrm{~W} / \mathrm{m}^{2}$, respectively. $Q_{x}$ is usually near zero over a year (if the lake level is relatively constant) because energy moves into and out of storage through the seasons, but for this study, $Q_{x}$ and $Q_{v}$

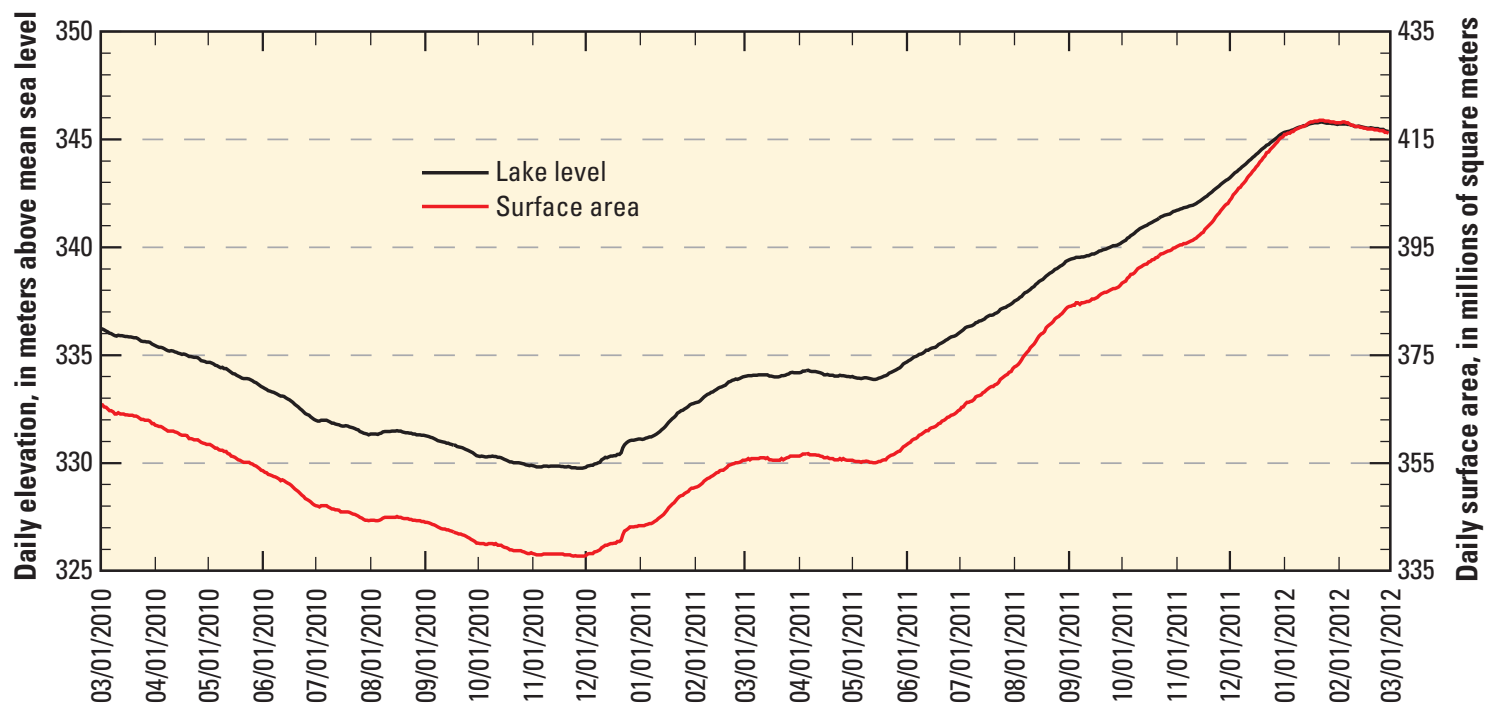

Figure 8. Daily elevation and surface area, Lake Mead, March 2010 through February 2012. 
Table 5. Monthly and annual water budget, Lake Mead, Nevada and Arizona, March 2010 through February 2012.

[Monthly values in million cubic meters unless otherwise noted; EOM, end of month; ft, feet; SNWP, Southern Nevada Water Project]

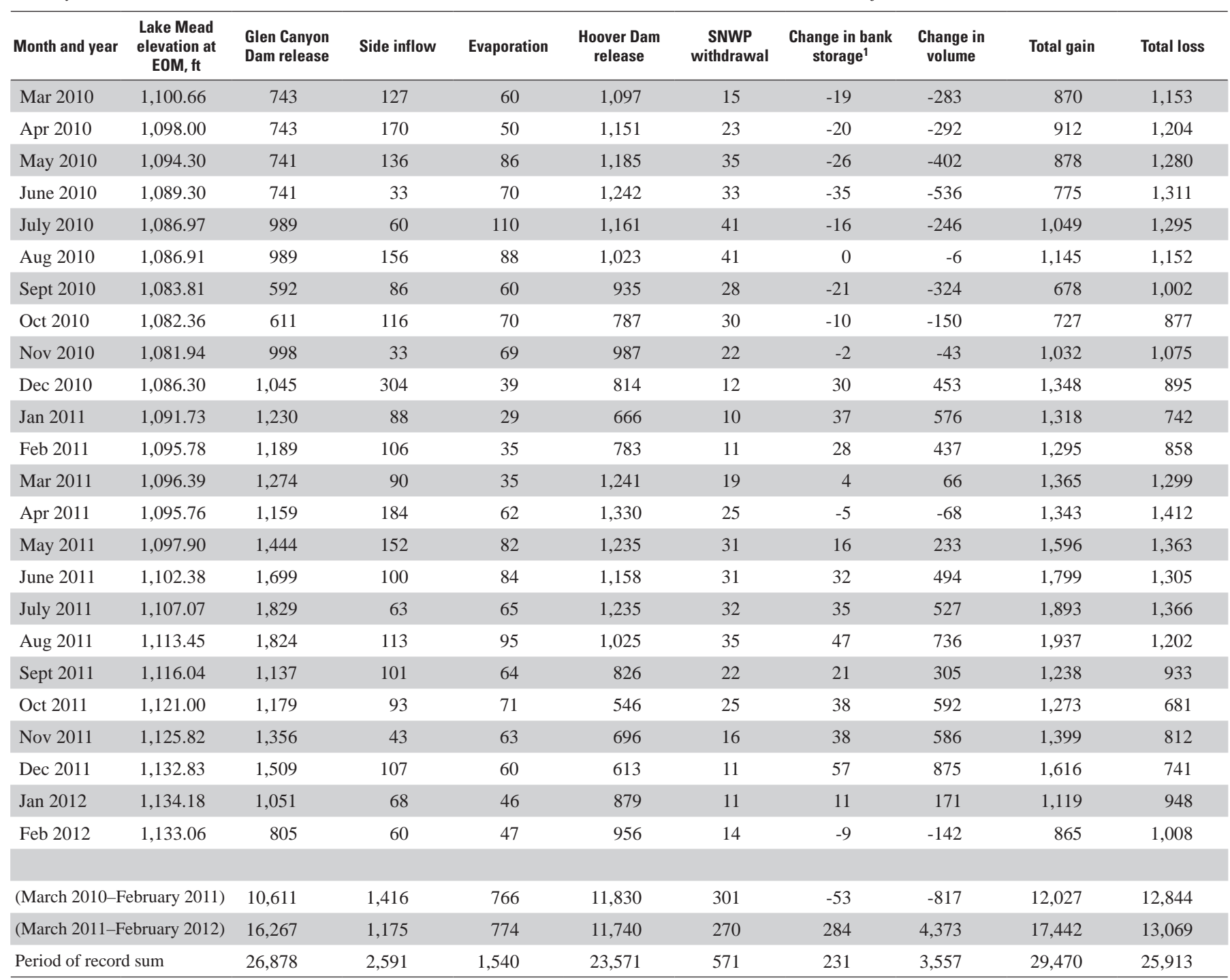

${ }^{1}$ Change in bank storage is positive when water flows into storage from the lake (when stage is rising).

were higher in the second year because of the large increase in lake volume. Monthly $Q_{x}$ ranged from -200 to $164 \mathrm{~W} / \mathrm{m}^{2}$, a wider range than any other energy-budget term including $Q_{e b}$ (77 to $291 \mathrm{~W} / \mathrm{m}^{2}$ ) and $Q_{n}\left(6\right.$ to $282 \mathrm{~W} / \mathrm{m}^{2}$ ).

Deep lakes will have larger $Q_{X}$ than shallow lakes because the thicker water column can store more energy; therefore, lake depth has a substantial effect on seasonal evaporation patterns (Sacks and others, 1994; Blanken and others, 2003; Finch and Hall, 2005). Evaporation is usually correlated to net radiation, but this relation for deep lakes will be weaker than for shallow lakes because in deep lakes a larger proportion of the net radiation goes to heating up the deep water in the first half of the year when the lake is still cold, and therefore is not available to drive evaporation. The opposite is true in the fall for deep lakes; more energy comes out of deep storage in the second half of the year and evaporation stays high even though net radiation decreases. For example, net radiation at Lake
Mead follows the solar pattern, with peaks in June and lows in December, but the peak in net radiation also coincides with the period when most energy goes into storage (when $Q_{x}$ is largest). Because energy goes into storage rather than to evaporation during spring and early summer months, evaporation peaks in July or August, later than net radiation. $Q_{\chi}$ at Lake Mead usually turns negative in September, and as that additional energy is released from storage, evaporation increases in the fall even though $Q_{n}$ decreases (fig. 10).

The Bowen ratio calculated for the energy budget at Lake Mead is negative during 7 to 8 months of the year because the lake surface is colder than the air (table 4, fig. 6B), making the temperature difference negative in equation 7. Thus $Q_{h b}$, energy conducted from the lake to the atmosphere (sensibleheat flux), is also negative in those months, meaning the water "extracts" energy from the air. 

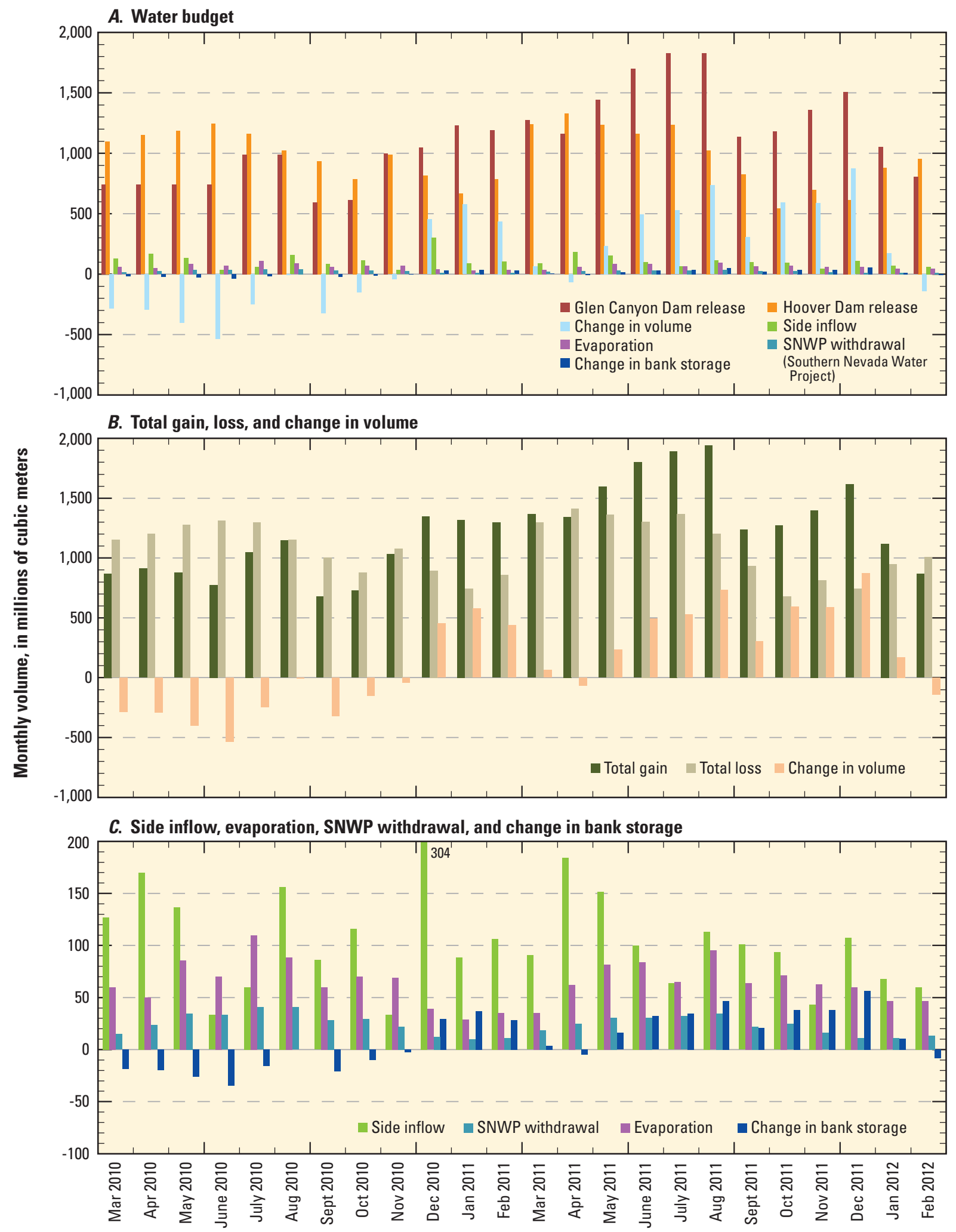

Figure 9. Monthly $A$, Water budget, $B$, Total gain, loss, and change in volume, and $C$, Side inflow, evaporation, SNWP withdrawal, and change in bank storage, Lake Mead, March 2010 through February 2012. 


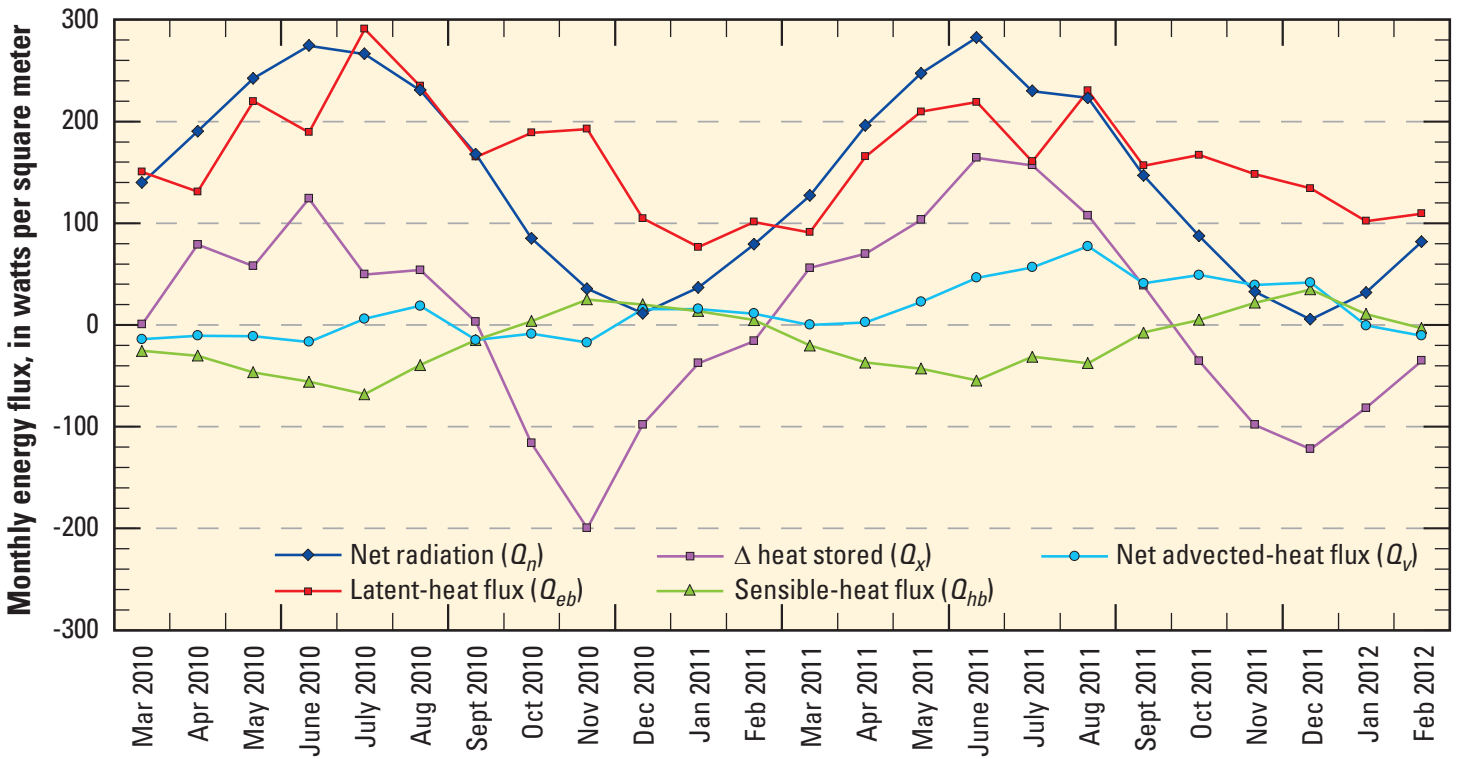

Figure 10. Monthly net radiation, heat stored, and latent-heat, sensible-heat, and net advected-heat fluxes, Lake Mead, March 2010 through February 2012.

Advected-heat flux $\left(Q_{v}\right)$ was more important during the second year of the study at Lake Mead than during the first because inflows exceeded outflows by over 4 billion $\mathrm{m}^{3}$ that year (tables 4 and 5). The temperatures of the major inflows and outflows (Colorado River inflow and Hoover Dam releases) dominate $Q_{v}$. Other water-budget gains and losses have much less influence on $Q_{v}$ because they are smaller volumes. Inflowing water from the Colorado River is warmer than outflowing water from Hoover Dam in the summer months, but is colder in the winter (fig. 11). Outflow temperatures were colder during the summer months of the second year because the Hoover Dam intakes are at a fixed elevation and were deeper in the lake that year because the lake level was higher. Temperatures downstream from Glen Canyon Dam were also substantially colder during the summer months of the second year of the study compared to the first (http://www.gcmrc.gov) because Lake Powell was also deeper that year; however, water still warmed to almost $18^{\circ} \mathrm{C}$ before reaching Lake Mead in the summer of 2011, similar to temperatures the previous summer. From March through October, cold outflow from Glen Canyon Dam warms about 2 to $8^{\circ} \mathrm{C}$ as it flows through the Grand Canyon, but the amount of increase varies year to year (Voichick and Wright, 2007).

In years when the lake level rises or falls substantially, advected heat can be an important term in the energy budget. During the early studies at Lake Mead before Glen Canyon

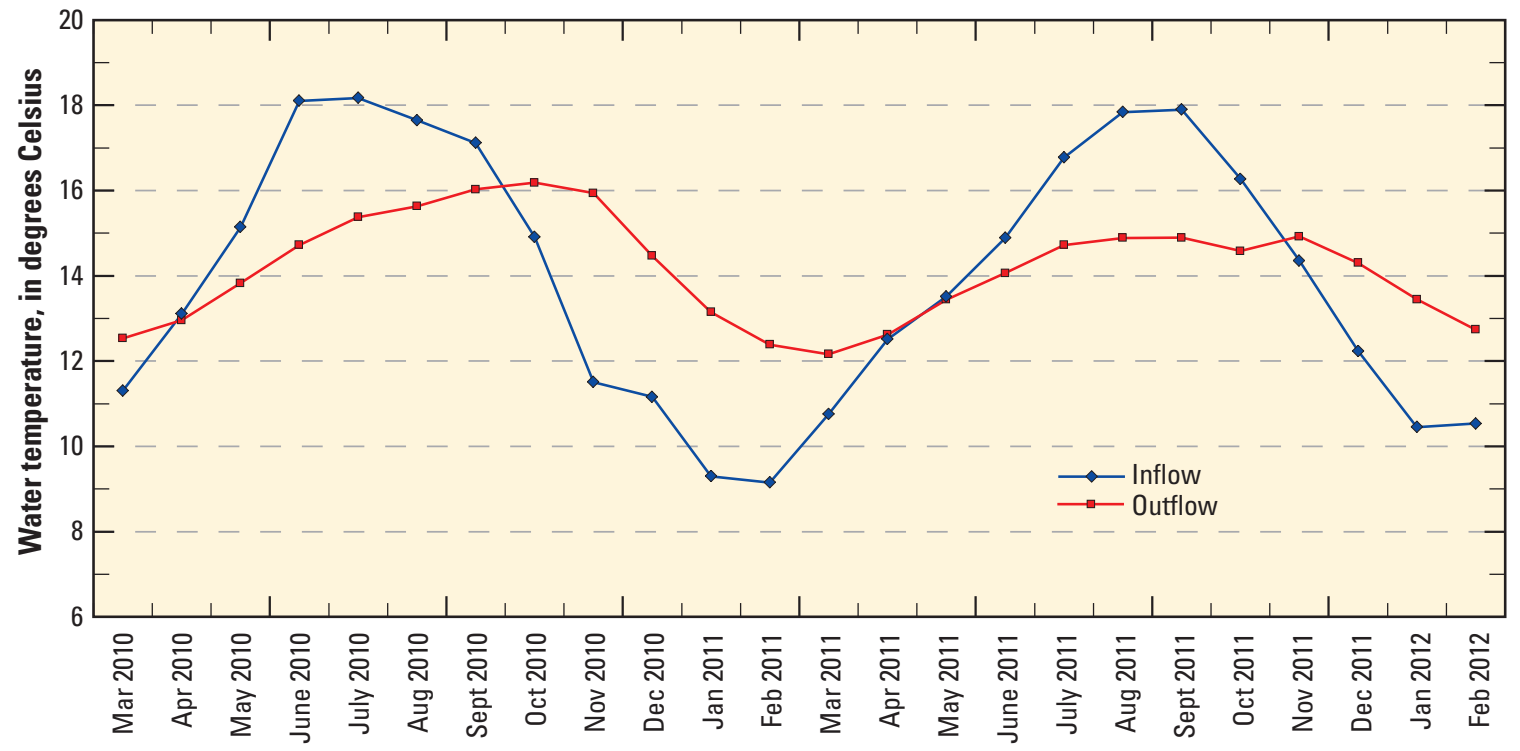

Figure 11. Monthly average temperature of inflow to and outflow from Lake Mead, March 2010 through February 2012. 
Dam was built, advected heat was larger than $Q_{n}$ during spring runoff months (Anderson and Pritchard, 1951; Harbeck and others, 1958). Even cold water from snowmelt contains heat that is added to the lake along with the water. The BREB method was tested at Lake Hefner in Oklahoma before it was used for the comprehensive Lake Mead studies (Harbeck and others, 1958). Compared to Lake Hefner, where net advected energy was near zero, in these early studies Lake Mead showed a net influx of $56 \mathrm{~W} / \mathrm{m}^{2}$ in advected energy, which contributed to higher evaporation rates (Harbeck and others, 1958). Because the majority of inflows to and outflows from Lake Mead are now controlled flows (dam releases), the variability of $Q_{\nu}$ has been reduced. During years when stage changes are relatively small because inflows and outflows are balanced, ignoring $Q_{v}$ will not cause significant error in the energy budget. However, when the lake level rises or falls substantially, ignoring $Q_{v}$ will produce energy-budget evaporation rates that are lower or higher than actual rates, respectively.

\section{Eddy Covariance}

Pre-energy-balance-corrected EC evaporation from Lake Mead was 1,958 and 1,787 mm (77.09 and $70.37 \mathrm{in}$.) for the first and second years of the study (March 2010-February 2011, and March 2011-February 2012), respectively (fig. 12). The annual evaporation rate decreased by 8.6 percent in the second year compared to the first, similar to the 7.4-percent decrease computed using the BREB method. The depth and low albedo of Lake Mead, and the large heat capacity of water, resulted in notable thermal loading and a seasonal lag in surface energy availability. During spring and summer, an increase in stored energy $\left(+Q_{x}\right)$ reduced surface energy availability and limited turbulent energy exchange. During fall and winter, turbulent energy exchanges were greater than net radiation (fig. 10) because stored energy was released to the surface. Peak latent-heat flux $\left(Q_{e c}\right)$ lagged peak $Q_{n}$ by about 2 months during both years (fig. 13), resulting in a weak correlation $\left(\mathrm{R}^{2}=0.17\right)$; however, there was a good correlation $\left(\mathrm{R}^{2}=0.72\right)$ between monthly mean $Q_{e c}$ and available energy $\left(Q_{n}-Q_{x}+Q_{v}\right)$. During spring and summer, the air temperature was warmer than the water-surface temperature (fig. $6 B$ ), resulting in net sensible heat transfer from the air to the water $\left(-Q_{h c}\right)$ and a negative Bowen ratio. During fall and winter, the water surface was warmer than the air, resulting in a sensible heat transfer to the atmosphere $\left(+Q_{h c}\right)$ and a positive Bowen ratio. Stored energy also fueled nighttime (net shortwave radiation $=0$ ) evaporation, ranging from 31 to 43 percent of total monthly evaporation and averaging 37 percent (fig. 12), similar to the 45 percent reported by Liu and others (2009).

For any given month, evaporation varied from the mean monthly evaporation by as much as \pm 20 percent during the 2-year study. The largest second year decreases in EC evaporation occurred during July, August, and September. To better understand these interannual variations in monthly evaporation rates, analyses of well-known controls on open-water evaporation and their relative influence on EC evaporation rates at Lake Mead are presented in the following sections.

\section{Source-Area and Fetch Analysis}

The source area of turbulent-flux measurements was evaluated for each site location to determine the degree to which upwind measurements represented the desirable open-water surface, and the degree to which measurements may have been "contaminated" by the desert surface surrounding the lake, particularly in limited-fetch (500 to 2,000 m) directions. The

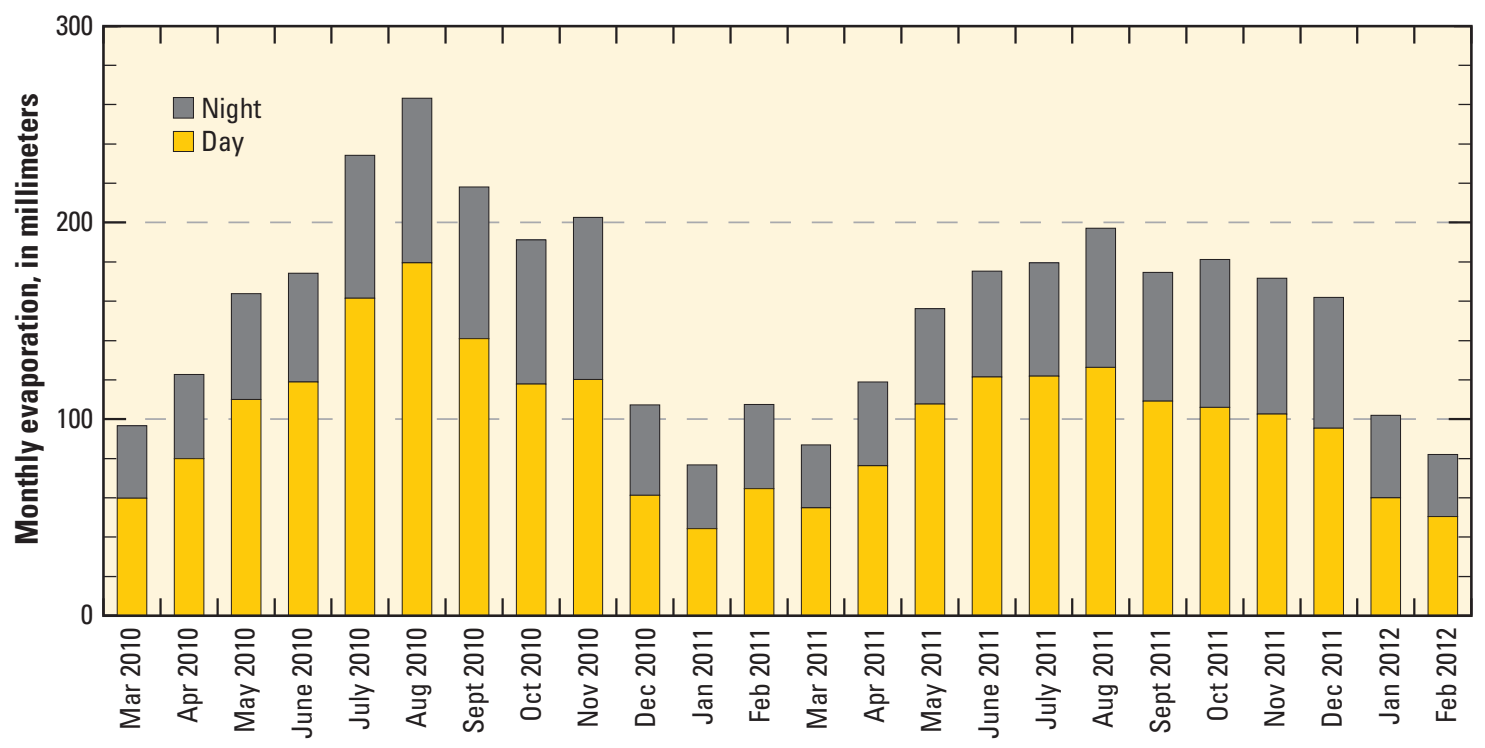

Figure 12. Monthly evaporation, Lake Mead, March 2010 through February 2012. 


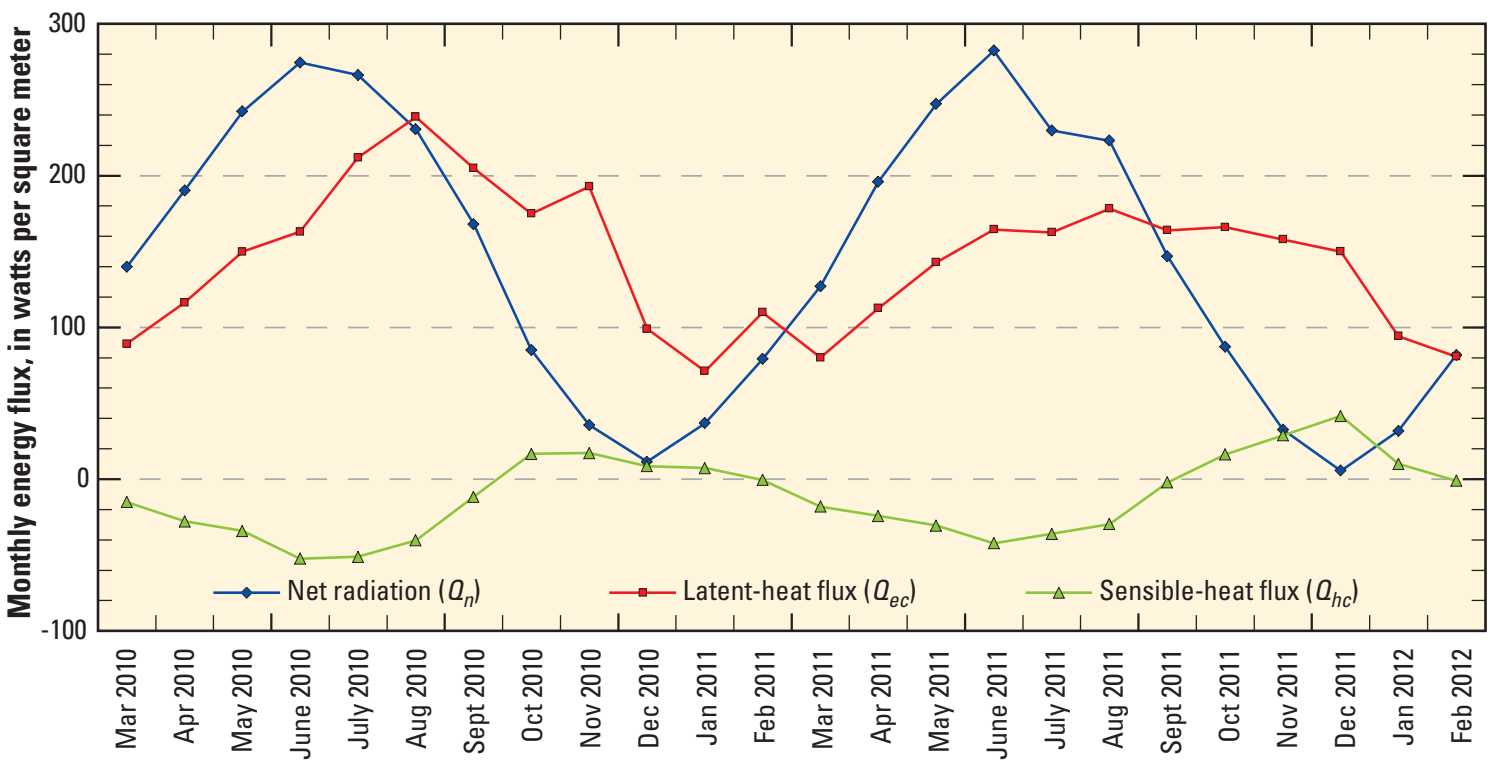

Figure 13. Monthly net radiation, and latent- and sensible-heat fluxes, Lake Mead, March 2010 through February 2012.

mean sensor height (z), median ASL stability parameter $(\mathrm{z} / \mathrm{L})$, median cumulative normalized flux (CNF), and the proportion of all 30-minute measurements originating from limited-fetch azimuths were computed for each processing period and site location (table 6). The proportion of limited-fetch 30-minute measurements for all sites was 4.5 percent for EC-1, 5.9 percent for EC-2, 5.2 percent for EC-3, and 15.2 percent for EC-4. The mean friction velocity $\left(u_{*}\right)$ and roughness length $\left(z_{o}\right)$ for the period of record was $0.27 \mathrm{~m} / \mathrm{s}$ and $0.51 \mathrm{~mm}$, respectively.

The source areas for EC-3 and EC-4 (measurements from August 25, 2011 to March 1, 2012) were smaller than for EC-1 and EC-2 (measurements from March 1, 2010 to August 25, 2011). The size of the source areas was inconsequential when the wind was from $45^{\circ}$ to $225^{\circ}$ (62 percent of all 30 -minute flux measurements) because the fetch was always substantial $(6,000$ to $16,000 \mathrm{~m})$ from those directions at all sites except EC-4. Even though the fetch at EC-4 was limited to 500 to $1,000 \mathrm{~m}$ to the southwest, the CNF represented greater than 90 percent open water-similar to the period of record for all sites combined (table 6, fig. 4a). The lake was at its highest stage of the study when EC-4 was active and portions of the northeastern section of Saddle Island were underwater, along with the outcrop where EC-1 and EC-3 were located. The relatively small source area at EC-4 is attributed to a relatively low instrument height and unstable atmospheric conditions $(-z / L)$ while the site was active. Similarly, the limitedfetch (700 $\mathrm{m}$ and 1,300 to 1,900 m) weighted-average CNF exceeded 90 percent at EC-3. The CNF at EC-1 was similar to EC-2, but there was a period (May 20, 2010 to September 16, 2010) when the CNF at EC-1 was larger than usual, with a weighted-average of only 77 percent at 2,000 m. However, an average of only 3.7 percent of 30 -minute flux measurements were from the limited-fetch direction during this period, which corresponded with 1) stable to very stable atmospheric conditions $(+z / L)$, and 2$)$ a declining lake stage and associated increase in the sensor height $(z)$ above the lake surface (table 6). Despite these relatively stable conditions and larger footprint, monthly EC evaporation rates during this summer period were greater than at any other time during the study.

Overall, 94 percent of 30-minute turbulent-flux measurements originated from wind directions where the fetch ranged from 2,000 to $16,000 \mathrm{~m}$. The CNF at 2,000 $\mathrm{m}$ for the period of record was 92 percent-well within the range considered representative of the surface-of-interest (Gockede and others, 2008). Six percent of 30-minute turbulent-flux measurements originated from limited-fetch directions where the CNF represented more than 80 percent open water, still within an acceptable representative range. Therefore, the turbulent-flux measurements in this study are considered adequate to represent open-water conditions. However, some small degree of influence on flux measurements by the desert surface cannot be ruled out.

\section{Energy-Balance Closure and Trends}

The energy-balance ratio (EBR) for EC fluxes measured in this study was 0.89 for the first year and 0.90 for the second year, considerably better than the average value reported by Wilson and others (2002) (see Energy Balance of an OpenWater Body and the Energy "Imbalance” Problem). Monthly EBRs ranged from 0.59 to 1.29. Monthly energy-balance closure (EBC) values, the difference between available and turbulent energy, ranged from -43 to $62 \mathrm{~W} / \mathrm{m}^{2}$ (table 7 ). When divided into two distinct groups that generally separated fall months from the rest of the year, the variable that correlated 


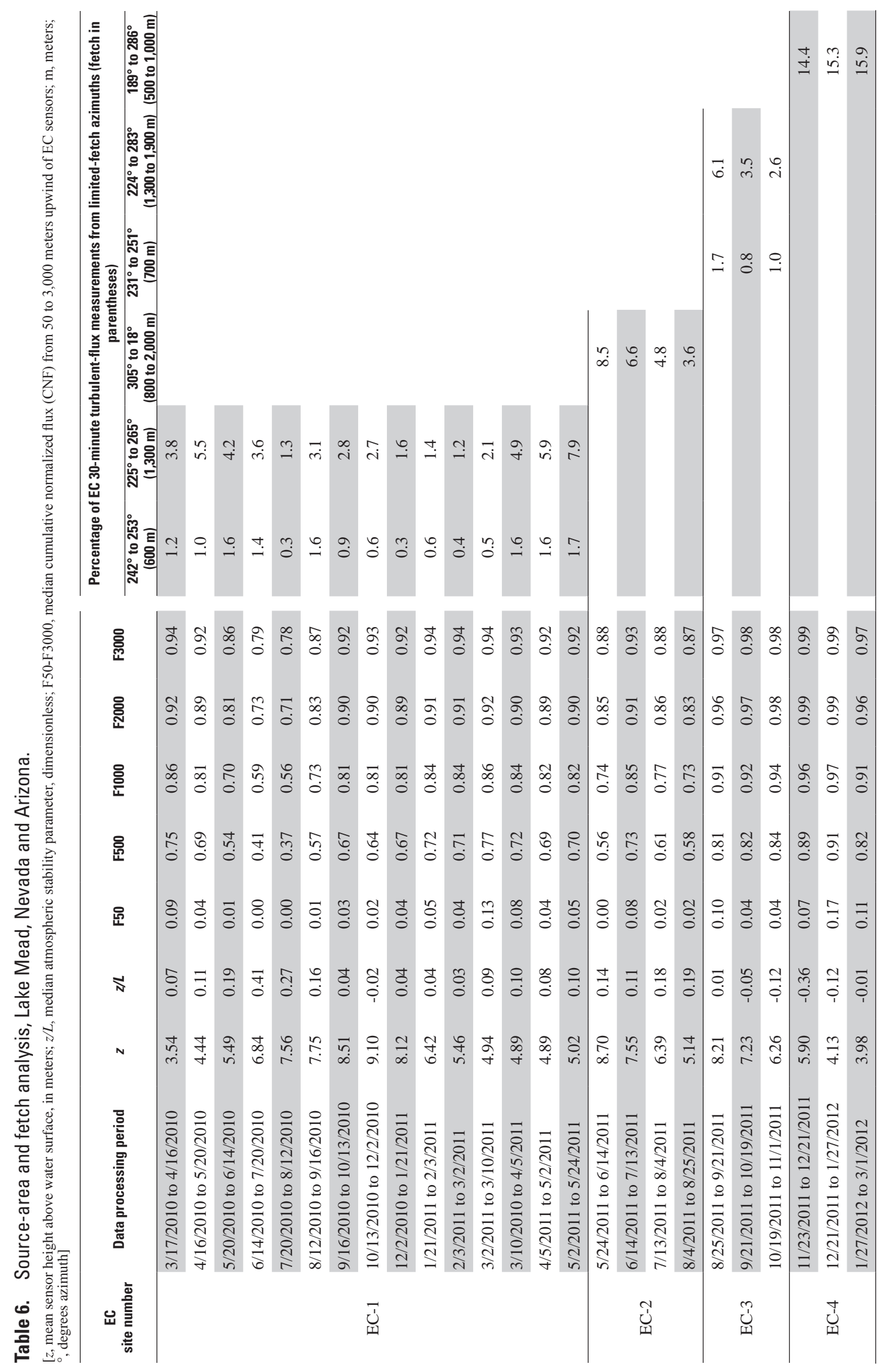


Table 7. Monthly and annual available energy and turbulent energy computed using the eddy-covariance method, Lake Mead, Nevada and Arizona, March 2010 through February 2012.

[Daily mean values in watts per square meter unless otherwise noted; EBC, energy-balance closure; EBR, energy-balance ratio]

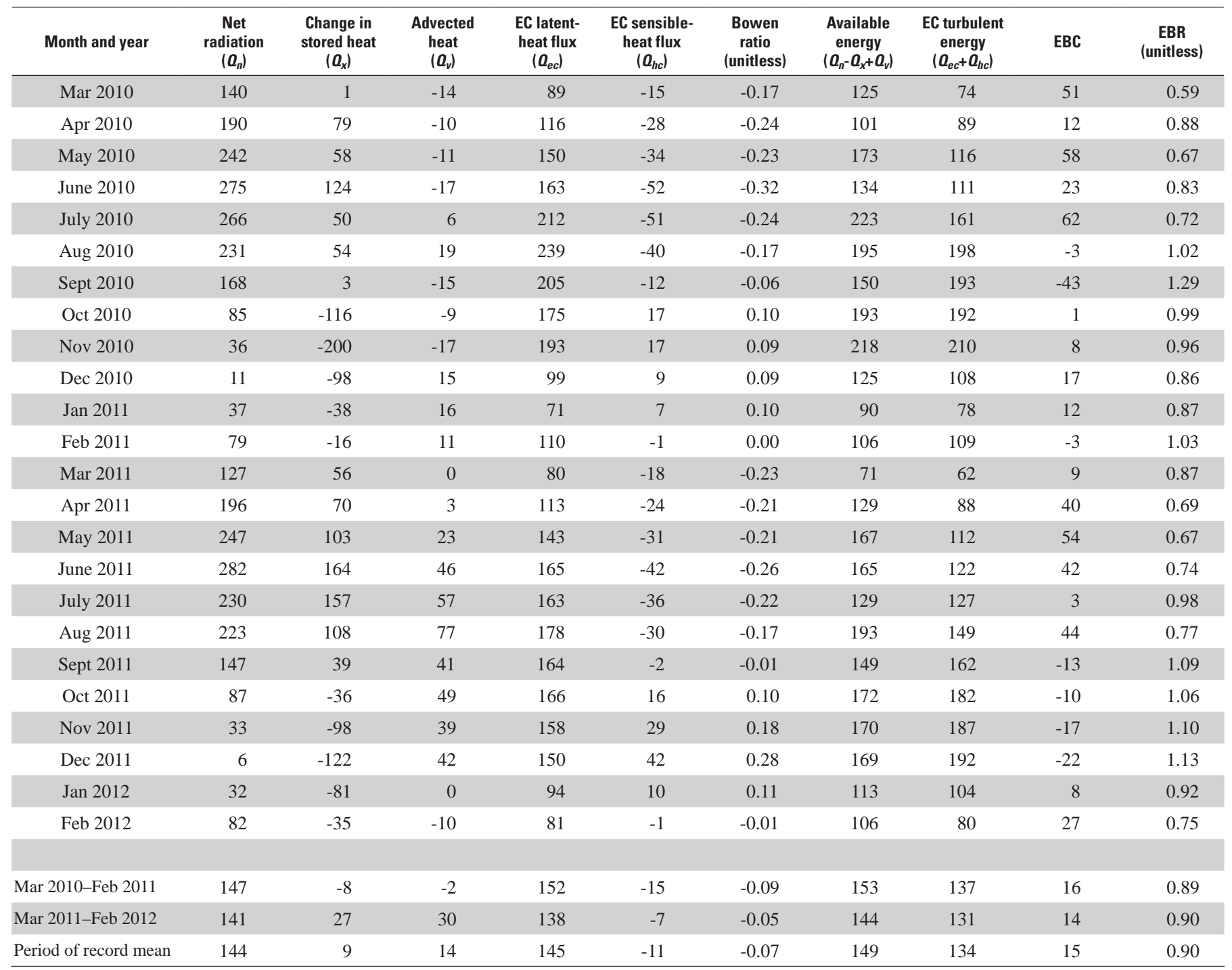

best to monthly EBC values was available energy (fig. 14). Specifically, the first group was August through November 2010, and September through December $2011\left(\mathrm{R}^{2}=0.68\right)$, and the second group comprised the remaining months $\left(\mathrm{R}^{2}=0.62\right)$. The mean EBR was 1.08 during the fall periods, indicating EC fluxes exceeded the available energy during a period when water temperatures in the upper profile were cooling and the rate of energy release from storage was greatest (table 7, figs. 7 and 14). The EBR was consistently the lowest during spring and early summer months when thermal loading was increasing to the annual maximum. This indicates that the magnitude of $Q_{X}$ may have been underestimated both when energy was going into storage (when the thermocline was rapidly developing and advancing), and when energy was being released from storage (when the epilimnion was rapidly cooling). The reason for this apparent underestimation is not clear. In general, the temporal pattern of EBC values closely follows monthly available energy, with a tendency toward greater imbalance during spring through early summer months and near-closure during late summer through early winter months (fig. 14). The consistently low EBR values during the spring and summer months also coincide with periods when the uncertainty in available energy estimates is highest (see Uncertainty Analysis).

Potential errors stemming from the use of four different EC site locations likely had only a minimal effect on the measured energy balance. Energy imbalances are expected to be greater if a significant proportion of measured turbulent fluxes originated from the desert surrounding the lake. Available energy at the desert surface is less than at the lake surface because the lighter-colored desert surface reflects a greater amount of incoming shortwave radiation back to the atmosphere. Monthly EBRs generally were lower during the spring and early summer when stable ASL conditions $(+z / L)$ prevail and 


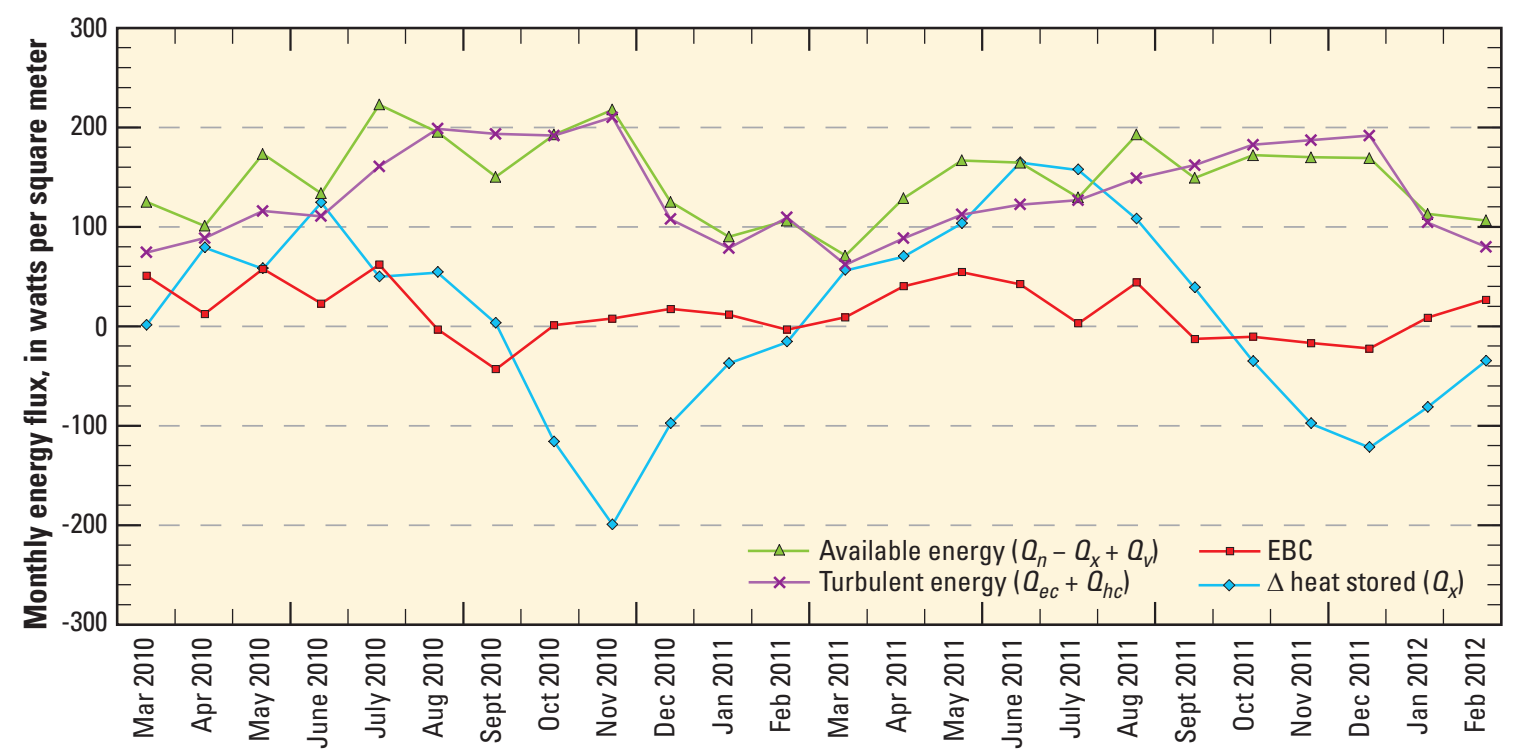

Figure 14. Energy-balance closure (EBC), turbulent energy, available energy, and change in stored heat energy, Lake Mead, March 2010 through February 2012.

the source area is larger (tables 6 and 7). However, monthly EBRs were only weakly correlated with $z / L\left(R^{2}=0.28\right)$. Also, the monthly EBC values are greater than can be accounted for by the small amount of time when turbulent fluxes were potentially contaminated by the desert surface. Furthermore, if the adjacent desert had a significant effect on the energy balance, then a higher Bowen ratio (due to less water vapor) would be evident. An evaluation of the Bowen ratio during stably stratified periods (when the source area is larger) and when the wind direction was from limited-fetch directions did not reveal a greater proportion of sensible- to latent-heat flux. This energy-balance analysis, including the consistent and very good annual EBRs, support the source-area analysis conclusion that EC fluxes are representative of open water, and that any impact on flux measurements by the desert surface was minimal.

Considering the state of knowledge regarding the "energy imbalance problem", the decision whether or not to force closure often is subjective. In this study measured EC fluxes were considered a probable minimum because measurements may have been affected by the adjacent desert. A probable maximum was computed by adjusting measured annual EC fluxes upward by 11.8 percent during the first year and 10.4 percent during the second year to achieve energy-balance closure while maintaining consistency with the EC-measured Bowen ratio. The annual EBR is considered more accurate than monthly EBRs in this study because estimating monthly $Q_{x}$ and $Q_{v}$ in a lake as large, complex, and dynamic as Lake Mead is subject to large uncertainties (see Uncertainty Analysis); therefore, monthly probable maximum adjustments are based on the annual EBR rather than individual monthly EBRs.

Accordingly, the best (most probable) estimate of monthly and annual latent-heat (evaporative) flux in this study is the mean of the probable minimum and probable maximum estimates
Table 8. Monthly and annual minimum, maximum, and most probable (corrected) eddy-covariance (EC) evaporation, Lake Mead, Nevada and Arizona, March 2010 through February 2012.

[Monthly and annual sum values in millimeters]

\begin{tabular}{|c|c|c|c|}
\hline Month and year & $\begin{array}{c}\text { EC probable } \\
\text { minimum }\end{array}$ & $\begin{array}{c}\text { EC most } \\
\text { probable } \\
\text { (corrected) }\end{array}$ & $\begin{array}{c}\text { EC probable } \\
\text { maximum }\end{array}$ \\
\hline Mar 2010 & 97 & 102 & 108 \\
\hline Apr 2010 & 123 & 130 & 137 \\
\hline May 2010 & 164 & 174 & 183 \\
\hline June 2010 & 174 & 184 & 195 \\
\hline July 2010 & 234 & 248 & 262 \\
\hline Aug 2010 & 263 & 279 & 294 \\
\hline Sept 2010 & 218 & 231 & 244 \\
\hline Oct 2010 & 191 & 203 & 214 \\
\hline Nov 2010 & 203 & 215 & 227 \\
\hline Dec 2010 & 107 & 114 & 120 \\
\hline Jan 2011 & 77 & 81 & 86 \\
\hline Feb 2011 & 107 & 114 & 120 \\
\hline Mar 2011 & 87 & 92 & 96 \\
\hline Apr 2011 & 119 & 125 & 131 \\
\hline May 2011 & 156 & 164 & 173 \\
\hline June 2011 & 175 & 184 & 194 \\
\hline July 2011 & 180 & 189 & 198 \\
\hline Aug 2011 & 197 & 207 & 218 \\
\hline Sept 2011 & 175 & 184 & 193 \\
\hline Oct 2011 & 181 & 191 & 200 \\
\hline Nov 2011 & 172 & 181 & 190 \\
\hline Dec 2011 & 162 & 171 & 179 \\
\hline Jan 2012 & 102 & 107 & 113 \\
\hline Feb 2012 & 82 & 86 & 91 \\
\hline Mar 2010-Feb 2011 & 1,958 & 2,074 & 2,190 \\
\hline Mar 2011-Feb 2012 & 1,787 & 1,881 & 1,975 \\
\hline
\end{tabular}


(table 8). The most probable estimate is referred to as "corrected” for the rest of this report. Corrected EC evaporation was $2,074 \mathrm{~mm}$ (81.65 in.) for the first year and $1,881 \mathrm{~mm}$ (74.06 in.) for the second year.

\section{Aerodynamic Relations and Atmospheric Stability}

The turbulent exchanges of heat and water vapor over Lake Mead are affected by several key micrometeorological and limnological factors already discussed. However, much of the variability of turbulent exchanges can be explained by the variability in three quantities: 1 ) wind speed $(U), 2)$ the vapor pressure difference between the water surface and the overlying atmosphere $\left(e_{o}-e_{a}\right)$, and 3$)$ the temperature difference between the water surface and the overlying atmosphere $\left(T_{o}-T_{a}\right)$. Daily mean $Q_{e c}$ was correlated to wind speed $\left(\mathrm{R}^{2}=0.47\right.$; fig. $\left.15 \mathrm{~A}\right)$, vapor pressure difference $\left(\mathrm{R}^{2}=0.34\right.$; fig. $15 B)$, and the product of wind speed and vapor pressure difference $U\left(e_{o}-e_{a}\right)$, also known as the mass-transfer product $\left(\mathrm{R}^{2}=0.77\right.$; fig. 15C) (Harbeck and others, 1958). Similarly, correlations were examined between daily mean $Q_{h c}$ and wind speed $\left(\mathrm{R}^{2}=0.22\right.$; fig. $\left.15 D\right)$, temperature difference $\left(T_{o}-T_{a}\right)$ $\left(\mathrm{R}^{2}=0.73\right.$; fig. $\left.15 E\right)$, and the product of wind speed and temperature difference $U\left(T_{o}-T_{a}\right)\left(\mathrm{R}^{2}=0.86\right.$; fig. $\left.15 F\right)$. Daily $Q_{e c}$ and the mass-transfer product, and $Q_{h c}$ and $U\left(T_{o}-T_{a}\right)$ are well correlated; 86 percent of the variability in daily mean $Q_{h c}$ can be explained by $U\left(T_{o}-T_{a}\right)$, and 77 percent of the variability in daily mean $Q_{e c}$ can be explained by the mass-transfer product. The relation between $Q_{e c}$ and the mass-transfer product is improved slightly $\left(\mathrm{R}^{2}=0.81\right)$ when monthly means are considered rather than daily means; furthermore, two distinct groupings become evident at a monthly timescale (fig. 16). For the 18 months when the mass-transfer product was less than $6.3 \mathrm{kPa} \mathrm{m} / \mathrm{s}$, the correlation to $Q_{e c}$ is excellent $\left(\mathrm{R}^{2}=0.92\right)$. For the 6 months when the mass-transfer product was greater than $6.3 \mathrm{kPa} \mathrm{m} / \mathrm{s}$, the correlation to $Q_{e c}$ also is quite good $\left(\mathrm{R}^{2}=0.86\right)$. The 6 months that constitute the second group correspond to June, July, and August of both years. During these summer periods, the difference between $T_{a}$ and $T_{o}$ is most negative (fig. 6B). As the air temperature increases during the summer, the water temperature also increases but not as steeply. Sensible-heat flux becomes increasingly negative (fig. 13), and the ASL becomes more stable as a result of the increased downward temperature difference (table 6). As the ASL became more stable $(z / L>>0)$, turbulent exchanges were increasingly suppressed. In other words, when the atmospheric surface layer was stably stratified and a downward temperature gradient was in place, vertical wind velocities were inhibited and turbulent mixing and exchanges were suppressed (Mahrt, 1999; Granger and Hedstrom, 2011). Atmospheric stability and turbulent exchange suppression increased as the difference between $T_{o}$ and $T_{a}$ increased in the negative direction. Atmospheric stability is inversely correlated to $Q_{h c}\left(R^{2}=-0.82\right)$ and $T_{o}-T_{a}\left(\mathrm{R}^{2}=-0.75\right)$.
Downward temperature differences and atmospheric stability were greatest during the summer months, whereas unstable conditions were dominant during winter. The upward transport of turbulent flux was enhanced during unstable atmospheric conditions by convective forces and high turbulence intensity, resulting in a shorter travel time/distance (Rannik and others, 2012). For the 2-year period of this study, $z / L$ is summarized by the following five general categories (Ramamurthy and Pardyjak, 2007), followed by the percent of the period of record those conditions occurred:

- $\quad$ Very stable $(z / L>1) 11$ percent

- $\quad$ Stable $(1<z / L<0.2) 21$ percent

- $\quad$ Near neutral $(0.2<z / L<-0.2) 48$ percent

- Unstable $(-0.2<\mathrm{z} / \mathrm{L}<-1) 12$ percent

- $\quad$ Very unstable $(z / L<-1) 8$ percent

In general, evaporation from Lake Mead occurred at a rate proportional to $e_{o}-e_{a}$. Dry air advection from the adjacent desert surface increased $e_{o}-e_{a}$, and the rate of this increase was dampened during periods when the ASL was most stable. These results are similar to those found in other recent lake studies by investigators using the EC method (Blanken and others, 2003; Liu and others, 2009; Granger and Hedstrom, 2011).

\section{Uncertainty Analysis}

Uncertainty $(\delta)$ is the range of values within which the true value is believed to lie. An assessment of uncertainty gives an indication of measurement accuracy. Uncertainties in monthly and annual available energy and EC measurements are quantified in the following sections.

\section{Available Energy}

The maximum probable uncertainty associated with available energy estimates $\left(Q_{n}-Q_{x}+Q_{v}\right)$ is estimated by combining the uncertainty for each component using standard error propagation techniques (Winter, 1981; Lee and Swancar, 1997; Taylor, 1997). For $Q_{n}$, measurements from two CNR2 net radiometers were calibrated to a higher-standard CNR1 4-component radiometer. The expected accuracy of the CNR1 is stated by the manufacturer to be \pm 10 percent of daily totals (Campbell Scientific, Inc., 2011). Winter (1981) points out that because sensor errors are often random, accuracy improves over longer times. Blonquist and others (2009) compared several radiometer makes and models for 33 days over a uniform turfgrass surface and concluded that the two CNR1s used in their study were 2.9 and 5.9 percent higher than their reference. These results are probably better than can be achieved at Lake Mead, however, because their radiometers were cleaned and re-leveled every 2 to 3 days. This level of attention is not possible for most field studies. Additionally, perfect level with respect to gravity was seldom realized at Lake Mead because the sensor was located on a floating platform that frequently oscillated because of wave motion. As a result, for both 

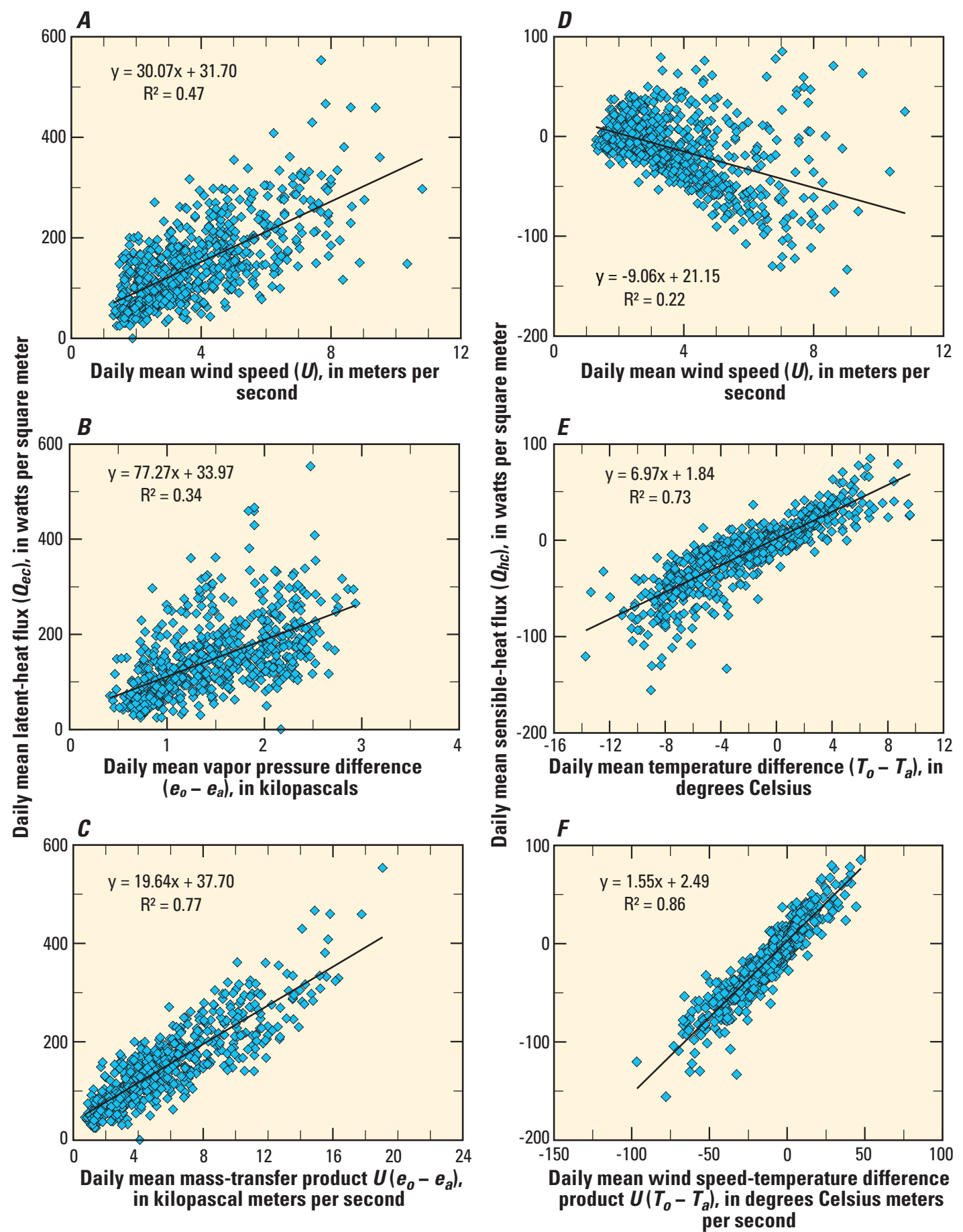

Figure 15. Relations between daily mean latent-heat flux $\left(Q_{e c}\right)$ and $A$, Wind speed, $B$, Vapor pressure difference, and $C$, Mass-transfer product; and relations between daily mean sensible-heat flux $\left(Q_{h c}\right)$ and $D$, Wind speed, $E$, Temperature difference, and $F$, Wind speedtemperature difference product, Lake Mead. 


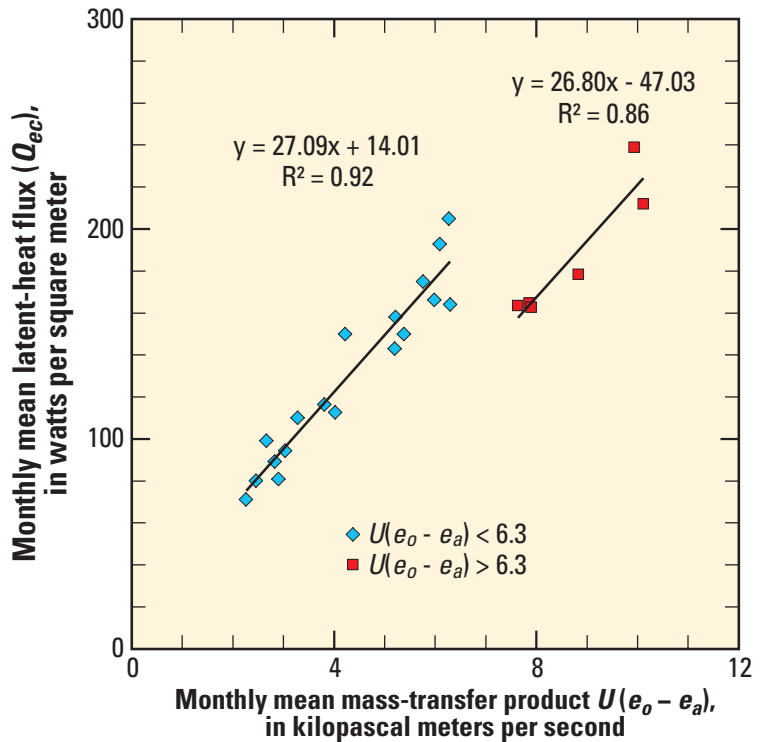

Figure 16. Relations between monthly mean latent-heat flux and monthly mean mass-transfer product, Lake Mead.

monthly and annual estimates, the uncertainty associated with $Q_{n}$ measurements $\left(\delta Q_{n}\right)$ at Lake Mead was assumed to be \pm 10 percent.

The uncertainty in $Q_{x}\left(\delta Q_{x}\right)$ takes into account the accuracy of lake stage and volume estimates (assumed to be \pm 5 percent), but is largely influenced by and is proportional to the accuracy of the water temperature sensor $\left( \pm 0.15^{\circ} \mathrm{C}\right)$ and the change in water-profile temperatures for each monthly period. The monthly mean $\delta Q_{x}$ for the reporting period was \pm 15 percent and ranged from \pm 10 to \pm 35 percent.

The uncertainty in $Q_{v}\left(\delta Q_{v}\right)$ is related to the accuracy of the incoming and outgoing water temperature sensors and the volume of the incoming and outgoing water. Only Colorado River flow is considered because it accounts for greater than 90 percent of total gains or losses during the study. Incoming water temperatures are assumed to be less accurate $\left( \pm 0.5^{\circ} \mathrm{C}\right)$ than the reported accuracies for the sensors (from $0.15^{\circ} \mathrm{C}$ to $0.32{ }^{\circ} \mathrm{C}$ ) to account for seasonal variations in the change in water temperature between Lake Mead and the sensors located from $55 \mathrm{~km}$ (34 mi) to $87 \mathrm{~km}$ (54 mi) upstream. The accuracy of outgoing temperatures is based on the YSI 600R waterquality sampling sonde $\left( \pm 0.15^{\circ} \mathrm{C}\right)$ maintained by Reclamation at Hoover Dam. The accuracy of incoming and outgoing volume measurements is assumed to be \pm 5 percent. Monthly mean $\delta Q_{V}$ for the reporting period was \pm 9 percent and ranged from \pm 8 to \pm 11 percent.

Component uncertainties relative to monthly available energy uncertainty $(\delta A E)$ are shown in figure $17 A$. The largest relative uncertainty in monthly $\delta A E$ was $\delta Q_{n}$, which accounted for a high of 90 percent and a low of 3 percent of the total uncertainty in March 2010 and December 2011, respectively, with a mean for the reporting period of 48 percent. The next largest relative uncertainty was $\delta Q_{x}$, which averaged
43 percent and ranged from 1 percent in March 2010 to 82 percent in December 2010. $Q_{v}$ consistently had the smallest relative uncertainty, averaging 8 percent of monthly $\delta A E$ and ranging from 0 percent to 24 percent.

The absolute monthly $\delta A E$ averaged $20 \mathrm{~W} / \mathrm{m}^{2}$ and ranged from $8 \mathrm{~W} / \mathrm{m}^{2}$ in January 2011 to $35 \mathrm{~W} / \mathrm{m}^{2}$ in June 2011 (fig. 17B). The $\delta A E$ during the second year was greater than the first year even though $\delta Q_{n}$, which mimics $Q_{n}$, was less in the second. The rising stage and net inflow to the lake of relatively warm water increased $\delta Q_{X}$ and $\delta Q_{\nu}$, which accounted for a larger proportion of $\delta A E$ in the second year. When $Q_{n}$ was small during the fall and winter months, $\delta A E$ was dominated by $\delta Q_{X}$. $Q_{X}$ and $\delta Q_{X}$ were smallest during months when the lake transitions between energy sink $\left(+Q_{\chi}\right)$ and source $\left(-Q_{x}\right)$ (figs. 10 and $17 C$ ). $\delta Q_{x}$ can increase abruptly relative to $\delta A E$ following these transition periods, and is greatest when the lake is undergoing the greatest amount of heat storage or release.

Combining the components, the monthly mean $\delta A E$ was \pm 13 percent and ranged from \pm 6 to \pm 25 percent (fig. $17 C$ ). $\delta A E$ averaged \pm 9 percent during the fall and winter months, corresponding generally with decreased energy availability and $-Q_{x}$. During the spring and summer months $\delta A E$ averaged \pm 18 percent, corresponding to greater energy availability and $+Q_{x}$ (fig. 17C, $D$ ). The relatively higher uncertainty during the spring and summer months can be explained by going back to equation 6 , and noting that positive $Q_{x}$ has the effect of decreasing the available energy; the uncertainty is higher because the sum of component errors is divided by a relatively smaller total available energy. At an annual timescale, $Q_{x}$ and $Q_{V}$ account for 6.3 and 9.5 percent, respectively, of available energy (table 4); therefore, $\delta Q_{x}$ and $\delta Q_{v}$ are small relative to $\delta Q_{n}( \pm 10$ percent). These computed uncertainties are considered a probable maximum.

\section{Eddy Covariance}

The complicated algorithm of the EC method does not allow for the determination of errors according to error propagation law (Foken, 2008, p.122). Instead, the uncertainty of EC turbulent energy $(\delta E C)$ was assessed in this study according to the annual energy imbalance. As stated previously, 1) the measured EC fluxes were assumed to be the probable minimum, 2) the probable maximum was computed by adjusting measured annual EC fluxes upward by 11.8 percent for the first year and 10.4 percent for the second year to achieve energy-balance closure, and 3) the best (most probable) latentheat flux is the mean of the probable minimum and probable maximum estimates. Accordingly, the annual $\delta E C$ is \pm 5.9 percent for the first year and \pm 5.2 percent for the second year. The additional uncertainty added by the MDV gap-filling method was also assessed. As mentioned previously, a monthly bias of up to \pm 5 percent was introduced by this method, but the annual bias was negligible. On average, monthly gaps filled using the MDV method accounted for 24 percent of 30-minute flux periods during the first year (mostly because of insufficient fetch 

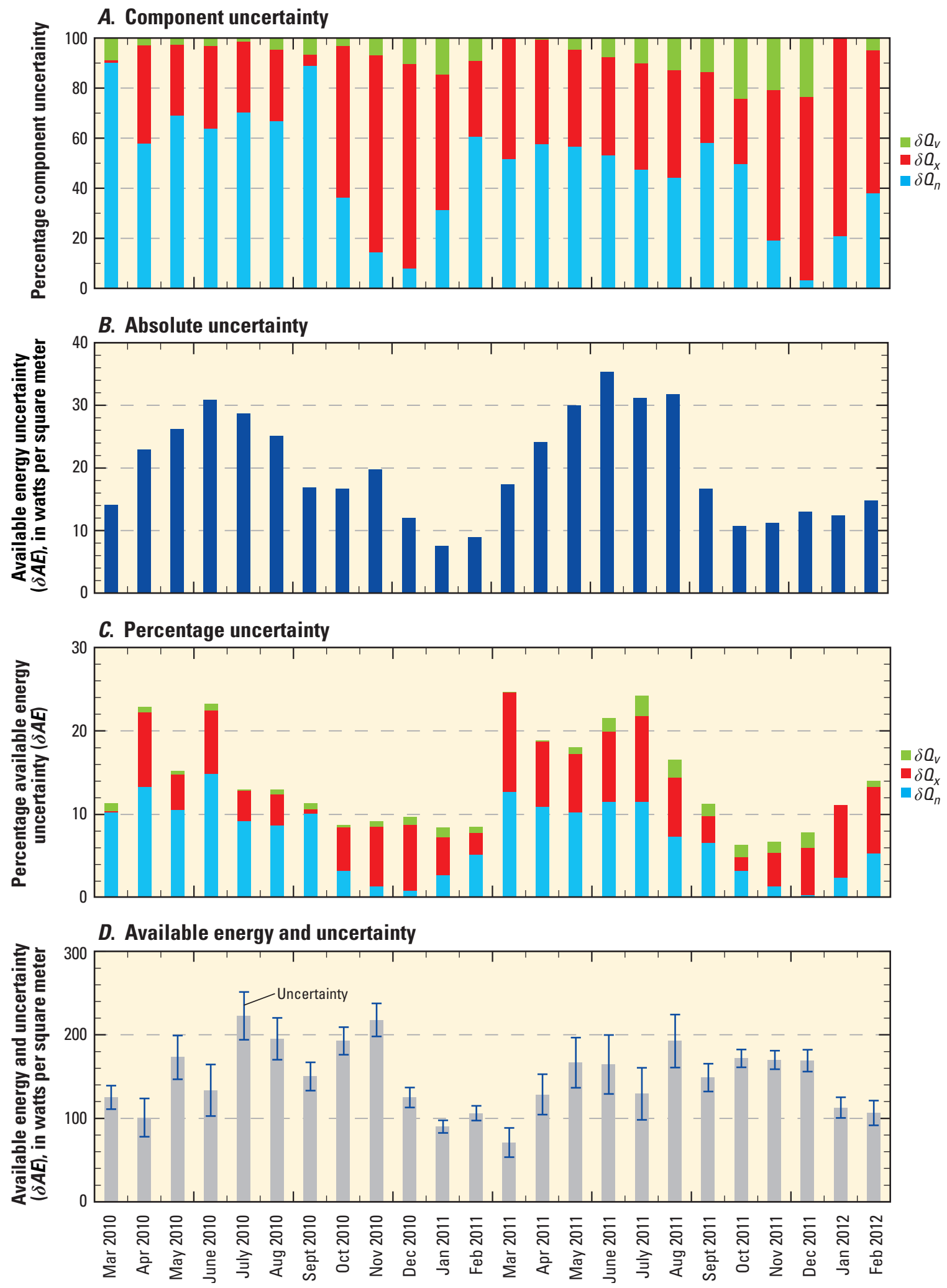

Figure 17. Monthly available energy and maximum-probable uncertainty, Lake Mead, March 2010 through February 2012. 
at site EC-1), and 7 percent during the second year. Assuming the maximum monthly bias of 5 percent, the maximum weighted-average (Lee and Swancar, 1997) monthly $\delta E C$ was \pm 7.1 percent for the first year ( \pm 5.9 percent based on energybalance closure +1.2 percent for MDV gap-filling), and \pm 5.6 percent for the second year $( \pm 5.2$ percent based on energybalance closure +0.35 percent for MDV gap-filling). Monthly and annual $\delta E C$ estimates for this study are within the 5- to 10-percent range reported by Foken (2008, p. 122).

The possibility of substantial error in $Q_{e c}$ measurements by the single EC station used in this study because of a faulty sensor or calibration was investigated by comparison to a check station. A check station consisting of identical sensors was located $6 \mathrm{~m}$ from the primary station at site EC-1. Sensor heights and orientations were identical. Both stations ran concurrently for 25 days (March 10, 2011 to April 5, 2011). The data post-processing programs were identical except for the calibration coefficients unique to each $\mathrm{KH} 2 \mathrm{O}$. The mean 30-minute $Q_{e c}$ for the comparison period was $77.30 \mathrm{~W} / \mathrm{m}^{2}$ at the primary station and $77.70 \mathrm{~W} / \mathrm{m}^{2}$ at the check station, a difference of only $0.40 \mathrm{~W} / \mathrm{m}^{2}$. The root mean square deviation of $14.0 \mathrm{~W} / \mathrm{m}^{2}$ indicates a fair amount of scatter in the paired 30-minute data, which is typical for these high-speed measurements. These results indicate that the measurements made by the EC station in this study are repeatable with little error, which enhances confidence in the EC system and the sensors/ calibrations used for this study.

\section{Comparison of Eddy-Covariance Evaporation with Bowen Ratio Energy Budget Evaporation}

In general, there is a good relation between BREB and corrected EC evaporation (fig. 18). Annual BREB evaporation was 6 and 8 percent greater than corrected EC evaporation during the first and second years, respectively. Both methods indicate there was a 7- to 9-percent decrease in evaporation from the first year to the second. A single-tailed paired t-test was conducted on monthly evaporation rates to determine whether both methods are statistically different at the $\alpha=0.05$ probability level. The data set is normally distributed. The null hypothesis is no significant difference between the means, and the alternative hypothesis is that the BREB mean is greater than the corrected EC mean. The test resulted in a t-statistic of $1.68(p=0.05)$, indicating that it is inconclusive as to whether the null hypothesis can be rejected and the alternative hypothesis accepted.

The relation between monthly evaporation rates for both methods is fairly good $\left(R^{2}=0.65\right)$. BREB evaporation fell within a 7-percent uncertainty range of corrected EC evaporation for 9 of the 24 months (fig. 18). Neglecting uncertainty in the Bowen ratio computed for the BREB method, and assuming BREB evaporation uncertainty is equal to $\delta A E$, the uncertainty ranges for both methods overlapped for 16 of the 24 months (not shown in figure). BREB evaporation ranged from 24 percent less than to 61 percent more than EC evaporation, with a mean difference of 17.3 percent and a standard deviation of 15.5 percent. BREB evaporation generally was greater than corrected EC evaporation during the spring months and

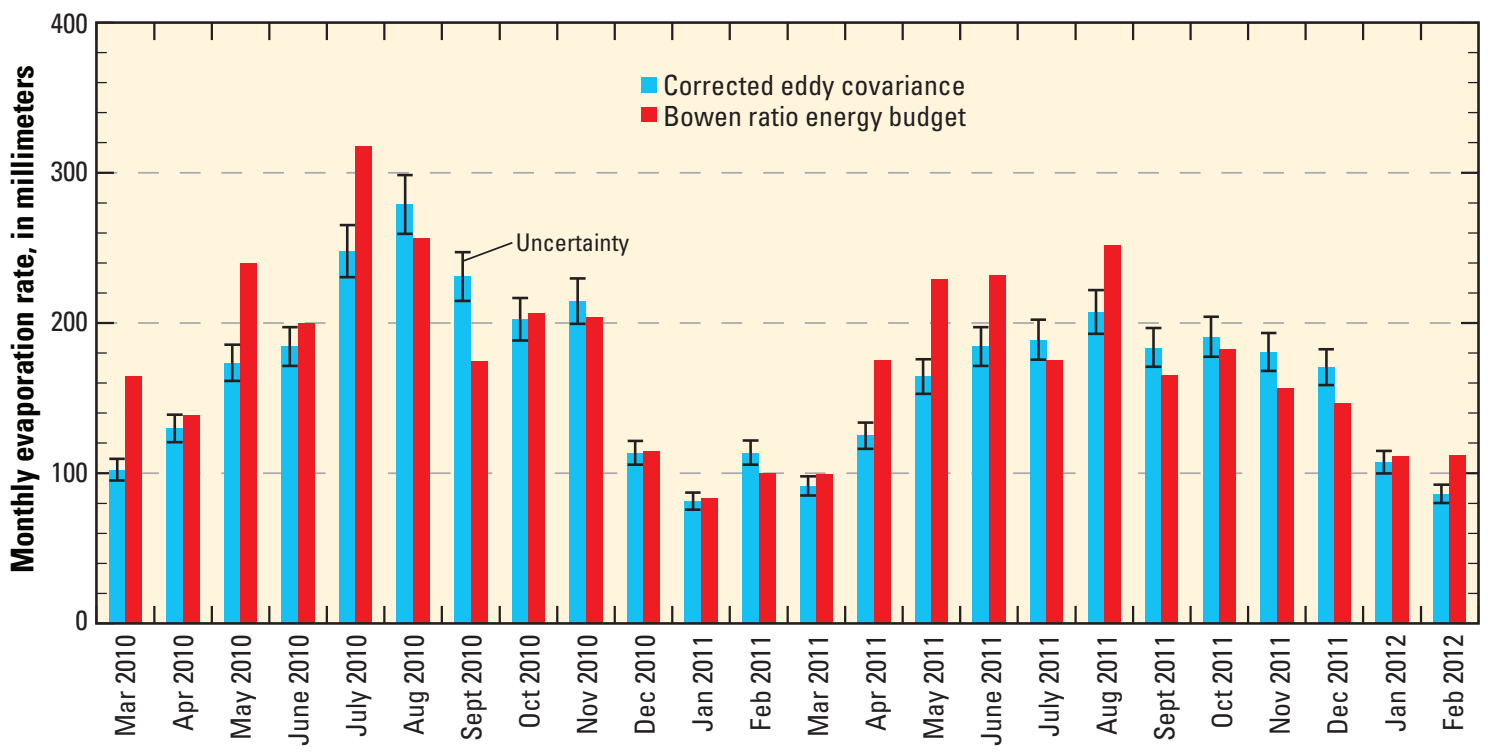

Figure 18. Monthly corrected eddy-covariance evaporation and uncertainty, and Bowen ratio energy-budget evaporation, Lake Mead, March 2010 through February 2012. 
less than EC evaporation during the fall months. This seasonal pattern follows the EBC pattern discussed previously because the BREB method is strongly dependent on available energy estimates. The most plausible explanation for this seasonal pattern is that the magnitude of $Q_{x}$ was underestimated both when energy was going into and being released from storage.

Monthly Bowen ratios for the BREB method can be subject to large errors because they are calculated as the ratio of differences between absolute measurements of temperature and vapor pressure (equation 7); however, Bowen ratios derived from both methods for the current study were very similar $\left(\mathrm{R}^{2}=0.94\right)$. The seasonal pattern of negative (downward temperature gradient and negative sensible-heat flux) and positive (upward temperature gradient and positive sensibleheat flux) values from both methods also were similar (tables 4 and 7). There was an excellent correlation $\left(\mathrm{R}^{2}=0.99\right)$ during months when the Bowen ratio was negative (March through September of both years and February 2012), and only a fair correlation $\left(R^{2}=0.46\right)$ during the remaining fall and winter months. Accordingly, the Bowen ratio uncertainty $(\delta B R)$ averaged \pm 2 percent during the spring and summer months when $\delta A E$ was greatest and \pm 26 percent during the fall and winter months when $\delta A E$ was least. A 26-percent difference in the Bowen ratio during these months results in about a 3-percent difference in evaporation rates. This comparison of monthly Bowen ratios indicates the differences account for only a small portion of the differences in monthly evaporation rates, and that differences in monthly evaporation rates primarily are attributable to available energy estimates.
Sensible heat generally is small relative to other energy fluxes at Lake Mead. EC sensible heat $\left(Q_{h c}\right)$ accounted for -8 percent and BREB sensible heat $\left(Q_{h b}\right)$ accounted for -10 percent of turbulent energy. The negative sign means there was a net downward flux of sensible-heat energy to the lake, meaning sensible heat added to the available energy. Monthly sensible-heat values for both methods are well correlated $\left(R^{2}=0.94\right)$. Both methods produced negative sensible-heat flux during the same months, providing a strong validation of these two largely independent methods.

In this study, and in general, the fluxes determined with the BREB method are greater than those determined with the EC method. Foken (2008, p. 126) argues that the crucial disadvantage of the BREB method is, because of the apparent unclosed energy balance, the residual is either added to the available energy, or distributed according to the Bowen ratio to the latent- and sensible-heat flux. Therefore, the accuracy of latent- and sensible-heat fluxes may be limited because the method relies on fulfilling the energy-budget equation. Another disadvantage of the BREB method for estimating monthly values at Lake Mead is the relatively high $\delta A E$ (up to \pm 25 percent) during some months. Foken (2008, p. 128) reports errors in the BREB method that range from 10 to 30 percent.

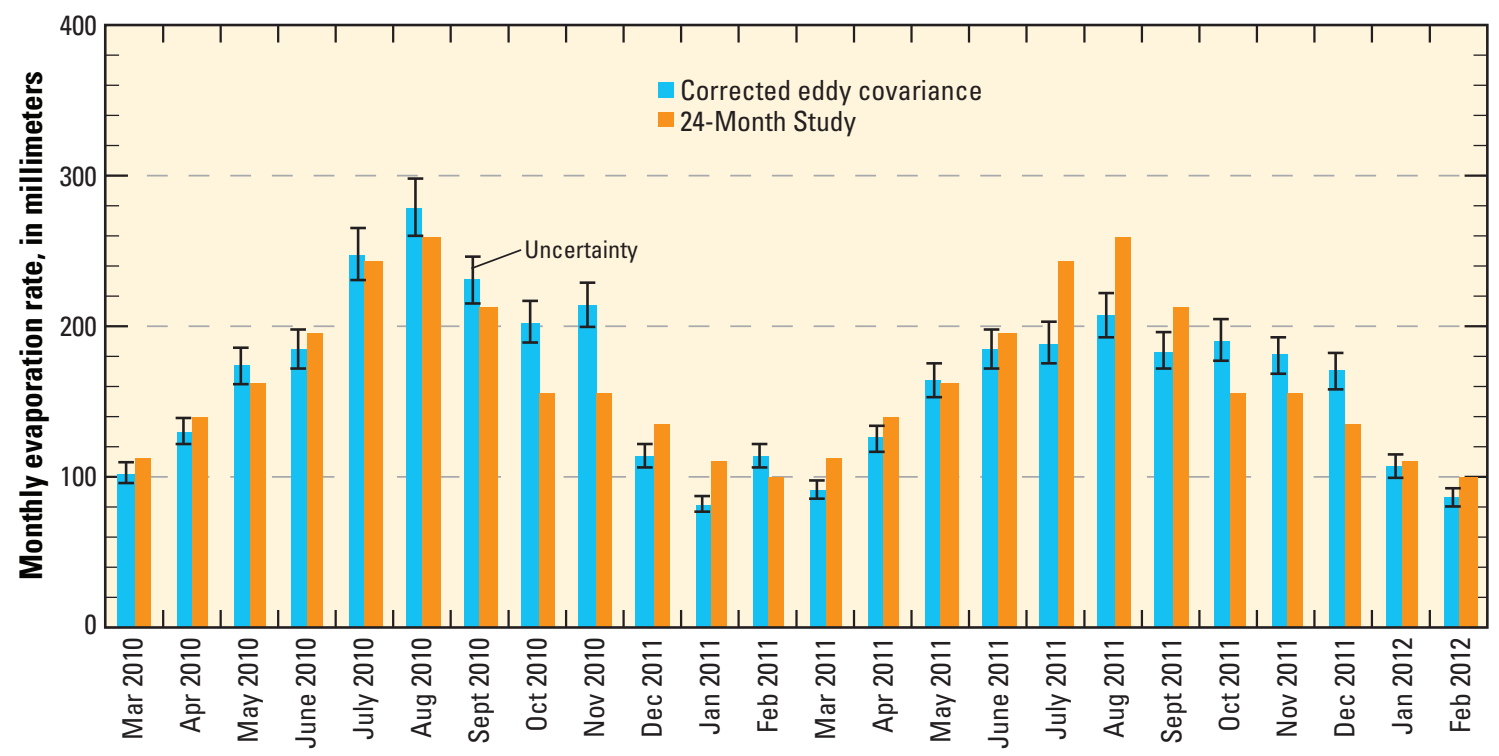

Figure 19. Monthly corrected eddy-covariance evaporation and uncertainty, and 24-Month Study (24MS) evaporation, Lake Mead, March 2010 through February 2012. 


\section{Evaporation from Lake Mead}

The volume of water evaporated from Lake Mead was computed monthly as a product of the corrected EC evaporation rate and the mean lake surface area. There was a 9.3-percent decrease in corrected EC evaporation and a 9.9-percent increase in the lake surface area (fig. 8) during the second year compared to the first. Because of these offsetting factors, the annual evaporation volume was nearly identical. Annual evaporation was $720 \mathrm{Mm}^{3}$ (584 Kaf) in the first year and $719 \mathrm{Mm}^{3}$ (583 Kaf) in the second. Evaporation during the summer months of the first year was the greatest for the period of record of this study because of relatively high winds and greater vapor pressure differences (figs. $6 D$ and 16). Evaporation during the winter months of the second year was greater than the first primarily because of 1) increased lake surface area (fig. 8), and 2) increased energy released from storage because of an increase in advected heat (table 4 and fig. 10).

Evaporation rates estimated for this study were compared with evaporation-rate coefficients used for the 24MS (fig. 19). The 24MS uses a standard set of monthly evaporation-rate coefficients that do not vary from year to year. 24MS evaporation-rate coefficients were obtained from Reclamation (D. Bunk, written commun., 2013). Corrected EC evaporation rates for this study were $2,074 \mathrm{~mm}(81.65 \mathrm{in}$.) in the first year and $1,881 \mathrm{~mm}$ (74.06 in.) in the second, and for the 24MS was $1,981 \mathrm{~mm}$ (78.00 in.) for both years. 24MS evaporation fell within a 7-percent uncertainty range of corrected EC evaporation for 7 of the 24 months (fig. 19). 24MS monthly evaporation ranged from 35 percent more than to 28 percent less than corrected EC evaporation, with a mean difference of 14.5 percent and a standard deviation of 9.3 percent. Annually, 24MS evaporation was 4.5 percent less than and 5.3 percent more than corrected EC evaporation for the first and second years, respectively. The temporal trend in the $24 \mathrm{MS}$ evaporation relative to the corrected EC evaporation indicates the effects of heat storage were underestimated, particularly during the fall months when energy was released from the lake.

The overall accuracy of evaporation estimates from Lake Mead documented by this report is limited by the accuracy of 1) lake surface area estimates, 2) evaporation rate estimates, and 3) the assumption that evaporation in Boulder Basin adequately represents the entire lake. The accuracy of the lake surface area reported by Reclamation was not evaluated for this study. Considering the very good EC energy-balance closure and agreement with the BREB method, the accuracy of monthly evaporation rates presented in this report is considered excellent. The combined source area from the four EC site locations used during the course of this study represents about 25 percent of Boulder Basin; therefore, measured evaporation rates are believed to represent the average micrometeorological and hydrodynamic conditions of Boulder
Basin. As with most scientific endeavors, the findings of this study rely on those of previous investigations. Based on the conclusions of a number of prior studies, the potential error resulting from the assumption that evaporation from Boulder Basin adequately represents the entire lake is not expected to substantially alter the estimates presented in this report.

Harbeck and others (1958) concluded that, for cost effectiveness, operational estimates of evaporation from Lake Mead are obtainable with data collected in Boulder Basin. The areal variation in water temperature is minimal based on observations of water-temperature profiles in Boulder Basin, Virgin Basin, Overton Arm, and Temple Bar (Harbeck and others 1958). Similarly, Anderson and Pritchard (1951) concluded that a single water-temperature-profile measurement in Boulder Basin reasonably represents the entire lake. These conclusions are supported by analyses of water-temperature profiles contained within this report and additional data reported in Veley and Moran (2012). Based on a less than 2-percent difference in net incoming radiation from the four stations in the Lake Mead area used by Harbeck and others (1958), there is "no basis to conclude that there is a significant areal variation in radiation". A maximum deviation in the Bowen ratio of 0.079 between these four sites indicates a maximum variation in evaporation of 8 percent.

Westenburg and others (2006) evaluated the spatial variation in monthly evaporation at three open-water sites and one partially wind-sheltered site using the BREB method, and concluded that the spatial variation in evaporation was minimal for open-water areas of Lake Mead. The excellent correlation between the three open-water sites (Sentinel Island, Virgin Basin, and Overton Arm) and the three-site mean $\left(\mathrm{R}^{2}\right.$ ranging from 0.96 to 0.98 ), with no clear bias for any site, indicates that evaporation rates are similar in the three primary openwater areas of the lake (fig. 1). Monthly evaporation at the wind-sheltered site (Water Barge Cove) generally was about 10 percent less than evaporation at the open-water stations, with the greatest differences during months when rates were less than $16.5 \mathrm{~cm}$; however, these wind-sheltered coves are estimated to account for less than 5 percent of the lake.

The spatial variations in evaporation reported by both Westenburg and others (2006) and Harbeck and others (1958) are within the 5- to 10-percent uncertainty range for the EC method reported by Foken (2008, p. 122). To re-evaluate the spatial variability of evaporation from Lake Mead, it would be necessary to deploy three or four additional monitoring stations which, because of the size of the lake, would involve substantial effort. Even though evaporation is a huge and uncontrollable loss, it is a relatively small water-budget component, and the costs for an effort of this magnitude probably exceed the benefit of minor expected improvements necessary for operational estimates of evaporation. 


\section{Summary and Conclusions}

The U.S. Geological Survey and the Bureau of Reclamation (Reclamation) are cooperating on a multi-phase study to improve monthly estimates of evaporation from Lake Mead and other lower Colorado River Basin reservoirs. The first phase of this study is the subject of this report. Sensors necessary to measure evaporation using two largely independent methods were deployed on Lake Mead for the 2-year period from March 2010 through February 2012. The eddycovariance method was chosen as the primary evaporation method because latent-heat fluxes (the energy used in the evaporation process) could be measured directly. A second and more indirect method, the Bowen ratio energy budget, was chosen to validate annual eddy-covariance evaporation because this widely-used lake evaporation method is fairly accurate at annual timescales. Eddy-covariance sensors were located on a series of rock outcrops that were exposed by the historically low lake elevation that occurred during the study, and most of the sensors necessary to measure energy-budget terms were located on a floating platform in Boulder Basin.

The lowest daily lake elevation since the reservoir was first filled (329.760 m or 1,081.89 ft) occurred in November 2010. There was a net decline in lake elevation of $2.265 \mathrm{~m}(7.43 \mathrm{ft})$ during the first year of this study and a net increase of $11.363 \mathrm{~m}$ (37.28 ft) during the second year. Flow in the Colorado River dominates the Lake Mead water budget, accounting for greater than 90 percent of total gains or losses during the study. Change in volume was the next largest term, with a net loss of $817 \mathrm{Mm}^{3}$ the first year and a substantial gain of $4,373 \mathrm{Mm}^{3}$ the second year. The smaller water-budget terms, side inflow, evaporation, Southern Nevada Water Project withdrawals, and change in bank storage, account for the remaining gains and losses.

When corrected for energy imbalances, eddy-covariance evaporation rates were $2,074 \mathrm{~mm}$ and 1,881 $\mathrm{mm}$ (81.65 and $74.07 \mathrm{in}$.) for the first and second years of the study, respectively. Monthly evaporation rates were best correlated to wind speed, vapor pressure difference, and atmospheric stability. Net radiation provided most of the energy available for evaporative processes; however, change in stored heat has the largest range of values, and advected heat was an important energy source during the second year. The depth of Lake Mead resulted in notable thermal loading and seasonal lag in surface energy availability. Peak evaporation lagged peak net radiation by about 2 months. During spring and summer, the air temperature was warmer than the water surface, resulting in negative sensible-heat fluxes and negative Bowen ratios; during fall and winter, the water surface was warmer than the air, resulting in positive sensible-heat fluxes and Bowen ratios. Most of the second year decreases in EC evaporation compared to the first year occurred during the summer when cloudier and less windy conditions prevailed, which led to a decrease in available energy and vapor pressure differences.

Annual eddy-covariance evaporation was within the range of previous estimates for Lake Mead. The energy-balance ratio was 90 percent on average and varied only 1 percent between the 2 years, indicating that 90 percent of estimated available energy was accounted for by turbulent energy. A probable minimum and maximum evaporative flux range was computed based on this energy imbalance. Monthly and annual eddy-covariance evaporation uncertainty ranged from 5.2 to 7.1 percent. More than 90 percent of the turbulent-flux source area represented open-water surfaces, and 94 percent of 30-minute averaged turbulent-flux measurements originated from wind directions where the fetch ranged from 2,000 to $16,000 \mathrm{~m}$.

There was a good relation between annual corrected eddy-covariance and Bowen ratio energy-budget evaporation estimates, providing a strong validation of these two largely independent methods. Annual Bowen ratio energy-budget evaporation estimates were 6 and 8 percent greater than eddy-covariance estimates. Both methods produced negative Bowen ratios and sensible-heat fluxes during the same months, even though these terms are computed differently by each method. Both methods indicate there was a 7- to 9-percent decrease in evaporation from the first year to the second. There was a strong correlation between sensible-heat fluxes and Bowen ratios (both with $\mathrm{R}^{2}=0.94$ ) derived from the two methods. The correlation between monthly evaporation rates $\left(\mathrm{R}^{2}=0.65\right)$, however, was not as strong. The monthly variability between the two methods was attributed primarily to errors in heat storage estimates.

The volume of water evaporated from Lake Mead was computed as the product of the evaporation rate and the lake surface area. There was a 9.3-percent decrease in the evaporation rate and a 9.9-percent increase in lake surface area during the second year compared to the first. Because of these offsetting factors, the annual evaporation volume for the 2 years was nearly identical -720 $\mathrm{Mm}^{3}$ (584 Kaf) and $719 \mathrm{Mm}^{3}$ (583 Kaf), respectively.

Evaporation rates estimated for this study were compared with evaporation-rate coefficients used for the 24-Month Study. The 24-Month Study is an operational planning tool used by Reclamation to project future Colorado River reservoir volumes and potential dam operations based on current and forecasted hydrologic conditions, and operational policies and guidelines. The 24-Month Study monthly evaporation ranged from 35 percent more than to 28 percent less than corrected eddy-covariance evaporation, with a mean difference of 14.5 percent and a standard deviation of 9.3 percent. Annually, 24-Month Study evaporation was 4.5 percent less than and 5.3 percent more than corrected eddy-covariance evaporation for the first and second years, respectively. The temporal trend in the 24-Month Study evaporation relative to the corrected eddy-covariance evaporation indicates the effects of heat storage were underestimated, particularly during the fall months when energy is released from the lake.

The evaporation estimated for this study is believed to be representative of Boulder Basin. Previous studies have concluded that evaporation from Boulder Basin is reasonably representative of Lake Mead. The evaporation estimates documented by this report and Reclamation's commitment to long-term evaporation monitoring will result in an improvement to this water-budget term, which will improve Reclamation's ability to accurately account and forecast water availability. 


\section{References Cited}

Allen, R.A., Pereira, L.S., Raes, Dirk, and Smith, Martin, 1998, Crop evapotranspiration-Guidelines for computing crop water requirements-AO irrigation and drainage paper 56: Food and Agricultural Organization of the United Nations, Rome, Italy, 300 p.

Anderson, E.R., 1954, Energy-budget studies, in Water-loss investigations: Lake Hefner studies, technical report: U.S. Geological Survey Professional Paper 269, p. 71-119, http://pubs.er.usgs.gov/publication/pp269.

Anderson, E.R., and Pritchard, D.W., 1951, Physical limnology of Lake Mead: U.S. Navy Electronics Lab Report 258, 153 p.

Baldocchi, D.D., 2003, Assessing the eddy covariance technique for evaluating carbon dioxide exchange rates of ecosystems: past, present, and future: Global Change Biology, v. 9, no. 4, p. 479-492.

Blanken, P.D., Rouse, W.R., Culf, A.D., Spence, C., Boudreau, L.D., Jasper, J.N., Kochtubajda, B., Schertzer, W.M., Marsh, P., and Verseghy, D., 2000, Eddy covariance measurements of evaporation from Great Slave Lake, Northwest Territories, Canada: Water Resources Research, v. 36, no. 4, p. 1,069-1,077.

Blanken, P.D., Rouse, W.R., and Schertzer, W.M., 2003, Enhancement of evaporation from a large northern lake by the entrainment of warm, dry air: Journal of Hydrometeorology, v. 4, p. 680-693.

Blonquist, J.M., Jr., Tanner, B.D., and Bugbee, B., 2009, Evaluation of measurement accuracy and comparison of two new and three traditional net radiometers: Agricultural and Forest Meteorology, v. 149, p. 1,709-1,721.

Bowen, I.S., 1926, The ratio of heat losses by conduction and by evaporation from any water surface: Physics Review, v. 27, p. 779-787.

Brutsaert, W.H., 1982, Evaporation into the atmosphere: Boston, Mass., D. Reidel Publishing, 299 p.

Bureau of Reclamation, 2007, Colorado River interim guidelines for lower basin shortages and coordinated operations for Lakes Powell and Mead: Final Environmental Impact Statement, accessed October 10, 2012 at http://www.usbr. gov/lc/region/programs/strategies/FEIS/index.html.

Campbell Scientific, Inc., 2010a, Instruction manual for CNR2 net radiometer, revision 5/10, accessed October 10, 2012 at http://s.campbellsci.com/documents/us/manuals/cnr2.pdf.
Campbell Scientific, Inc., 2010b, Instruction manual for KH2O krypton hygrometer, revision 2/10, accessed December 23, 2010 at http://s.campbellsci.com/documents/us/ manuals/kh20.pdf.

Campbell Scientific, Inc., 2010c, Instruction manual for CSAT3 three dimensional sonic anemometer, revision 6/10, accessed September 28, 2011 at http://s.campbellsci.com/ documents/us/manuals/csat3.pdf.

Campbell Scientific, Inc., 2011, Instruction manual for CNR1 net radiometer, revision 5/11, accessed November 16, 2012 at http://s.campbellsci.com/documents/us/manuals/cnr1.pdf.

Clement, R., 1999, EdiRe data software: University of Edinburgh, version 1.5.0.10, http://www.geos.ed.ac.uk/abs/ research/micromet/EdiRe/.

Crow, F.R., and Hottman, S.D., 1973, Network density of temperature profile stations and its influence on the accuracy of lake evaporation calculations: Water Resources Research, v. 9, no. 4, p. 895-899.

Falge, E., Baldocchi, D., Olson, R., and others, 2001, Gap filling strategies for long term energy flux data sets: Agricultural and Forest Meteorology, v. 107, p. 71-77.

Ferrari, R.L., 2008, 2001 Lake Mead sedimentation survey: Bureau of Reclamation report, Technical Service Center, Denver, Colo., 212 p.

Finch, J.W., and Hall, R. L., 2005, Evaporation from lakes, in Anderson, M.G., ed., Encyclopedia of Hydrological Sciences: John Wiley \& Co, Ltd., http://onlinelibrary.wiley. com/book/10.1002/0470848944.

Foken, Thomas, 2008, Micrometeorology: Berlin-Heidelberg, Springer, $306 \mathrm{p}$.

Foken, T., Leuning, R., Oncley, S., Mauder, M., and Aubinet, M., 2012, Corrections and data quality control, in Aubinet, M., Vesala, T., and Papale, D., eds., chap. 4, Eddy covariance - a practical field guide to measurement and data analysis: Dordrecht-Heidelberg-London-New York, Springer, $438 \mathrm{p}$.

Gordon, J.D., 2002, Evaluation of candidate rain gages for upgrading precipitation measurement tools for the National Atmospheric Deposition Program: U.S. Geological Survey Water-Resources Investigations Report 02-4302, 30 p., http://pubs.er.usgs.gov/usgspubs/wri/wri024302.

Granger, R.J., and Hedstrom, N., 2011, Modelling hourly rates of evaporation from small lakes: Hydrology and Earth System Sciences, v. 15, p. 267-277.

Harbeck, G.E., Kohler, M.A., Koberg, G.E., and others, 1958, Water-loss investigations: Lake Mead studies: U.S. Geological Survey Professional Paper 298, 100 p., http://pubs. er.usgs.gov/publication/pp298. 
Højstrup, J., 1993, A statistical data screening procedure: Measurement Science and Technology, v. 4, p. 153-157.

Kaimal, J.C., and Finnigan, J.J., 1994, Atmospheric boundary layer flows, their structure and measurement: New York, Oxford University Press, 289 p.

Kormann, R., and Meixner, F., 2001, An analytical footprint model for non-neutral stratification: Boundary-Layer Meteorology, v. 99, no. 2, p. 207-224.

Langbein, W.B., 1960, Water budget, in Smith, W.O., Vetter, C.P., Cummings, G.B., and others, Comprehensive survey of sedimentation in Lake Mead, 1948-49: U.S. Geological Survey Professional Paper 295, p. 95-102, http://pubs.er.usgs.gov/publication/pp295.

Larsen, L.W., and Peck, E.L., 1974, Accuracy of precipitation measurements for hydrologic modeling: Water Resources Research, v. 10, no. 4, p. 857-863.

Lee, T.M., and Swancar, A., 1997, Influence of evaporation, ground water, and uncertainty in the hydrologic budget of Lake Lucerne, a seepage lake in Polk County, Florida: U.S. Geological Survey Water-Supply Paper 2439, 61 p., http://pubs.er.usgs.gov/publication/wsp2439.

Leuning, R., van Gorsel, E., Massman, W.J., and Isaac, P.R., 2012, Reflections on the surface energy imbalance problem: Agricultural and Forest Meteorology, v. 156, p. 65-74.

Liu, H., Zhang, Y., Liu, S., Jiang, H., and Sheng, L., 2009, Eddy covariance measurements of surface energy budget and evaporation in a cool season over southern open water in Mississippi: Journal of Geophysical Research, v. 114, D04110, doi:10.12029/2008JD010891.

Mahrt, L., 1999, Stratified atmospheric boundary layers: Boundary-Layer Meteorology, v. 90, no. 3, p. 375-396.

Monin, A., and Obukhov, A., 1954, Basic laws of turbulent mixing in the surface layer of the atmosphere: Trudy Geofizicheskogo Instituta, Akademiya Nauk SSSR., v. 24, no. 151, p. 163-187.

Moore, C.J., 1986, Frequency response corrections for eddy correlation systems: Boundary-Layer Meteorology, v. 37, p. 17-35.

National Weather Service, 2013, The climate of Las Vegas, Nevada: National Weather Service Publication, updated November 6, 2013, 153 p., http://www.wrh.noaa.gov/vef/ climate/LasVegasClimateBook/Mean\%20Average\%20 Wind\%20Speed\%20And\%20Windiest\%20Months.pdf.

Omar, M.H., and El-Bakry, M.M., 1981, Estimation of evaporation from the lake of the Aswan High Dam (Lake Nasser) based on measurements over the lake: Agricultural Meteorology, v. 23, p. 293-308.
Parkhurst, R.S., Winter, T.C., Rosenberry, D.O., and Sturrock, A.M., 1998, Evaporation from a small prairie wetland in the Cottonwood Lake area, North Dakota — an energy-budget study: Wetlands, v. 18, p. 272-287.

Petrucci, R.H., 1985, General chemistry principles and modern applications: New York, Macmillan Publishing Company, $4^{\text {th }}$ ed., 873 p.

Ramamurthy, P., and Pardyjak, E., 2007, Observations of the effects of atmospheric stability on turbulence statistics deep within an urban street canyon: Journal of Applied Meteorology and Climatology, v. 46, p. 2,074-2,085.

Rannik, U., Sogachev, A., Foken, T., Gockede, M., Kljun, N., Leclerc, M., and Vesala, T., 2012, Footprint analysis, in Aubinet, M., Vesala, T., and Papale, D., eds., chap. 8, Eddy covariance--a practical field guide to measurement and data analysis: Dordrecht-Heidelberg-London-New York, Springer, $438 \mathrm{p}$.

Rosenberry, D.O., Winter, T.C., Buso, D.C., and Likens, G.E., 2007, Comparison of 15 evaporation methods applied to a small mountain lake in the northeastern USA: Journal of Hydrology, v. 340, p. 149-166.

Sacks, L.A., Lee, T.M., and Radell, M.J., 1994, Comparison of energy-budget evaporation losses from two morphometrically different Florida seepage lakes: Journal of Hydrology, v. 156, p. 311-334.

Saur, J.F.T., and Anderson, E.R., 1956, The heat budget of a body of water of varying volume: Limnology and Oceanography, v. 1, p. 247-251.

Schotanus, P., Nieuwstadt, F.T.M., and de Bruin, H.A.R., 1983, Temperature measurement with a sonic anemometer and its application to heat and moisture fluxes: BoundaryLayer Meteorology, v. 50, p. 81-93.

Schuepp, P.H., LeClerc, M.Y., Macpherson, J.I., and Desjardins, R.L., 1990, Footprint prediction of scalar fluxes from analytical solutions of the diffusion equation: BoundaryLayer Meteorology, v. 50, p. 355-373.

Smith, W.O., Vetter, C.P., Cummings, G.B., and others, 1960, Comprehensive survey of sedimentation in Lake Mead, 1948-49: U.S. Geological Survey Professional Paper 295, 254 p., http://pubs.er.usgs.gov/publication/pp295.

Stannard, D.I., Gannett, M.W., Polette, D.J., Cameron, J.M., Waibel, S., and Spears, J.M., 2013, Evapotranspiration from wetland and open-water sites at Upper Klamath Lake, Oregon, 2008-2010: U.S Geological Survey Scientific Investigations Report 2013-5014, 65 p., http://pubs.er.usgs. gov/publication/sir20135014.

Swinbank, W.C., 1951, The measurement of vertical transfer of heat and water vapor by eddies in the lower atmosphere: Journal of Meteorology, v. 8, no. 3, p. 135-145. 
Tanner, B.D., and Greene, J.P., 1989, Measurement of sensible heat and water-vapor fluxes using eddy-correlation methods: Final report prepared for U.S. Army Dugway Proving Grounds, U.S. Army, Dugway, Utah, 17 p.

Taylor, J.R., 1997, Error analysis: the study of uncertainties in physical measurements: Sausalito, California, University Science Books, 327 p.

Thomas, H.E., 1954, First fourteen years of Lake Mead: U.S. Geological Survey Circular 346, 27 p., http://pubs.er.usgs. gov/publication/cir346.

Tighi, S., and Callejo, R., 2011, Lake Mead area and capacity tables: Bureau of Reclamation Lower Colorado Region report, $149 \mathrm{p}$.

Turner, K., Rosen, M.R., Holdren, G.C., Goodbred, S.L., and Twichell, D.C., 2012, Environmental setting of Lake Mead National Recreation Area, in Rosen, M.R., Turner, K., Goodbred, S.L., and Miller, J.M., eds., 2012, A synthesis of aquatic science for management of Lakes Mead and Mohave: U.S. Geological Survey Circular 1381, 162 p., http://pubs.er.usgs.gov/publication/cir1381.

U.S. Geological Survey, 1954, Water-loss investigations: Lake Hefner studies, technical report: U.S. Geological Survey Professional Paper 269, 158 p., http://pubs.er.usgs.gov/ publication/pp269.

Veley, R.J., and Moran, M.J., 2012, Evaluating lake stratification and temporal trends by using near-continuous waterquality data from automated profiling systems for water years 2005-09, Lake Mead, Arizona and Nevada: U.S. Geological Survey Scientific Investigations Report 2012-5080, 25 p., http://pubs.usgs.gov/sir/2012/5080/.

Voichick, Nicholas, and Wright, S.A., 2007, Water-temperature data for the Colorado River and tributaries between Glen Canyon Dam and Spencer Canyon, northern Arizona, 1988-2005: U.S. Geological Survey Data Series 251, 28 p., http://pubs.usgs.gov/ds/2007/251/.

Webb, E.K., Pearman, G.I., and Leuning, R., 1980, Correction of flux measurements for density effects due to heat and water vapour transfer: Quarterly Journal of the Royal Meteorological Society, v. 106, p. 85-100.

Westenburg, C.L., DeMeo, G.A., and Tanko, D.J., 2006, Evaporation from Lake Mead, Arizona and Nevada, 1997-99: U.S. Geological Survey Scientific Investigations Report 2006-5252, 24 p., http://pubs.er.usgs.gov/publication/ sir20065252.

Wetzel, R.G., 1975, Limnology: Philadelphia-LondonToronto, W.B. Saunders Company, 743 p.
Wilson, K., Goldstein, A., Falge, E., Aubinet, M., Baldocchi, D., Berbigier, P., Bernhofer, C., Ceulemans, R., Dolman, H., Field, C., Grelle, A., Ibrom, A., Law, B., Kowalski, A., Meyers, T., Moncrieff, J., Monson, R., Oechel, W., Tenhunen, J., Valentini, R., and Verma, S., 2002, Energy balance closure at FLUXNET sites: Agricultural and Forest Meteorology, v. 113, p. 223-243.

Winter, T.C., 1981, Uncertainties in estimating the water balance of lakes: Water Resources Bulletin, v. 17, no. 1, p. 82-115.

Wright, S.A., Anderson, C.R., and Voichick, Nicholas, 2009, A simplified water temperature model for the Colorado River below Glen Canyon Dam: River Research and Applications, v. 25, p. 675-686, http://pubs.er.usgs.gov/ publication/70036593. 


\section{Appendix 1. Evaporation data for Lake Mead, Nevada and Arizona, March 2010 through February 2012}

The spreadsheet distributed as part of this report is in Microsoft ${ }^{\circledR}$ Excel 2010 format. Column headers are described within the spreadsheet. Selected daily data are presented in native units. Eddy covariance latent- and sensible-heat flux data are not corrected for energy imbalances at daily or subdaily time steps. Appendix 1 daily data are available for download at , http://dx.doi.org/10.3133/sir20135229. Sub-daily (30-minute) data are available for download at $h t t p: / / n e v a d a$. usgs.gov/water/et/index.htm. 



\section{甦}

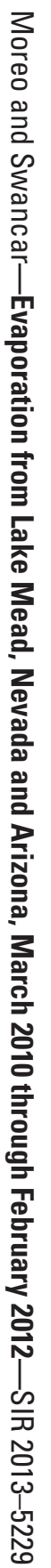

